Final Technical Report

\title{
Development of Advanced Wear and Corrosion Resistant Systems Through Laser Surface Alloying and Materials Simulation
}

DOE Award Number DE-FG36-04G014042

\author{
Project Period of \\ May 2004 - August 2006 \\ Authors: \\ Dr. Richard Martukanitz \\ Applied Research Laboratory, The Pennsylvania State University \\ P.O. Box 30, State College, PA 16803 \\ (814) 863-3991, rxm44@psu.edu \\ Dr. Suresh Babu \\ Oak Ridge National Laboratory, One Bethel Road, P.O. Box 2008, MS-6096, \\ Oak Ridge, TN 37831-6096 \\ (Currently with the Edison Welding Institute, Columbus $\mathrm{OH}$ )
}

May 3, 2007 
Project Team Members:

Dr. John Vitek, Senior Research Staff, Oak Ridge National Laboratory (865) 574-5061, vitekjm@ornl.gov

Mr. Paul Colby, Jr., President, Spirex Corporation (330) 726-4001, ptcolby@spirex.com

Dr. Rolland Gassmann, Senior Scientist, Praxair Surface Technologies

(724) 598-1358, ext. 358, Roland_Gassmann@praxair.com

Mr. Ronald Boyer, President, Alvord-Polk Corporation

(717) 692-2128, rboyer@epix.net

Mr. John Haake, Vice President-Marketing, NUVONYX Corporation

(314) 209-7755, jhaake@nuvonyx.com

Acknowledgment:

This report is based upon work supported by the U. S. Department of Energy under Award No. DE-FG36-04G014042.

Disclaimer:

Any findings, opinions, and conclusions or recommendations expressed in this report are those of the author(s) and do not necessarily reflect the views of the Department of Energy. 
TABLE OF CONTENTS

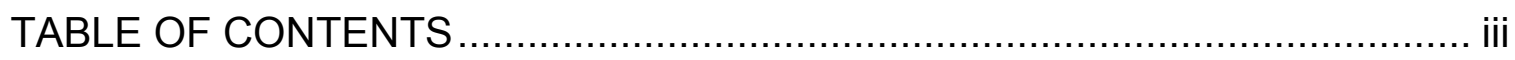

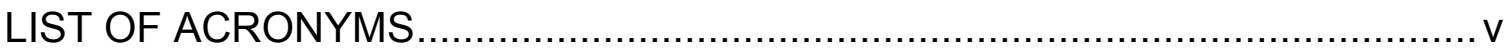

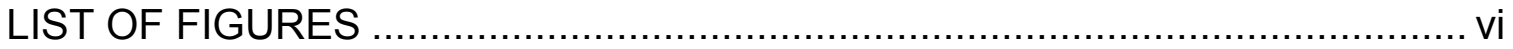

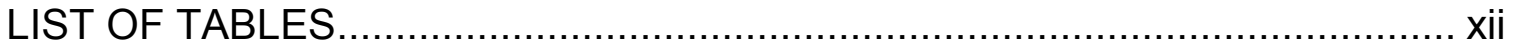

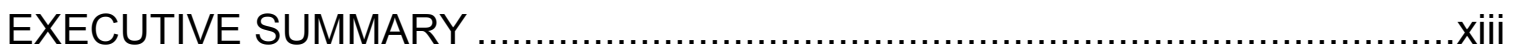

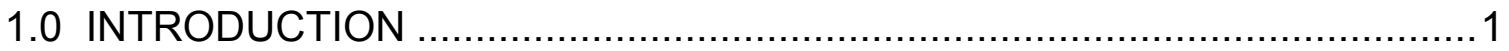

1.1 Laser Surface Modification Processes .......................................................2

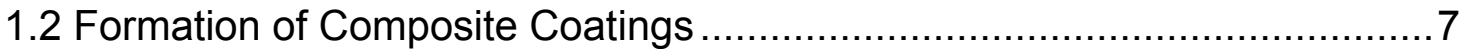

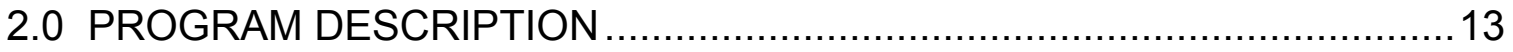

3.0 THEORETICAL AND EXPERIMENTAL TASKS ...................................17

3.1 Formulation of Materials Simulation Techniques .....................................17

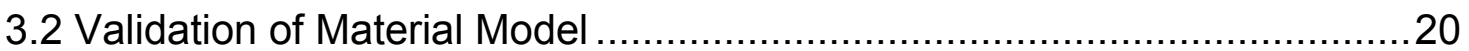

3.3 Formulation of Laser Process Model ...............................................29

3.3.1 Numerical Formulation ................................................................................ 30

3.3.2 Representation of Laser Energy Absorption................................................... 38

3.3.3 Experimental Determination of Laser Attenuation............................................ 44

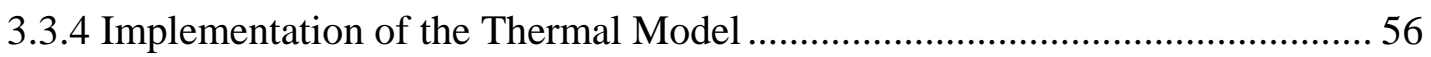

3.4 Experimental Validation of Process Model .........................................5

3.5 Laser Deposition Analysis and Experiments ......................................63

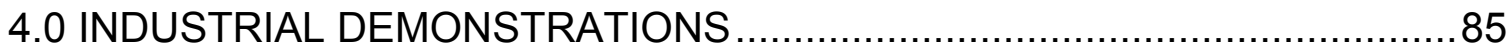

4.1 Industrial Demonstrations for Internal Cladding ......................................

4.2 Industrial Demonstrations for Producing Tooling Material ........................98

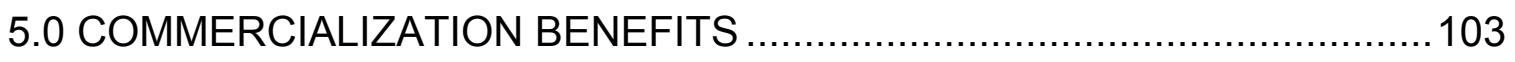

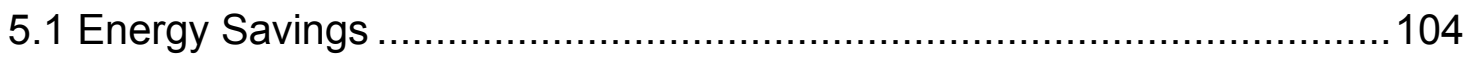

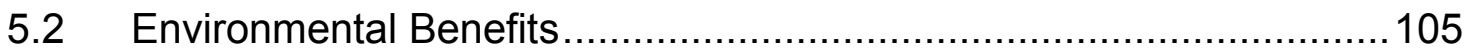

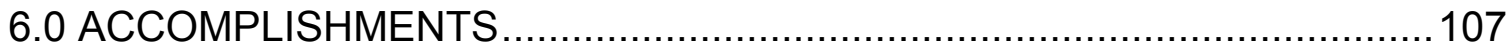




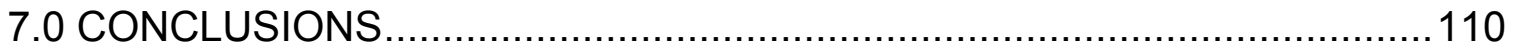

8.0 RECOMMENDATIONS FOR FURTHER WORK ...................................113

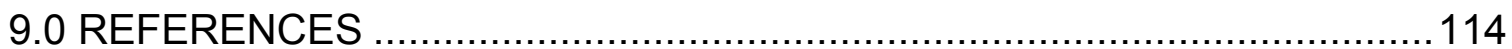




\title{
LIST OF ACRONYMS
}

\author{
Applied Research Laboratory (ARL) \\ Oak Ridge National Laboratory (ORNL) \\ Scanning Electron Microscopy (SEM) \\ Hardness Value (HV) \\ Body Centered Cubic (BCC) \\ Face Centered Cubic (FCC) \\ Carbon Dioxide Laser ( $\mathrm{CO}_{2}$ Laser) \\ Neodymium Doped Yttrium-Aluminum-Garnet Laser (Nd:YAG Laser)
}




\section{LIST OF FIGURES}

Figure 1 - Schematics of the laser surface alloying processes. ........................ 4

Figure 2 - Schematic of high-power $\mathrm{CO}_{2}$ laser cladding process and photograph of this type of configuration being used to clad at $12 \mathrm{~kW}$ of laser power.

Figure 3 - Photographs of commercial laser-based deposition systems being used to deposit high carbide containing ferrous alloys ........................................ 5

Figure 4 - Component from a heavy excavating system that had been clad using a martensitic-grade of stainless steel.

Figure 5 - Microstructures and range of microhardness for common alloys used for the laser cladding process

Figure 6 - Wear rate for composite materials as a function of volume fraction of the matrix based on rule of mixtures and experimental data..........................

Figure 7- Enthalpy of formation of various hard particles. 11

Figure 8 - Graphical illustration of development tasks for research program showing progression to implementation.

Figure 9. Free energy of a $\alpha$-phase and $\beta$-phase and the common-tangent construction for the description of the tie line and chemical potential of elements $A$ and $B$.

Figure 10 - Comparison of calculated phase boundary regions for ternary alloy systems representing Fe-W-C and Ni-W-C.

Figure 11- Comparison of phase evolution during solidification in two ternary alloy systems calculated using Scheil assumption.

Figure 12 - Schematic illustration of the one-dimensional diffusion geometry used to calculate the diffusion controlled dissolution of tungsten carbide in a liquid pool as it cools from $2300 \mathrm{~K}$ to $1800 \mathrm{~K}$.

Figure 13 - Predicted position of the interface between liquid and MC carbide as a function of time with assumed diffusivity of $1 \times 10-6 \mathrm{~m} 2 \mathrm{~s}-1$.

Figure 14 - Calculated tungsten and carbon concentration profiles in the liquid melt pool in contact with $\mathrm{MC}$ carbide as a function of time..

Figure 15 - Predicted position of interface between liquid and MC carbide as a function of time with assumed diffusivity of $1 \times 10^{-6} \mathrm{~m}^{2} \mathrm{~s}^{-1}$. 
Figure 16 - Calculated tungsten and carbon concentration profiles in the liquid melt pool in contact with $\mathrm{MC}$ carbide as a function of time for Fe-W-C and Ni-W-C.

Figure 17 - Grid spacing used in finite differencing scheme with laser distribution shown at the surface.

Figure 18 - Generic binary liquid-vapor phase diagram................................ 32

Figure 19 - General change in thermal conductivity of powder upon melting.....33

Figure 20 - Effective conductivity of the powder material versus conductivity in solid state for pure iron....

Figure 21 - Modification to interface temperature based on the ratio of thermal conductivities of powder and substrate materials.

Figure 22 - Schematic of laser irradiation of a powder layer showing scattering within the porous powder.

Figure 23 - Schematic of sphere integrator arrangement for experiments to measure transmitted and reflected irradiation from powder layers.

Figure 24 - Photographs of the pure copper powder and pure iron powder after Nd:YAG irradiation of approximately $10 \mathrm{~W}$ for 5 seconds.

Figure 25 - Experimental data showing transmittance versus powder depth for iron irradiated by $\mathrm{CO}_{2}$ and $\mathrm{Nd}$ :YAG lasers.

Figure 26 - Experimental data showing transmittance versus powder depth for copper irradiated by $\mathrm{CO}_{2}$ and $\mathrm{Nd}$ :YAG lasers.

Figure 27 - Ratio of measured intensity to initial intensity as a function of powder depth for Nd:YAG laser irradiation with iron powder.

Figure 28 - Ratio of measured intensity to initial intensity as a function of powder depth for $\mathrm{CO}_{2}$ laser irradiation with iron powder.

Figure 29 - Ratio of measured intensity to initial intensity as a function of powder depth for Nd:YAG laser irradiation with copper powder.

Figure 30 - Ratio of measured intensity to initial intensity as a function of powder depth for $\mathrm{CO}_{2}$ laser irradiation with copper powder.

Figure 31 - Internal energy density within the powder layer during Nd:YAG irradiation with a Gaussian energy source for iron and copper powders. 55

Figure 32 - Internal energy density within the powder layer during Nd:YAG irradiation with a uniform energy source for iron and copper powders 55 
Figure 33 - Comparison of experimental to simulation data for laser deposition using a Nd:YAG laser.

Figure 34 - Comparison of experimental to simulation data for laser deposition using a $\mathrm{CO}_{2}$ laser.

Figure 35 - Cross-sectional view from model of maximum penetration into substrate for $\mathrm{Nd}$ :YAG irradiation.

Figure 36 - Cross-sectional view from model of maximum penetration into substrate for $\mathrm{CO}_{2}$ irradiation.

Figure 37 - Macrograph of Nd:YAG laser deposition of Inconel 625 on a mild steel substrate using a $2 \mathrm{~mm}$ thick preplaced powder layer.

Figure 38 - Macrograph of $\mathrm{CO}_{2}$ laser deposition of Inconel 625 on a mild steel substrate using a $2 \mathrm{~mm}$ thick preplaced powder layer.

Figure 39 - Thermodynamic stability diagram and solid volume fraction during cooling for a system represented by titanium or tungsten with carbon in stainless steel alloy 431 .

Figure 40 - Thermodynamic calculations of MX stability as a function of carbon and nitrogen for simple Fe-based and a complex Fe-base alloy

Figure 41 - Macrographs of representative Nd:YAG laser deposits made using various combinations of 431 and TiC powder and shielding gas.

Figure 42 - Microstructures of representative Nd:YAG laser deposits made using various combinations of 431 and $\mathrm{TiC}$ powder and shielding gas.

Figure 43 - Scanning electron micrograph images show coarse original $\mathrm{Ti}(\mathrm{CN})$, dendritic $\mathrm{Ti}(\mathrm{CN})$, and secondary $\mathrm{Ti}(\mathrm{CN})$ phases in the interdendritic region.

Figure 44 - Orientational imaging microscopy analysis showing distribution of FCC crystal strucuture.

Figure 45 - Orientational imaging microscopy analysis of BCC grains showing the presence of predominantly fine ferrite grain size with misorientations above 10 degrees.

Figure 46 - Hardness distributions for Nd:YAG laser deposits made using various combinations of 431 and TiC powder and shielding gas 77

Figure 47 - Comparison of hardness distributions of the Nd:YAG laser deposits made using various combinations of 431 and TiC powder and shielding gas. 
Figure 48 - Comparison of average hardness of the laser deposits using 431 and TiC powder

Figure 49 - Optical mcirograph of laser surface alloyed region showing fine TiCN dendrites with a small dendritic ferrite grain size in the background.

Figure 50 - Orientational imaging microscopy maps showing the distributions of ferrite and TiCN crystal structure showing fine inter-twinning microstructure.

Figure 51 - Predicted variation of solid fraction versus temperature during solidification is shown with different phase regions.

Figure 52 - Comparison of overlapping bead shapes made with diode laser source made with argon shielding and nitrogen shielding.

Figure 53 - Comparison of optical microstructures from the last deposit made with a direct diode laser source with $100 \%$ argon and $100 \%$ nitrogen shielding gas

Figure 54 - Processing arrangement used for depositing WC onto external surface of a bar using the $14 \mathrm{~kW} \mathrm{CO}$ laser.

Figure 55 - Processing arrangement used for depositing BN onto internal surface of a shaft using the $5 \mathrm{~kW} \mathrm{Nd:YAG} \mathrm{laser.}$

Figure 56 - Photograph of surface of bar representing the WC deposition using the $14 \mathrm{~kW} \mathrm{CO}$ laser showing deposition of coatings using three precursor thickness.

Figure 57 - Micrograph of unetched Specimen A representing WC deposit produced using the $14 \mathrm{~kW} \mathrm{CO}$ laser.

Figure 58 - Micrograph of unetched Specimen B representing BN deposit produced using the $5 \mathrm{~kW} \mathrm{Nd:YAG} \mathrm{laser.}$

Figure 59 - Micrograph of etched Specimen A representing WC deposit produced using the $14 \mathrm{~kW} \mathrm{CO}$ laser.

Figure 60 - Micrograph of ethced Specimen B representing BN deposit produced using the $5 \mathrm{~kW} \mathrm{Nd:YAG} \mathrm{laser.}$

Figure 61 - Micrograph at higher magnification of etched Specimen A representing $\mathrm{WC}$ deposit produced using the $14 \mathrm{~kW} \mathrm{CO}$ laser.

Figure 62 - Micrograph at higher magnification of etched Specimen B representing $\mathrm{BN}$ deposit produced using the $5 \mathrm{~kW}$ Nd:YAG laser. 
Figure 63 - Hardness profiles for the WC deposit produced using the $\mathrm{CO}_{2}$ laser and the BN deposit produced using the Nd:YAG laser.

Figure 64 - Orientations of the transverse and longitudinal views represented in micrographs.

Figure 65 - Micrograph showing transverse view of unetched Specimen A representing WC precursor deposited on steel using a $14 \mathrm{~kW} \mathrm{CO}_{2}$ laser.

Figure 66 - Micrograph at higher magnification showing transverse view of unetched Specimen A representing WC precursor deposited on steel using a $14 \mathrm{~kW} \mathrm{CO}$ laser.

Figure 67 - Micrograph at higher magnification showing transverse view of unetched Specimen A representing WC precursor deposited on steel using a $14 \mathrm{~kW}$ CO2 laser.

Figure 68 - Micrograph showing longitudinal view of unetched Specimen A representing WC precursor deposited on steel using a $14 \mathrm{~kW} \mathrm{CO}_{2}$ laser. 96

Figure 69 - Micrograph showing longitudinal view of unetched Specimen A representing WC precursor deposited on steel using a $14 \mathrm{~kW} \mathrm{CO}_{2}$ laser.

Figure 70 - Micrograph showing longitudinal view of unetched Specimen A representing WC precursor deposited on steel using a $14 \mathrm{~kW} \mathrm{CO}_{2}$ laser.

Figure 71 - Photograph of Specimen C with insert showing deposition and location of samples that were removed for metallographic preparation.

Figure 72 - Photograph of Specimen D with insert showing deposition and location of samples that were removed for metallographic preparation.

Figure 73 - Photograph of Specimen E with insert showing deposition and location of samples that were removed for metallographic preparation 100

Figure 74 - Photograph of Specimen $\mathrm{F}$ with insert showing deposition and location of samples that were removed for metallographic preparation ..... 100

Figure 75 - Micrographs of Specimen C showing transverse cross-section and longitudinal section of laser deposition.

Figure 76 - Micrographs of Specimen D showing transverse cross-section and longitudinal section of laser deposition 101

Figure 77 - Micrographs of Specimen E showing transverse cross-section and longitudinal section of laser deposition 102 
Figure 78 - Micrographs of Specimen F showing transverse cross-section and longitudinal section of laser deposition. 


\section{LIST OF TABLES}

Table 1 - Size, density, and porosity of powders used during the experiment. ...45

Table 2 - Estimated attenuation coefficients obtained from the absorption experiments.

Table 3 - Various model parameters used for the $\mathrm{CO}_{2}$ and Nd:YAG laser deposition simulations.

Table 4 - Beam and powder material interaction parameters used for the $\mathrm{CO}_{2}$ and $\mathrm{Nd}$ :YAG laser deposition simulations.

Table 5 - Powder and shielding gas parameters used for laser deposition experiments for evaluating $\mathrm{TiC}$ in a 431 stainless steel matrix.

Table 6 - Measured hardness data in the substrate and the coating of a deposit representing 431and TiC produced using a Nd:YAG laser and various shielding gas. 


\section{Development of Advanced Wear and Corrosion Resistant Systems Through Laser Surface Alloying and Materials Simulation}

\section{EXECUTIVE SUMMARY}

There is a continued need for new and improved coatings that provide increased life for critical mechanical components. This is particularly true for heavy industries such as mining and mineral processing, materials producers and fabricators, paper and pulp, and agriculture. Typically, coating technology utilized for these industries requires metallurgical bonding for durability, relatively large depositions for dimensional requirements and restoration, and hard surfaces for improved wear resistance. Laser surfacing in the form of cladding, alloying, and modifications are gaining widespread use because of its ability to provide high deposition rates, low thermal distortion, and refined microstructure due to high solidification rates. Because of these advantages, laser surface alloying is considered a prime candidate for producing ultra-hard coatings through the establishment or in situ formation of composite structures.

In response to these needs, a program was conducted by the Applied Research Laboratory, Pennsylvania State University and Oak Ridge National Laboratory to develop the scientific and engineering basis for performing laser-based surface modifications involving the addition of hard particles, such as carbides, borides, and nitrides, within a metallic matrix for improved wear, fatigue, creep, and corrosion resistance. This has involved the development of advanced laser processing and simulation techniques, along with the refinement and application of these techniques for predicting and selecting materials and processing parameters for the creation of new surfaces having improved properties over current coating technologies. This program has also resulted in the formulation 
of process and material simulation tools capable of examining the potential for the formation and retention of composite coatings and deposits produced using laser processing techniques, as well as positive laboratory demonstrations in producing these coatings.

Several industrial partners, chosen based on their broad industry representation and interest in improved laser-based coatings, also participated during program execution. These companies included: Spirex Corporation of Youngstown, Ohio; Praxair Surface Technologies, Incorporated of New Castle, PA; Alvord-Polk Corporation of Millersburg, PA; and Nuvonyx Incorporated of Bridgeton, MO. In most instances, the industrial partners provided input into the requirements for improved deposition materials and helped identify potential application for the improved coatings, as well as provided materials and performance evaluations during process demonstrations.

Results obtained during this program included details concerning material formulation and constitution for obtaining composite microstructures during laser deposition, as well as process related information to support this technology. The use of an explicit finite differencing model to describe heat transfer during the laser cladding process, with the incorporation of an internal absorption submodel, was found to provide a fairly accurate representation of the thermal histories within the deposit and the substrate material. The formulation of the internal absorption sub-model required the establishment of critical parameters governing energy transfer between the beam and porous powder. These parameters were obtained through novel experimentation designed to measure the amount of energy transmitted through various thickness of a pre-placed powder layer. The technique enabled the establishment of the absorptivity and attenuation coefficients for pure iron and pure copper powders during $\mathrm{CO}_{2}$ and $\mathrm{Nd}$ :YAG laser irradiation. 
In conjunction with the process simulation techniques, the application of computational thermodynamic and kinetic models to design laser surface alloying materials was demonstrated and resulted in a vast improvement in the formulation of materials used for producing composite coatings. The methodology was used to identify materials and to selectively modify microstructures for increasing hardness of deposits produced by the laser surface alloying process. Computational thermodynamic calculations indicated that it was possible to induce the precipitation of titanium carbonitrides during laser surface alloying provided there was sufficient amount of dissolved titanium, carbon, and nitrogen in the liquid steel. This was confirmed experimentally by using a powder mixture of 431-martensitic steel, titanium carbide powder, and nitrogen shielding, during laser deposition to produce deposits exhibiting relatively high hardness (average surface hardness of $724 \mathrm{HV}$ ). The same approach was extended to direct diode laser processing and similar microstructures were attained. The above analysis was extended to develop an in-situ precipitation of $\mathrm{Ti}(\mathrm{CN})$ during laser deposition. The Ti addition was achieving by mixing the 431 martensitic steel powders with ferro-titanium. The dissolution of nitrogen was achieved by using 100\% nitrogen shielding gas, which was indicated by thermodynamic analysis.

Demonstrations were also conducted utilizing the tools developed during the program and resulted in several viable composite coating systems being identified. This included the use of $\mathrm{TiC}$ and ferro-titanium in martensitic-grade stainless steel matrix material with and without the use of active $\mathrm{N}_{2}$ shielding gas, WC hard particles in a martensitic-grade stainless steel matrix material, WC and $\mathrm{BN}$ in a nickel-based matrix material, and WC in highly alloyed iron-based matrix. Although these demonstrations indicated the potential of forming composite coatings, in certain instances, the intended industrial applications involved unique requirements, such as coating of internal surfaces, which hindered the full development of the improved coating technology. However, it is believed that the addition of common hard particles, such as WC or TiC, to matrix material 
representing martensitic grades of stainless steel offer opportunities for improved performance at relatively low material cost. 


\subsection{INTRODUCTION}

There is a continued need for new and improved coatings that provide increased life for critical mechanical components. This is particularly true for heavy industries such as mining and mineral processing, primary material production and fabrication, paper and pulp, and agriculture. Typically, coating technology utilized for these industries requires metallurgical bonding for durability, high deposition rates affordable restoration, and hard surfaces for maintaining high wear resistance. The ability to increase the operating life of critical components in these industries can result in significant savings in energy consumption and operating costs. It is anticipated that the implementation of new coating technologies resulting from the development and implementation of improved coating processes, such as laser-based composite coatings, could be relevant to approximately $5 \%$ of future industrial applications involving wear and corrosion critical needs. It is also anticipated that the development of composite coating techniques will result in a $1 \%$ improvement due to increased operational efficiency and life extension of effected components. Although the improvements in efficiency have been conservatively estimated, the application of advanced coating technologies may have a profound effect on energy consumption within the U.S. based on the magnitude of energy use by these industries.

Laser surface modifications, in the form of cladding and alloying are gaining widespread use because of its ability to provide high deposition rates, low thermal distortion, low base-metal dilution, low metallurgical degradation of the base material, and refined microstructures in the deposition due to high solidification rates. Because of these advantages, laser-based processing is considered a prime candidate for producing ultra-hard coatings through the formation of composite structures, and it is anticipated that these coatings will result in improvements in energy efficiency and productivity through improved component performance, reduced dependency on the environmentally 
unfavorable chromium electroplating process, and increased global competitiveness of U.S. industry.

\subsection{Laser Surface Modification Processes}

Laser surface modification is a versatile process through which one can modify the surface properties of metals and ceramics to obtain required properties. The properties of the surface are modified by localized melting and solidification. The laser surface modification process alters the solidified microstructure by alloyinduced transformations, composite strengthening through production of secondphase particles, or a combination of both. A variety of applications have been developed for the laser surface modification process. The most common uses are for improving resistance to corrosion, abrasion, erosion, oxidation, and wear. The properties of the modified surface depend on the microstructure that evolves during melting and cooling. One of the most common microstructural changes is the dissolution of primary phases, leading to precipitation of complex phases during melting and subsequent solidification [1]. For example, during laser surface modifications on nickel-based alloys with silicon carbide particles, the particles melt in the liquid pool, and during subsequent solidification, $\mathrm{M}_{7} \mathrm{C}_{3}$ carbides ${ }^{*}$ precipitate from the liquid [2]. Previous work has attempted to control the surface modified microstructure by adjusting the laser beam parameters and by changing the alloying additions through extensive experimental research [3, 4]. Adding alloying elements to the molten pool modifies the liquid pool composition. The alloying elements are added by pre-placing powders on the substrate, by injection into the trailing edge of the molten pool, or a combination of both techniques. In some instances, the major alloying elements are preplaced on the sample and secondary alloying elements or particles are added to the trailing edge of the molten pool. It is important to note that the microstructural evolution in the alloyed regions is controlled by the thermal cycles experienced in these regions and by the chemical stability of the various phases.

\footnotetext{
* Here the letter "M" corresponds to metal content including Fe, Cr and other alloying additions
} 
Laser surface modifications, related to material additions, may be grouped into two categories: laser surface alloying and laser cladding. These processes are illustrated schematically in Figure 1. Laser surface alloying involves the melting of the substrate followed by the addition of a second material, through powder or filler wire additions, to form a new composition or microstructure having properties that are better than either of the original materials; whereas, laser cladding entails the addition of a new material on the surface, primarily through the addition of powder, that melts and mixes with a small amount of molten material of the substrate. Shown in Figure 1 is a schematic illustration of the two processes of interest. The properties obtained by laser cladding are primarily dictated by the characteristics of the added, or clad, material. In both instances, the process results in complete metallurgical bonding between the coating that is produced and the substrate. Although both processes may benefit by the development of advanced composite coatings, the laser cladding process inherently provides increased deposition and is especially applicable to the manufacturing and refurbishment of large components used in many of the industries mentioned above.

Because of the positive attributes associated with the laser cladding process, it is rapidly being adopted for many manufacturing, repair, and refurbishment applications for engineered components. Shown in Figure 2 is a schematic of a typical laser cladding process utilizing a high-power $\mathrm{CO}_{2}$ laser for producing clads at relatively high deposition rates and a photograph of this type of system being used for cladding. Shown in Figure 3 are two examples of laser cladding systems currently being utilized for manufacturing of new components and refurbishment of used components. Figure 3a shows laser cladding being utilized to deposit a high, carbide-containing, ferrous-based material to produce a tooling-grade surface on the fluted areas of boring tools, and Figure $3 \mathrm{~b}$ shows a nickel-based material being applied for refurbishment of a part that will experience elevated temperature exposure. Various materials are currently used 
for laser surface alloying and laser cladding, and these materials are chosen based on the performance requirements of the part.

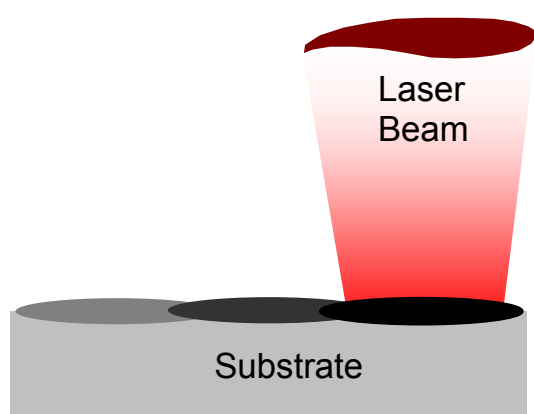

(a)

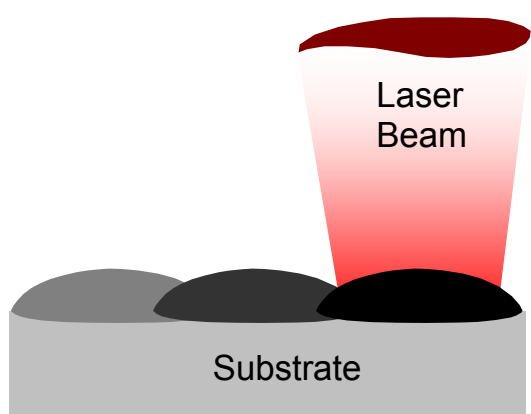

(b)

Figure 1 - Schematics of the (a) laser surface alloying process showing additions made to the substrate and the (b) laser cladding process where additions form a new coating (note, the schematics represent three passes being conducted in the direction of the plane of the figure).
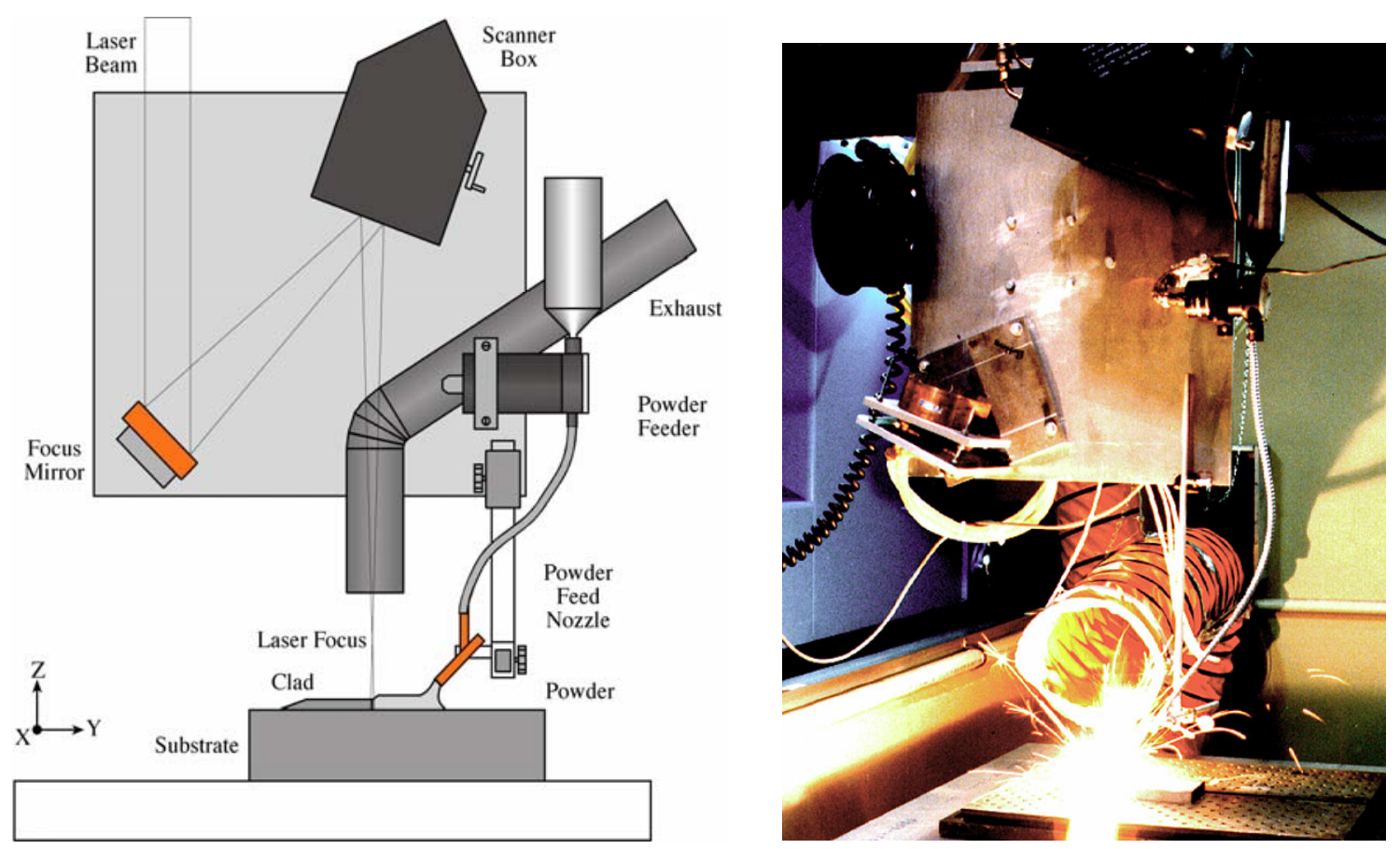

Figure 2 - Schematic of high-power $\mathrm{CO}_{2}$ laser cladding process and photograph of this type of configuration being used to clad at $12 \mathrm{~kW}$ of laser power.

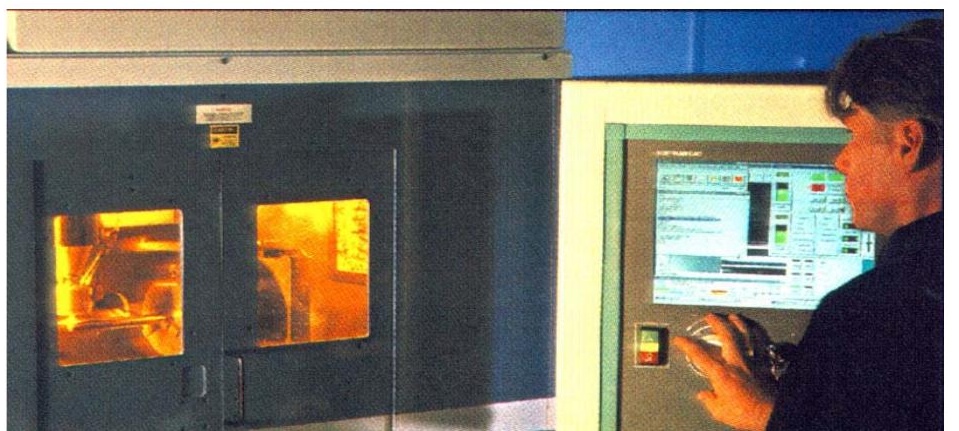


(a)

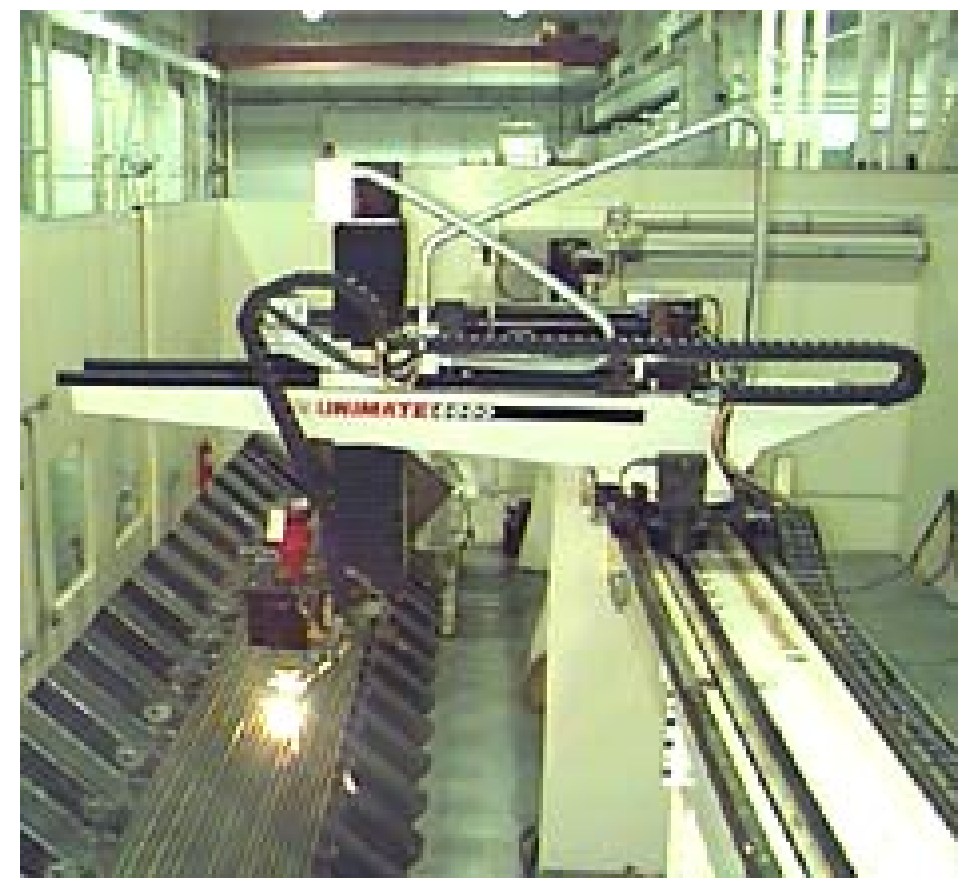

(b)

Figure 3 - Photographs of commercial laser-based deposition systems being used to deposit (a) high carbide containing ferrous alloys to produce boring tools and (b) deposition of a nickel-based material for elevated temperature resistance (photograph 3a is courtesy of Alvord Polk Corporation and photograph $3 \mathrm{~b}$ is courtesy of Praxair Surface Technologies, Inc.).

Typical material systems used for laser deposition on large components requiring good wear and corrosion resistance are cobalt-based alloys, such as the Stellite ${ }^{\mathrm{TM}}$ family of alloys, nickel-based alloys, such as Inconel ${ }^{\mathrm{TM}}$ and Hastelloy ${ }^{\mathrm{TM}}$ alloys, and martensitic grades of stainless steels. Shown in Figure 4 is a component from a heavy excavating system that had been laser clad using a 
martensitic-grade of stainless steel. A major equipment producer has replaced chromium electroplating with laser cladding to produce the component shown in the figure.

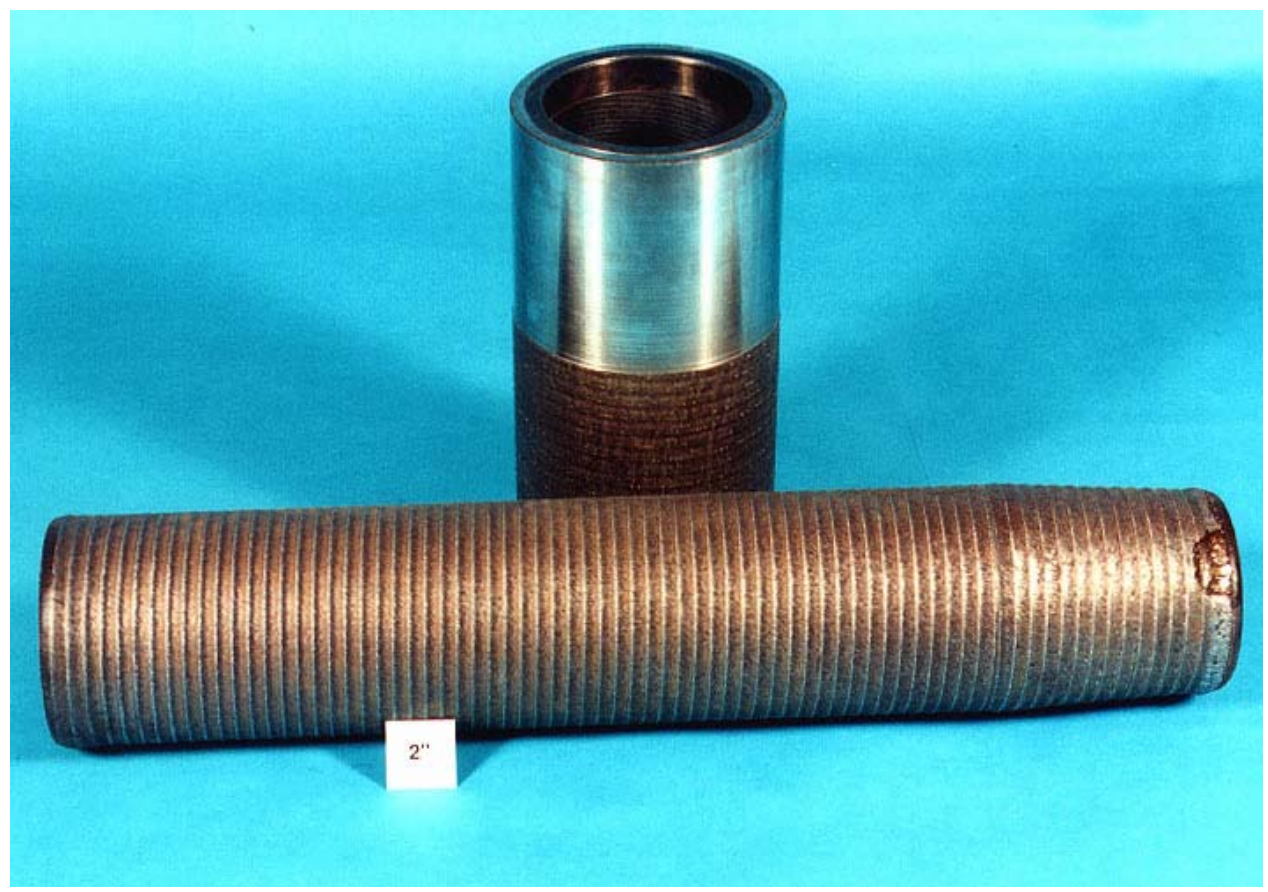

Figure 4 - Component from a heavy excavating system that had been clad using a martensitic-grade of stainless steel. The top portion of the coating on the standing component has been machined.

As mentioned earlier, the particular alloy chosen for deposition depends on the service requirements of the component to be manufactured, repaired, or refurbished. Corrosive environments seen in the metal processing, mining, paper, and energy industries may be extremely diverse, and hence, selection of a surfacing alloy for corrosion resistant service should be based on a particular service environment. In general, nickel-based alloys may be expected to provide better corrosion resistance than stainless steel alloys; however, the lower hardness achieved by these alloys would be expected to show lower wear life. The cobalt-based alloys, having good corrosion resistance and hardness, in many instances provide an optimal combination of properties for these 
applications. Although cost must also be considered in choosing a surfacing alloy, and should be weighed against the extended service life of the component. Nickel-based and cobalt-based alloys are the most costly at $\$ 25$ to $\$ 40$ per pound. Surfacing alloys representing the martensitic grades of stainless steel alloys are approximately $\$ 10$ to $\$ 20$ per pound.

Powders commonly used for high wear and corrosion resistance rely on various mechanisms for developing hardness within the laser deposition. The cobaltcontaining alloys rely primarily on increasing stacking fault energy and solid solution strengthening by $\mathrm{Cr}$ and $\mathrm{W}$ additions to develop high hardness within the deposition; whereas, the nickel-based alloys are generally solid solution strengthened by the addition of only $\mathrm{Cr}$ [5]. The martensitic grades of stainless steel rely on carbon for solid solution strengthening and to participate in the martensitic transformation during cooling. Shown in Figure 5 are micrographs and the range of microhardness for typical alloys representing cobalt-based, nickel-based, and martensitic stainless steel alloys used in laser surfacing.
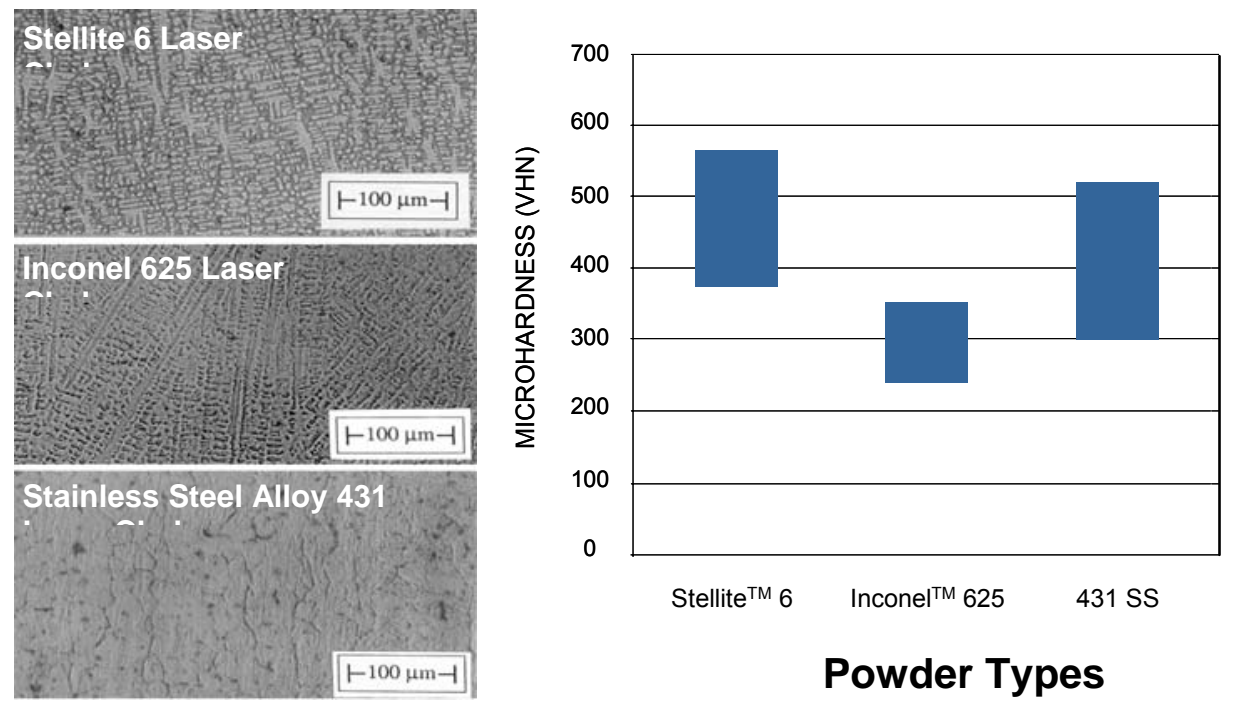

Figure 5 - Microstructures and range of microhardness for common alloys used for the laser cladding process (note, microstructures represent the last pass of a three-pass clad and microhardness is an average of at least five measurements).

\subsection{Formation of Composite Coatings}


As a means to achieve additional wear resistance of surface depositions, recent research has been directed at adding constituents that alter the solidified microstructure by alloy-induced transformations, developing composite microstructures containing hard particles, or a combination of both [6-9]. Of particular interest is the injection and retention of hard particles, such as carbides, nitrides, and borides, into ferrous and non-ferrous alloys that impart high hardness and wear resistance on the surface while retaining the toughness of the substrate material.

Although the theory concerning wear resistance associated with composite coatings is complicated by many factors, a basic description of the process may be used to gain insight into several of the governing parameters. When two surfaces are in contact under load, small asperities representing the microsurface are plastically deformed and ultimately fragment to become wear particles. Hence, the mechanism responsible for abrasive wear resistance of composite coatings involves the elastic, plastic, and viscous properties of the materials in contact [10], as well as the interfacial properties between the particles and matrix and fracture toughness of both phases [11-13]. Shown in Figure 6 is a diagram by Lee et al. [14] illustrating the effect of particle volume fraction on wear rate based on two relationships using rule of mixtures and various experimental data [11,15-21]. The straight-line between $\mathrm{W}_{\mathrm{m}}$ (wear rate of the matrix) and $W_{p}$ (wear rate of particles) in the figure represents a linear rule of mixtures with the wear rate being proportional to the particle volume fraction in the composite [22]. The curved line between $W_{m}$ and $W_{p}$ represents the inverse rule of mixtures between wear rate and volume fraction [23]. The gray bounded regions in the figure represent experimental observations of wear rate for various composite materials, where wear of ductile matrix material is governed by plastic deformation, and the wear mechanism of brittle matrix material is fracture on the surface [14].

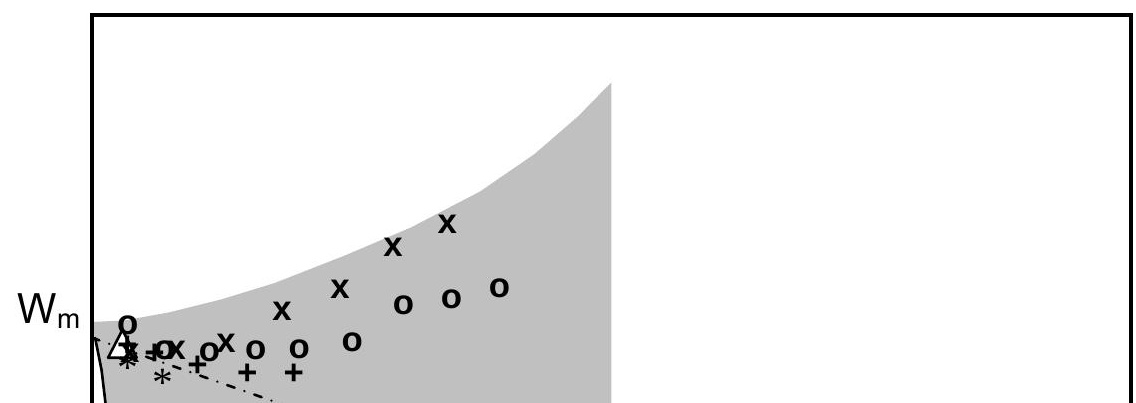


Figure 6 - Wear rate for composite materials as a function of volume fraction of the matrix based on rule of mixtures and experimental data (experimental data from 11,15-21).

It is obvious from the experimental data shown in Figure 6 that neither of the rule of mixture relationships accurately depict wear rate based on loading of the composite having a ductile matrix. Depending upon the matrix and second phase material within the composite, wear rates may be improved or degraded when compared to the matrix material. A recent model proposed by Lee et al. [14] to explain the abrasive wear resistance of a composite, $W_{c}$, has been developed utilizing a physically-based, mechanistic approach and is capable of accurately depicting observed experimental data:

$$
\frac{1}{W_{c}}=\frac{V_{m}}{W_{m}}+C \frac{V_{p}}{W_{p}}
$$

Where $\mathrm{V}$ is the respective volume fraction, $\mathrm{W}$ is the wear rate, $\mathrm{C}$ is a contribution coefficient parameter, and $m$ and $p$ are subscripts to denote the matrix and 
particulate reinforcement, respectively. The coefficient, $\mathrm{C}$, represents the contributing effects, both positive and negative, of the reinforcement on wear resistance of the composite and is related to the fracture toughness and relative size of the reinforcement particles.

The model discussed above physically describes the effects of matrix and reinforcement selection on overall wear resistance of the composite coating. Interfacial toughness between the reinforcement and the matrix can play a critical role in increasing wear rate with composites having hard particle reinforcement. In general, larger particles and particles having high interfacial bond strength lead to improved wear resistance.

Typically, the particle reinforcement is added in powder form by pre-blending with the matrix powder or injection into the rear of the melt pool. Injection of the reinforcement particles, secondary to the matrix material, is often utilized to prevent dissolution of the reinforcement phase by decreasing particle exposure to elevated temperatures. Although the reinforcement particles have the potential to significantly increase hardness and wear resistance, the ability to retain these constituents at temperatures experienced within the melt pool is crucial for successful surface hardening. Dissolution of these particles results in the loss of their ability to impart improved wear resistance, and in the case of carbides, the opportunity for available carbon to create brittle microstructures that increase the sensitivity to cracking upon cooling. Hence, the stability of the reinforcement phase during the rapid heating and cooling cycle experienced in the laser surface modification process is critical in developing affordable coatings having improved wear resistance.

The stability of hard particles may be described in terms of their equilibrium solubility in the molten pool and the temperatures experienced during processing. An indication of particle stability is its solubility over the temperature range of interest. The solubility of the particle may be estimated by its enthalpy of 
formation, $\Delta \mathrm{H}_{\mathrm{f}}$. In general, lower values of $\Delta \mathrm{H}_{\mathrm{f}}$ denote decreased solubility of the particle and greater stability. The enthalpy of formation for various carbides, nitrides, and borides is shown in Figure 7 [24]. Although the general solubility may be used as a guide for stability and retention of a second-phase particle, detailed analysis requires consideration of the composition of the solution, i.e. alloying elements within the molten pool, and the rate at which a particle may dissolve during the cooling cycle, i.e. isokinetic analysis for particle dissolution [25].

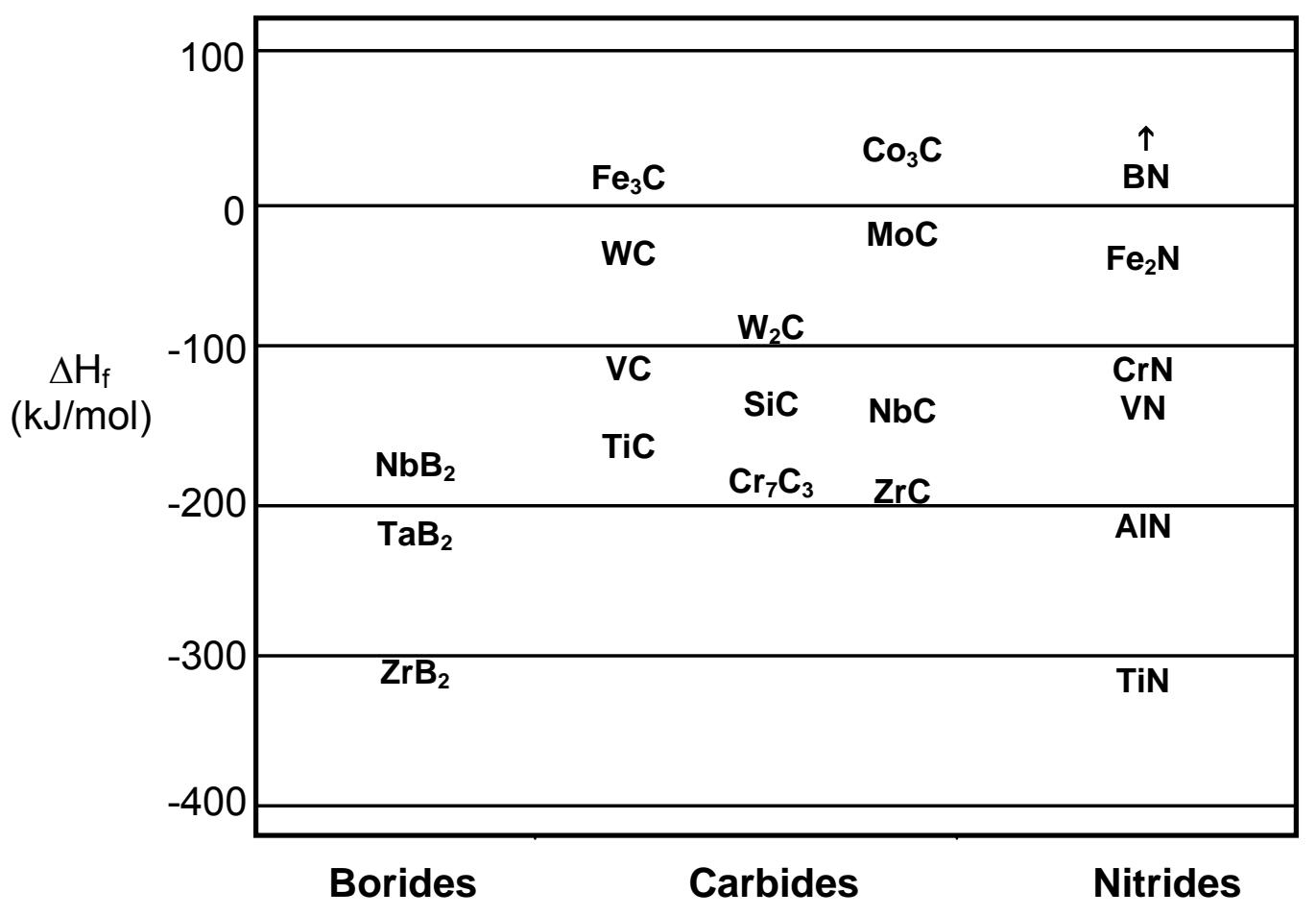

Figure 7- Enthalpy of formation of various hard particles.

Based on the information discussed above, the ability to determine the stability of hard particles within the melt pool and the resultant microstructure is paramount in developing these types of advanced coatings. In order to understand and control the microstructural evolution in laser surface modifications without resorting to substantial experimentation, various phase stability, solidification, and kinetic calculations must be performed before postulating new and improved 
alloy systems. The use of computational thermo-kinetic models have shown great utility and provided useful data in incorporating tungsten carbide particles in ferrous and nickel substrates [1]. However, certain processing and analysis considerations continue to pose challenging questions that must be addressed to successfully implement this technology. Hence, the research described in this report stresses computational thermo-kinetic and heat transfer analysis, in conjunction with experimentation and materials characterization, to understand and control the full development of material and process components related to the formulation of advanced composite coatings for laser surface modifications. 


\subsection{PROGRAM DESCRIPTION}

The research program described in this report involved a collaborative arrangement among the Applied Research Laboratory, Pennsylvania State University (ARL Penn State), Oak Ridge National Laboratory (ORNL), and selected industry representatives. These participants provided a natural progression of the process development and technology transfer functions necessary for successful development and implementation of advanced composite coating systems.

As discussed earlier, an important consideration in formulating composite coating systems involves the stability of the system during and immediately after processing. Hence, this research entailed the development of advanced processing and simulation techniques for predicting and selecting materials and appropriate processing parameters that would result in the retention of the hard particle reinforcement. The development of thermo-kinetic analyses, coupled with development of advanced processing techniques, offer a cost-effective method for designing and implementing composite coating systems that may have vast ramifications to the national industrial base. The approach utilized during this investigation is shown graphically in Figure 8.

Laser induced composite coatings capable of retaining selective hard particles (such as carbides, borides, or nitrides) onto the surface of ferrous, nickel-based, and bronze alloys offer significant benefits for improving wear and corrosion resistance. However, the retention of these particles is dictated by the reactions and transformations that occur at elevated temperatures during processing. The ability to efficiently design superior coating systems requires a detailed comprehension of these reactions so that processing conditions and coating performance may be optimized for a particular application. This predictive capability, when used concurrently during the development of laser processing 
techniques, provides an efficient and effective means for optimizing advanced coating systems.

Industries that will be served by this technology include mining, mineral processing, materials, agricultural, pulp and paper, foundry, and primary metal processing. All of these industries would benefit from improved coatings to improve wear resistance and corrosion protection under extremely harsh environments. The ability to economically produce composite coatings has the potential to provide a revolutionary improvement in wear capabilities of these components through the addition of ultra-hard particles to the coatings, while maintaining corrosion resistance through selection of the appropriate matrix material. Within this context, advanced composite coatings may be used to broaden the operating window of these energy intensive industries, while offering opportunities for improving process operating efficiency, reducing energy intensity, increasing productivity through improved performance and reduced down-time, and improving the viability of currently marginal processes.

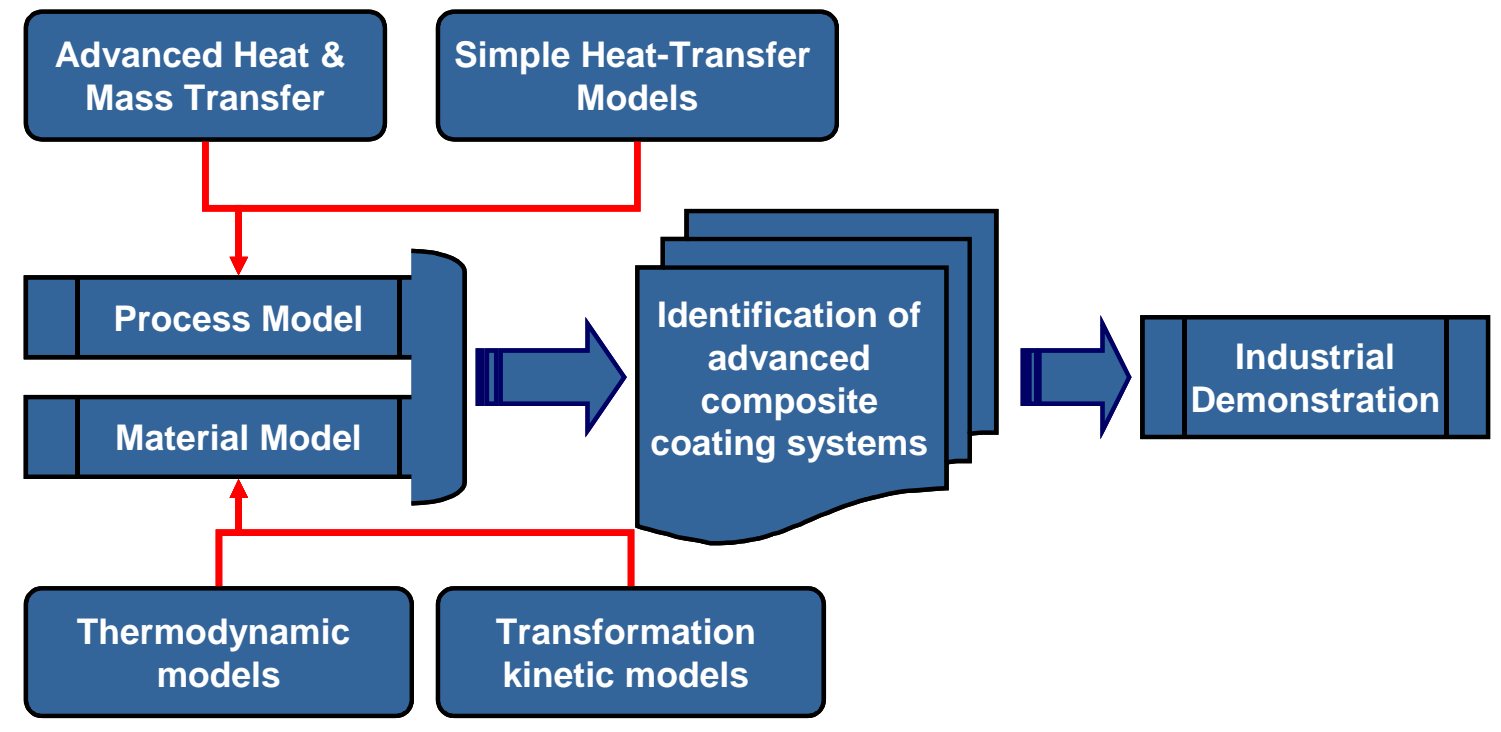

Figure 8 - Graphical illustration of development tasks for research program showing progression to implementation. 
The primary concepts that were proposed and explored during this research included the development of laser processing techniques that offer metallurgical bonding, superior coating performance, low thermal distortion, and minimal metallurgical degradation of the substrate, and the development of material simulation techniques that provide a cost-effective approach for developing and designing alloy systems applicable to laser processing. It is strongly believed that the development of these capabilities will ultimately benefit, both, the Department of Energy's Industries of the Future Program, as well as the crosscutting technologies of the Industrial Materials of the Future Program, that broadly support these industries. The program was directed at developing material and processing technology for advanced coatings for improved wear and corrosion resistance in various industrial applications. The target goals during this research were:

- construction of thermodynamic and kinetic models capable of providing predictive capabilities for describing the microstructural evolution of potential composite coatings

- development of a process model having the ability to accurately simulate the thermal laser response of the material during the laser deposition process, and

- the application of these models for producing selected composite coating for laboratory verification and industry demonstrations.

The economic benefits derived from this research is improved coating technology that will result in greater process and energy efficiencies and enhanced national competitiveness due to increased performance, life extension of critical components, decreased down time, superior wear performance over a wider environmental range, and low cost replacement of exotic materials by selective metallurgical coatings on lower cost substrates. It has been anticipated that the development of new coating technologies resulting from this research will be 
relevant to approximately $5 \%$ of future industrial applications involving wear and corrosion critical needs. It also has been anticipated that the development of the advanced coating technology will result in a $1 \%$ reduction in energy usage due to increased operating efficiency and life extension of effected components, as well as significant environmental benefits, such as the reduction of effluents containing hexavalent chromium $\left(\mathrm{Cr}^{6+}\right)$ produced by the chrome electroplating industry. 


\subsection{THEORETICAL AND EXPERIMENTAL TASKS}

\subsection{Formulation of Materials Simulation Techniques}

The ability of a hard particle to be retained within the laser melt pool is governed by the initial size of the particles, the thermal cycle that the particles experience, the thermodynamic stability of the particles within the molten pool, and the rate at which dilution may occur. The model recently presented by Babu et al. [26], which utilizes ThermoCalc $®$ software, may account for these complexities. In this approach, the composition of the substrate is initially used to determine thermodynamic equilibrium between the molten pool and the various possible reaction products. The phase having the greatest stability is based on the magnitude of the driving force for the reaction, i.e. the greatest change in free energy associated with a particular reaction. Subsequent kinetic analysis is based on the most suitable phase representing the rate-controlling process.

The stability of a phase is governed by its free energy, which is a function of temperature and its constitution. A generic description of free energy, $\mathrm{G}^{\phi}$, of a solid-solution phase, $\phi$, is given by the following equation [2]:

$$
G^{\phi}=G_{0}^{\phi}+G_{\text {ideal }}^{\phi}-\text { mix }+G_{\text {excess }}^{\phi}-\text { mix }
$$

Where $G_{0}^{\phi}$ is the free energy contribution from pure components in that phase, $\mathrm{G}_{\text {ideal-mix }}^{\phi}$ is the contribution from ideal mixing, and $\mathrm{G}_{\text {excess-mix }}^{\phi}$ is the contribution due to non-ideal interactions between the components. With the description of this $\mathrm{G}^{\phi}$ for all phases that can form in a given alloy, it is possible to estimate equilibrium relative fractions of each phase and their constitution at a given temperature. This is performed by minimization of free energy curves of various 
phases. This procedure also allows for the determination of the tie line, which is schematically shown in Figure 9.

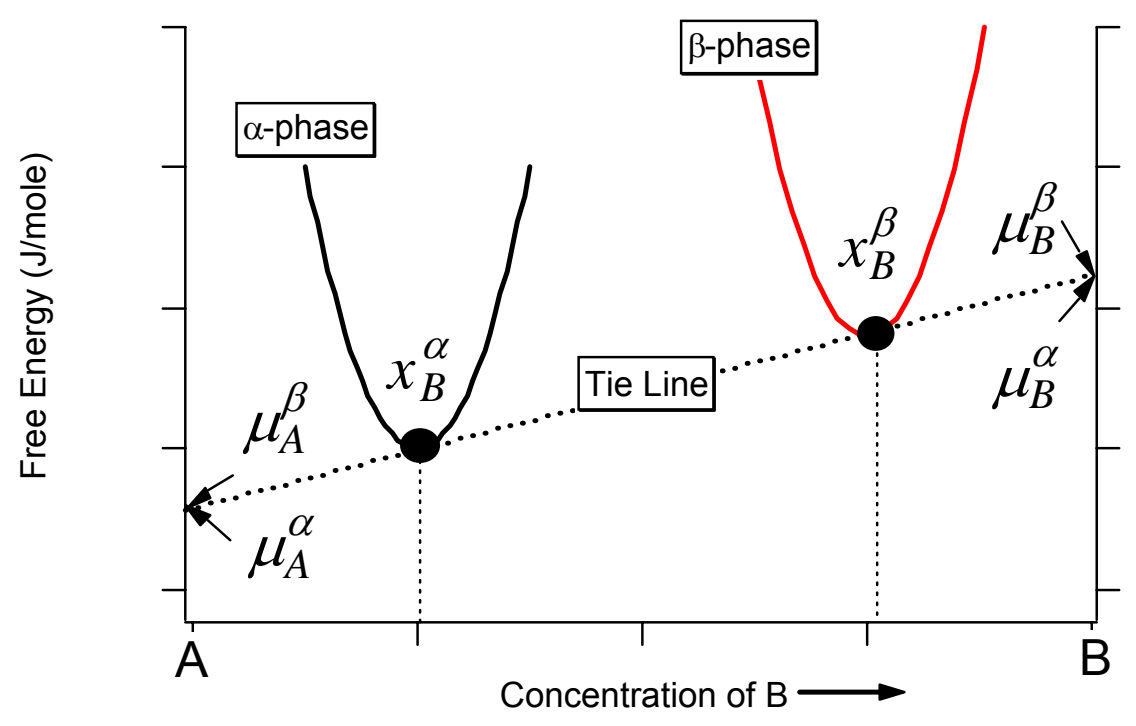

Figure 9. Free energy of a $\alpha$-phase and $\beta$-phase and the common-tangent construction for the description of the tie line and chemical potential of elements $\mathrm{A}$ and $\mathrm{B}$.

The chemical potential, $\mu_{i}^{\phi}$, of element $\mathrm{i}$ in $\phi$-phase are obtained from the free energy expressions given in Equation 2 using the following relationship:

$$
\mu_{A}^{\phi}=G^{\phi}-x_{B}^{\varphi} \frac{\partial G^{\phi}}{\partial x_{B}^{\phi}} ; \mu_{B}^{\phi}=G^{\phi}+\left(1-x_{B}^{\phi}\right) \frac{\partial G^{\phi}}{\partial x_{B}^{\phi}}
$$

Equations 2 and 3 can be extended to multi-component systems by invoking the equality of chemical potential of other components. As an example, the equation governing equilibrium $\alpha$ and $\gamma$ phases in the $\mathrm{Fe}-\mathrm{Cr}-\mathrm{Ni}-\mathrm{C}$ alloy system is given below.

$$
\mu_{\mathrm{C}}^{\vee}=\mu_{\mathrm{C}}^{\alpha} ; \mu_{\mathrm{Fe}}^{\vee}=\mu_{\mathrm{Fe}}^{\alpha} ; \mu_{\mathrm{Cr}}^{\vee}=\mu_{\mathrm{Cr}}^{\alpha} ; \mu_{\mathrm{Ni}}^{\vee}=\mu_{\mathrm{Ni}}^{\alpha} ;
$$


Using the above relation, with appropriate mathematical methods, one can calculate the phase equilibrium between $\gamma$ and $\alpha$ phases as a function of $\mathrm{Cr}, \mathrm{Ni}$ and $\mathrm{C}$ concentration.

Although the phase stability calculation allows one to estimate the equilibrium microstructure at a particular temperature, microstructural control in most thermal processes relies on the kinetics of product phase formation from the parent phase. For example, in low-alloy steels, it is important to understand the kinetics of austenite formation to control the microstructural mixture of ferrite and martensite in duplex steels. In addition to the kinetics of transformation, the equilibration of the non-equilibrium microstructure that is formed during processing is also of great interest. Both of the above phenomena can be described using diffusion controlled growth models. This can be achieved by coupling thermodynamic models and diffusion controlled growth calculations.

Formation of a product phase with a different composition from the parent phase involves diffusion of partitioning elements. By assuming that there exists a localequilibrium between the parent and product phase at the interface, the interfacial concentrations can be given by the tie-lines drawn in the phase diagram. Given this condition, it is possible to describe the movement of this interface as a function of temperature and time by solving Fick's second law and maintaining the mass-balance at the interface. The governing equation for $\alpha$-phase formation in $\gamma$-phase in one-dimension is given as an example below.

$$
\left(C_{l}^{m, a}-C_{l}^{m, y}\right)(d l / d t)=D_{y}^{m}\left(d C_{y}^{m} / d x\right)-D_{\alpha}^{m}\left(d C_{\alpha}^{m} / d x\right)
$$

In the above equation, $(\mathrm{dl} / \mathrm{dt})$ is the rate of interface movement or velocity. The terms $C_{1}^{m, \alpha}$ and $C_{1}^{m, \gamma}$ are the interface concentrations of element " $m$ " in the $\alpha$ phase and $\gamma$-phase. The terms $D_{\alpha}^{m}$ and $D_{\gamma}^{m}$ are the diffusivity of element "m" in 
$\alpha$-phase and $\gamma$-phase. The terms $\left(\mathrm{dC}_{\gamma}^{\mathrm{m}} / \mathrm{dx}\right)$ and $\left(\mathrm{dC}_{\alpha}^{\mathrm{m}} / \mathrm{dx}\right)$ are the concentration gradient of element "m" in $\alpha$-phase and $\gamma$-phase.

\subsection{Validation of Material Model}

Initial theoretical trials were conducted to validate the general utility of the thermodynamic and kinetic models. Potential coatings of tungsten carbide particles in iron and nickel-based matrices were chosen for validation since this system is of interest to industry and several of the industrial partners of the program had experience with coating development and microstructural information involving compositions within this system.

To understand the microstructural evolution of the laser surface modification process, various phase-stability, solidification, and kinetic calculations were performed in iron-tungsten-carbon (Fe-W-C) and nickel-tungsten-carbon (Ni-WC) alloy systems. First, ThermoCalc ${ }^{\text {TM }}$ software (version M) was used to perform thermodynamic calculations that determined the phase stability of the various phases in Fe-W-C and Ni-W-C at the melting point of a low-alloy steel, i.e., 1800 $\mathrm{K}$. The calculations considered the stability between following phases: liquid, $\mathrm{BCC}$ (ferrite), FCC (austenite), MC (tungsten carbide), graphite, $\mathrm{M}_{6} \mathrm{C}$ carbide, and $\mu$ phase. The calculated stability regions are shown in Figure 10. The significance of the above diagram can be understood by considering typical composition for a Fe-W-C system. If a laser deposit containing $20 \mathrm{wt} . \% \mathrm{MC}$ carbide is considered, the bulk composition would be approximately $\mathrm{Fe}-10$ at. \% W - 10 at. \% C. The stability diagram for this Fe-W-C system [see Figure (10a)] showed that, only the liquid phase is stable at $1800 \mathrm{~K}$. In contrast, the stability diagram for $\mathrm{Ni}-10$ at. $\% \mathrm{~W}-10$ at.\% $\mathrm{C}$ showed that both the liquid and $\mathrm{MC}$ phases are stable. This result supports the preferential dissolution of $\mathrm{MC}$ carbide observed in iron-rich liquid and the higher stability of tungsten carbide in nickelrich liquid. Even in nickel-rich liquid, the tungsten carbide will dissolve 
completely if the concentrations of $\mathrm{W}$ and $\mathrm{C}$ are reduced. Therefore, the stability of these phases are determined by the bulk alloy composition. It is important to note that the bulk composition of the alloy will be affected by the laser scanning speed.

The above thermodynamic calculations can be readily extended for evaluating the reprecipitation of $\mathrm{MC}$ carbides during solidification in the laser surface modification process deposit. In this case, during the laser surface modification process, both the matrix and the tungsten carbide melt and constitute a uniform liquid composition at high temperatures ( $>2300 \mathrm{~K}$ ). Upon cooling, the liquid composition may lead to reprecipitation of tungsten carbide or other phases and/or a different sequence of phase evolution. Scheil assumptions were used to calculate the sequence of phase evolution from the liquid phase [26]. The calculations assumed uniform liquid compositions of $\mathrm{Ni}-10$ at. \% W - 10 at. \% C and $\mathrm{Fe}-10$ at. $\% \mathrm{~W}-10$ at. $\% \mathrm{C}$ at $2300 \mathrm{~K}$. At $2300 \mathrm{~K}$, the liquid phase is the only stable phase for both compositions. The temperature was then lowered in 1 $\mathrm{K}$ steps, and the calculations were repeated. After each calculation, the fraction of solid formed was recalculated and the bulk composition was reset to the liquid composition. The calculations were repeated until the thermodynamic equilibrium indicated an absence of liquid.

The details of these calculations are given in references 26 and 27; results of the current analysis are shown in Figure 11. The calculations for the Fe-W-C system showed that the liquid phase remains stable until $1621 \mathrm{~K}$, at which point the calculations indicated that $\mathrm{M}_{6} \mathrm{C}$ is the first phase to solidify from liquid. Further cooling leads to the precipitation sequence of FCC (austenite), MC (tungsten carbide), $M_{6} C$ carbide, and graphite phases due to change of liquid composition. The calculated terminal solidification temperature was at $1413 \mathrm{~K}$. In contrast, the calculations for the Ni-W-C system show that the first phase to solidify from the liquid is $\mathrm{MC}$ (tungsten carbide) at $1844 \mathrm{~K}$ and that further cooling leads to the 
precipitation of FCC (austenite) and then graphite. The calculated terminal solidification temperature was at $1617 \mathrm{~K}$. Calculations indicate that when the iron-rich liquid solidifies it may contain austenite, $M_{6} C, M C$, and graphite, whereas the nickel-rich liquid may contain austenite, $\mathrm{MC}$, and graphite. The nickel-rich liquid does not promote the formation of $\mathrm{M}_{6} \mathrm{C}$ carbides. In addition, the nickel-rich alloy system has a higher melting point (1617 K) than that of the iron-rich system $(1413 \mathrm{~K})$. Although the thermodynamic calculations are useful in evaluating the reprecipitation of tungsten carbide, they do not yield insight into the dissolution rate of tungsten carbide when it is added to the trailing edge of the liquid pool. Therefore, the diffusion-controlled dissolution rate of the tungsten carbides was estimated as they were introduced into the liquid pool and during subsequent cooling.

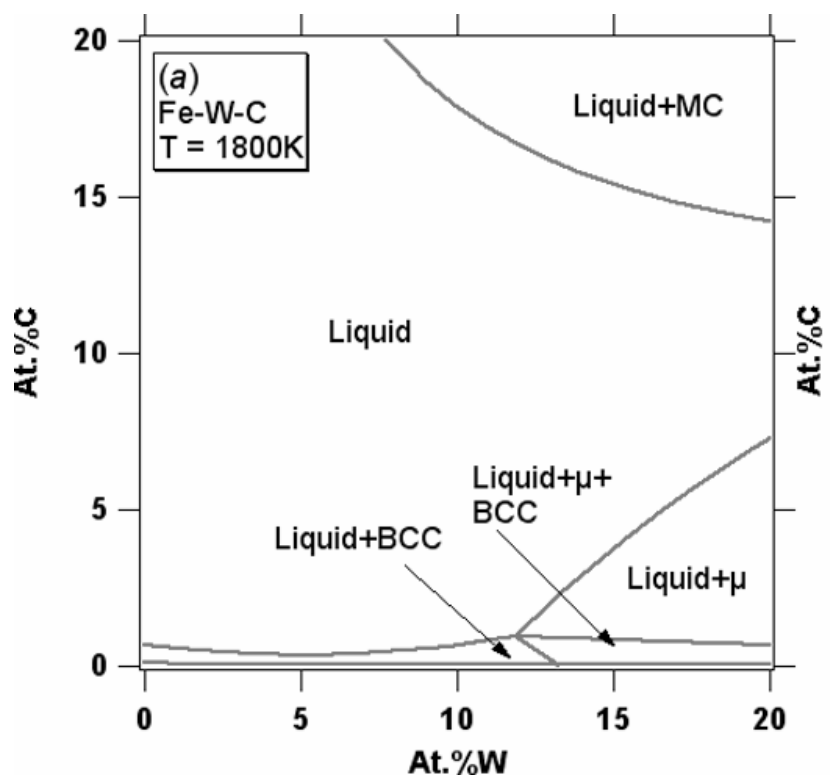

(a)

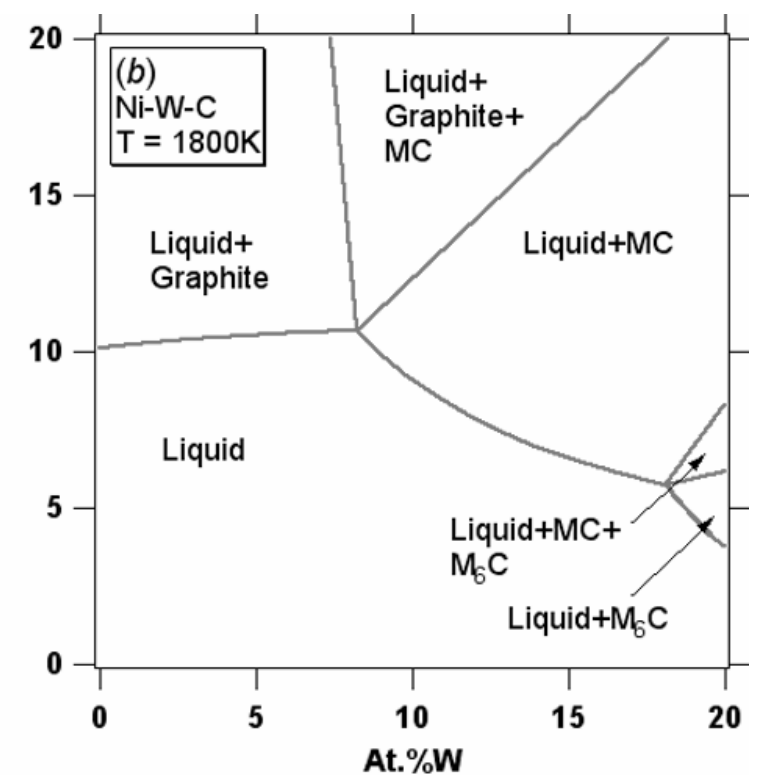

(b)

Figure 10 - Comparison of calculated phase boundary regions for ternary alloy system at $1800 \mathrm{~K}$ : (a) Fe-W-C system and (b) Ni-W-C system. 


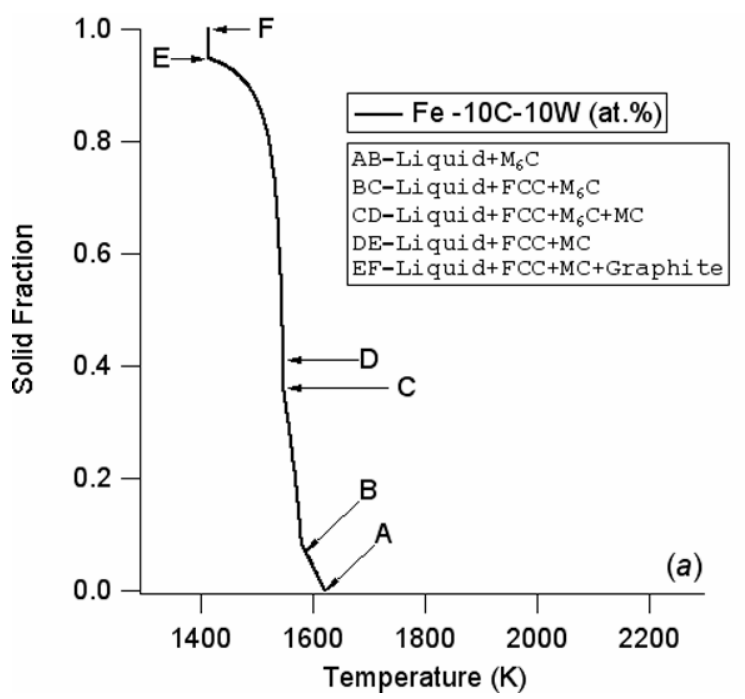

(a)

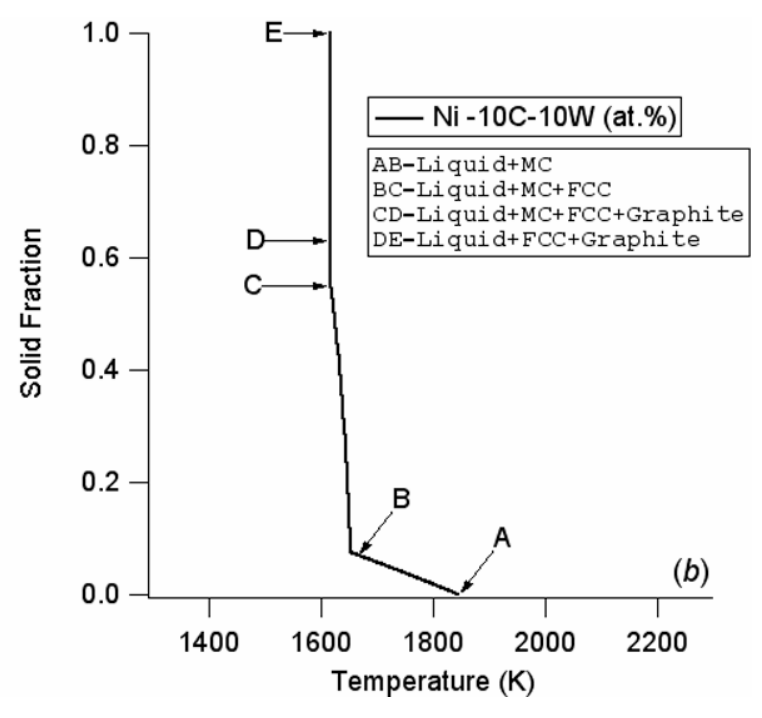

(b)

Figure 11- Comparison of phase evolution during solidification in two ternary alloy systems calculated using Scheil assumption (a) Fe - 10 at. \% W - 10 at. \%C system and (b) Ni - 10 at. \% W - 10 at. \%C system.

The laser surface modification process may lead to a wide range of surface temperatures within various regions. Because the tungsten-carbide powders can be added to the trailing edges of the molten pools, different carbides may experience different thermal cycles. If the temperature of the tungsten carbide exceeds that of melting point of tungsten carbide, there will be competition between the dissolution and melting phenomenon [26]. In those cases, melting will be governed by the heat-transfer conditions. Since the powders are added in the trailing edge of the weld pool, where the temperature may be lower than 2300 $\mathrm{K}$, the primary melting of tungsten carbide is not expected. In addition, if the particles are transported by fluid flow, they may experience a complex thermal cycle. Therefore, to describe the dissolution of MC particles, the following parameters are necessary: peak temperature, temperature-time history, and the local composition of the liquid. At this time, experimental descriptions of these parameters for all particles are difficult and often impossible. However, 
computational heat-transfer fluid-flow models have been used to describe these parameters in liquid welds when the growth and dissolution of $\mathrm{Al}_{2} \mathrm{O}_{3}$ inclusions in weld pools are being considered. The apparent movements of particles are indeed observed in our experiments. The extension of these models to the present experiment is extremely difficult because of the complexities involved in tungsten carbide impingement on the laser melt surface and local compositional gradients caused by dissolution. Therefore, in this work, the following assumptions were made to describe the dissolution of a single tungsten carbide particle.

The tungsten carbide was assumed to enter the liquid pool at a temperature of $2300 \mathrm{~K}$. This starting temperature is an assumption, and as mentioned earlier the particles may experience higher-temperature at laser-impingement areas. However, based on the previous work, the maximum temperature the powder that is added at the trailing edge of the weld pool is expected to be $2300 \mathrm{~K}$ or lower. The particle and the surrounding liquid were assumed to cool at $100 \mathrm{~K} / \mathrm{s}$ to a temperature of $1800 \mathrm{~K}$. This cooling rate is based on preliminary measurements made by thermocouple measurements during prior experiments. The initial composition of the liquid was assumed to be pure iron or pure nickel. The calculations assumed a local-equilibrium at the interface. One-dimensional diffusion-controlled growth or dissolution was performed to evaluate the stability of $\mathrm{MC}$ (tungsten carbide) as the liquid cools to a lower temperature. The schematic illustration of the geometry used for diffusion-controlled growth calculations is shown in Figure 12. The initial size of the MC carbide was $100 \mu \mathrm{m}$ and the inter-particle spacing was $1000 \mu \mathrm{m}$. The calculation methodology allows for complete dissolution, redistribution of alloying elements within the liquid region, and the reprecipitation of $\mathrm{MC}$ carbide at the right-hand side of the geometry shown in Figure 12. In these calculations, the barrier for nucleation (surface energy and critical radius) is not considered. Therefore, the reprecipitation of $\mathrm{MC}$ carbide from liquid is essentially decided when thermodynamic conditions are satisfied. The calculations ignore the effect of 
dendrite-tip undercooling because estimating it is uncertain for these process conditions.

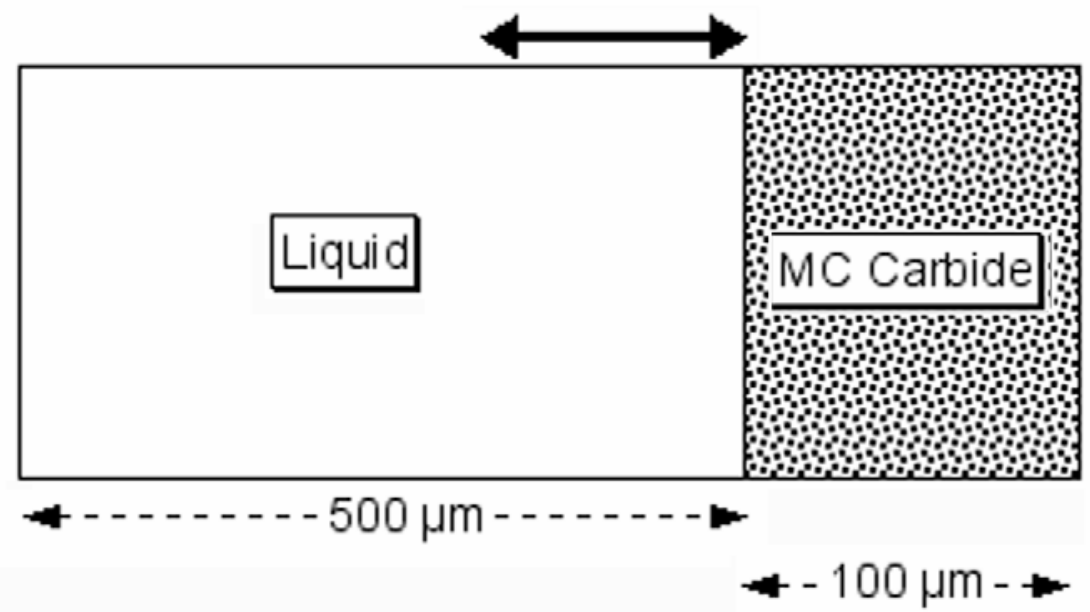

Figure 12 - Schematic illustration of the one-dimensional diffusion geometry used to calculate the diffusion controlled dissolution of tungsten carbide (MC) in a liquid pool as it cools from $2300 \mathrm{~K}$ to $1800 \mathrm{~K}$ at a rate of $100 \mathrm{~K} \mathrm{~s}^{-1}$.

The model does not consider the formation of nonstoichiometric carbides and therefore ignores diffusion within the carbide. DicTra software and standard solid solution database and mobility database were used to perform the calculations [27\&28]. Nominal diffusivity of alloying elements in liquid steel are assumed to be constant $\left(D_{M}=1 \times 10^{-9} \mathrm{~m}^{2} \mathrm{~s}^{-1}\right)$ for all the elements. The calculations also considered the effect of enhanced diffusion of alloying elements due to fluid flow by increasing the diffusivity arbitrarily to a value of $D_{M}=1 \times 10^{-6}$ $\mathrm{m}^{2} \mathrm{~s}^{-1}$. The results of kinetic calculations are presented in Figures 13 through 16. The calculated positions of the MC/liquid interface with nominal diffusivity are shown in Figure 13. The results indicate that the interface moves to the right from its initial position, indicating dissolution (see Figure 12); however, complete dissolution was not predicted. The dissolution rate of $\mathrm{MC}$ carbide in a nickel-rich liquid was lower than the rate in an iron-rich liquid. The concentration profiles of $W$ and $C$ in the liquid ahead of the interface are shown in Figure 14. The results from Fe-W-C and Ni-W-C systems indicate that the concentration of W and C 
vary from a local-equilibrium value to that of bulk concentrations over a distance of 100 to $200 \mu \mathrm{m}$. There were no significant differences in the shape of these concentration profiles except for the magnitudes. In general, the concentrations of $\mathrm{W}$ and $\mathrm{C}$ near the interface were higher in the iron-rich liquid than in the nickelrich liquid.

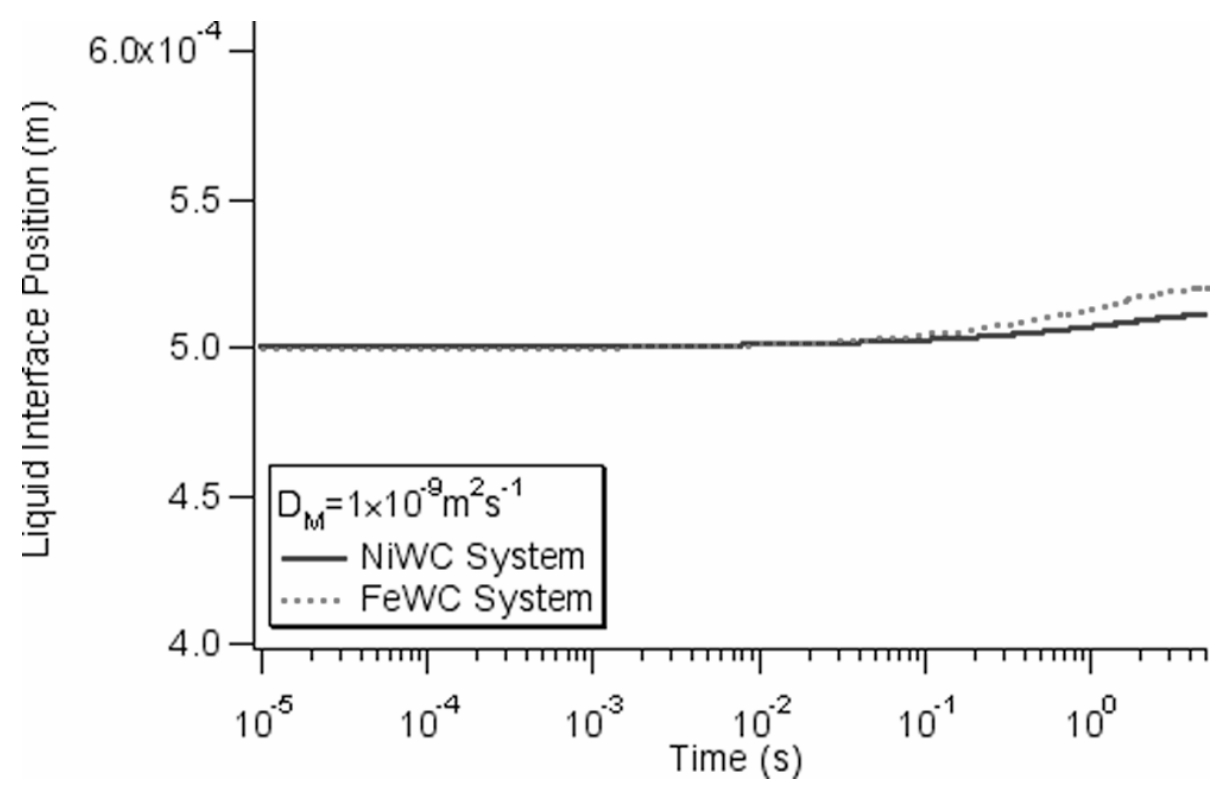

Figure 13 - Predicted position of the interface between liquid and MC carbide as a function of time with assumed diffusivity of $1 \times 10^{-9} \mathrm{~m}^{2} \mathrm{~s}^{-1}$.

The calculated positions of the MC/liquid interface with enhanced diffusivity are shown in Figure 15. In the Fe-W-C system, the MC dissolved at a rapid rate, and dissolution was complete at $2295 \mathrm{~K}$. Further cooling did not lead to any reprecipitation of MC. In contrast, in the Ni-W-C system, MC dissolved rapidly; however, complete dissolution was indicated at $2271 \mathrm{~K}$. In addition, the calculations based on further cooling indicated that the reprecipitation of $\mathrm{MC}$ carbides occurred at $2197 \mathrm{~K}$. Further cooling led to MC carbide growth to $41 \mu \mathrm{m}$ at $1800 \mathrm{~K}$. The results show that the MC carbides in Ni-W-C system have a low dissolution rate, even with enhanced diffusivity, and that they have enhanced 
stability at high temperature. The concentration profiles in both Fe-W-C and NiW-C system with enhanced diffusivity are shown in Figure 16 and are flatter then those observed in Figure 15. This is due to the overlap of diffusion profiles at the origin ( $0 \mu \mathrm{m}$ of diffusion geometry), as indicated by the increase in the $\mathrm{W}$ and $\mathrm{C}$ concentration.

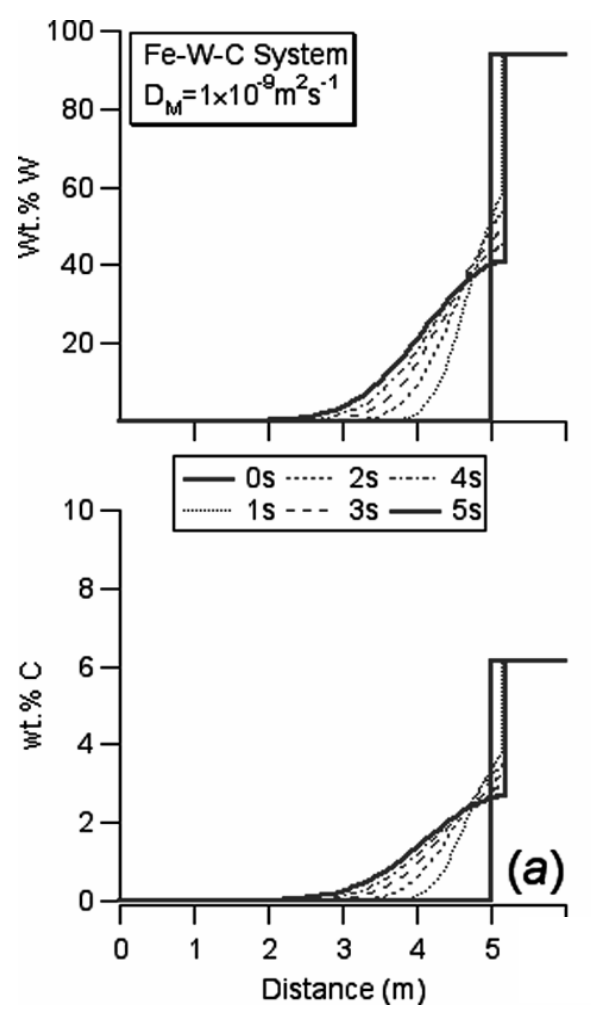

(a)
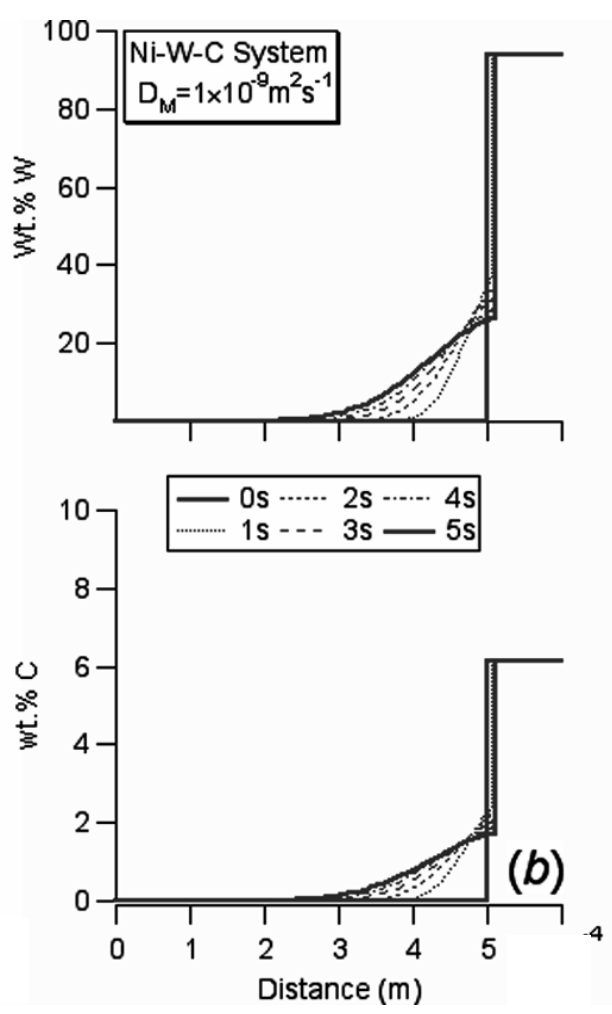

(b)

Figure 14 - Calculated tungsten and carbon concentration profiles in the liquid melt pool (left side) in contact with MC carbide (right side) as a function of time. The diffusivity of atoms in liquid is assumed to be $1 \times 10^{-9} \mathrm{~m}^{2} \mathrm{~s}^{-1}$ : (a) Fe-W-C and (b) Ni-W-C. 


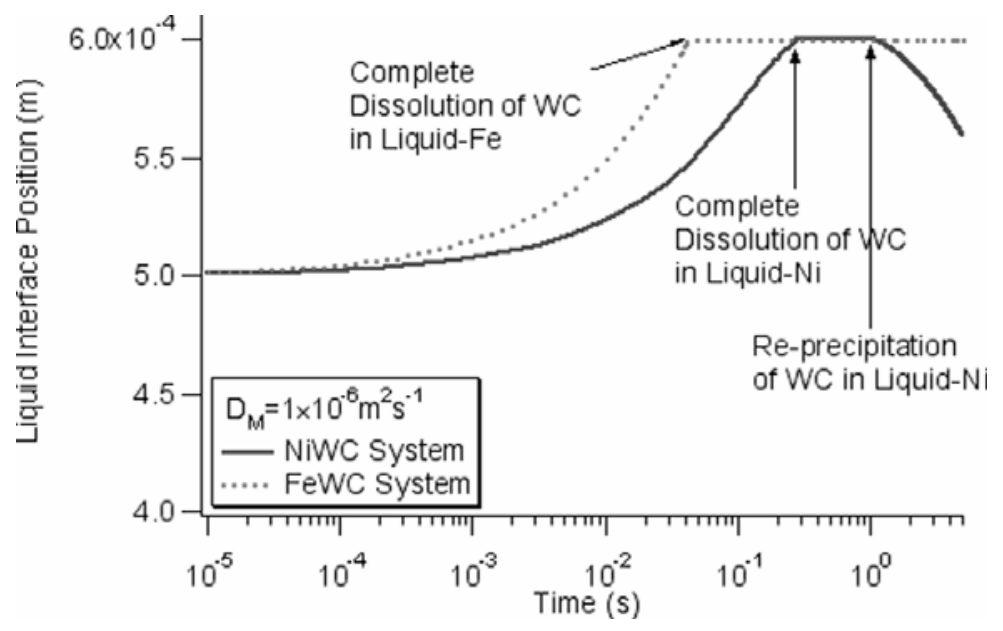

Figure 15 - Predicted position of interface between liquid and MC carbide as a function of time with assumed diffusivity of $1 \times 10^{-6} \mathrm{~m}^{2} \mathrm{~s}^{-1}$.
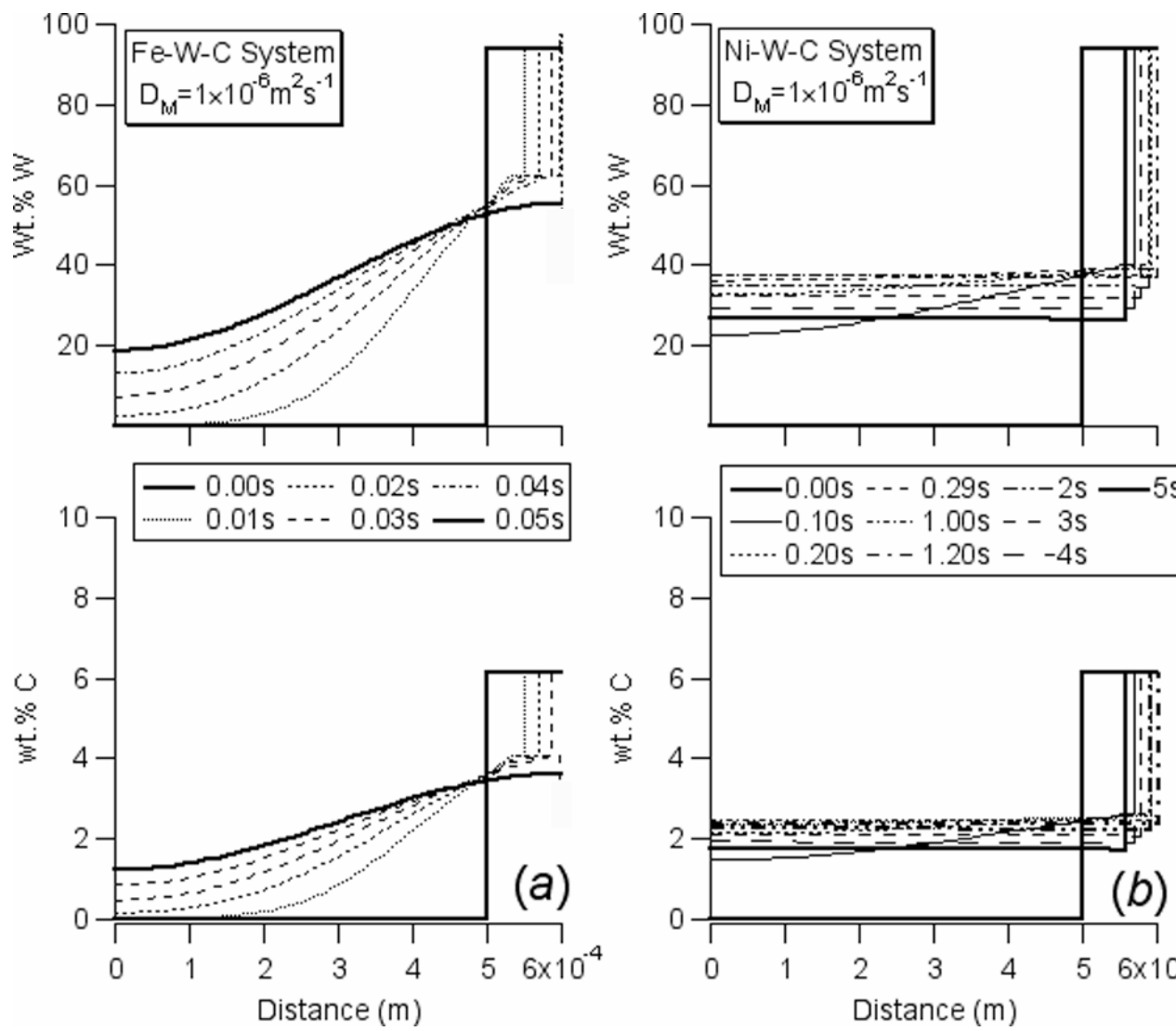

(a)

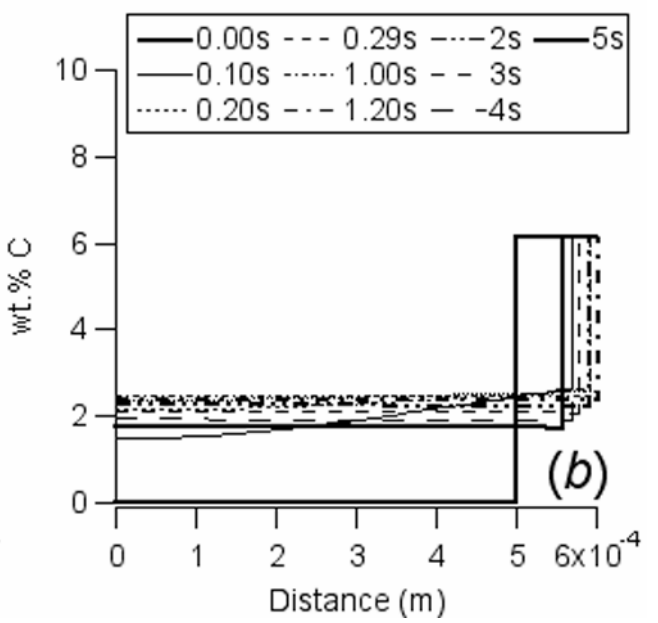

(b)

Figure 16 - Calculated tungsten and carbon concentration profiles in the liquid melt pool (left side) in contact with MC carbide (right side) as a function of time. The diffusivity of atoms in liquid is assumed to be $1 \times 10^{-6} \mathrm{~m}^{2} \mathrm{~s}^{-1}:$ (a) Fe-W-C and (b) Ni-W-C. 


\subsection{Formulation of Laser Process Model}

One of the most important factors in simulating the heat transfer phenomena during laser processing is the transfer of energy between the laser beam and the substrate, e.g. beam and material interaction. Until recently, models of the process surface modification process have relied on marginal energy transfer efficiency coefficients and have utilized the assumption that the energy input from a laser results in a surface distribution and absorption of energy, which can easily be implemented into the numeric model. However, recent experiments have shown that this assumption is inaccurate [29], and that although energy is distributed on the surface, absorption occurs within the powder layer due to scattering effects. The absorption of energy internally has significant consequences as to how the energy from the laser is utilized within the laser cladding model. Hence, the development of an accurate representation for the absorption of powder is necessary if greater accuracy of the model is desired.

The careful depiction of the properties of the powder is also extremely important in the development of an accurate heat transfer model for the laser surface modification process. Because the powder surface, either preplaced or added directly ahead of the beam, represents unconsolidated particles having a high proportion of voids, the physical properties are drastically different than the solid material. Hence, an accurate depiction of the laser surface modification process involving powder requires that the density, specific heat, and thermal conductivity of the porous powder and the consolidated powder be known or closely estimated.

The heat transfer model developed during this program utilizes a three dimensional central finite differencing scheme that calculates the temperature at each nodal point within the volume of the sample. An absorption model, which is embedded into the heat transfer model, is utilized to determine energy transferred to the powder layer and substrate. With the integrated model, the 
user is able to choose between a variety of parameters, including sample dimensions, materials, and laser parameters.

\subsubsection{Numerical Formulation}

The first formulation used within the model is the establishment of the computational grid required for the explicit finite differencing scheme. The grid uses a variable spacing that provides greater resolution near the heat source, as shown in Figure 17. This technique is used in order to decrease calculation time, yet obtain a greater accuracy near the laser beam where temperature gradients are high. Three different mesh spacings are used in the width direction, two in the depth direction, and one along the length.

Temperature is calculated based on an enthalpy relationship. The amount of energy, or enthalpy $(H)$, in a small volume element can be represented by:

$$
H=\rho\left(C_{p} T+L\right)
$$

where $\rho$ is density, $C_{p}$ is specific heat, $T$ is temperature, and $L$ is latent heat. Energy transfer due to conduction, and surface losses, as well as energy input from the laser can be described by:

$$
\frac{\partial \mathrm{H}}{\partial \mathrm{t}}=\nabla \cdot(\mathrm{k} \nabla \mathrm{T})+\mathrm{Q}
$$

where $k$ is thermal conductivity and $Q$ is net energy from the laser and surface heat losses. Using the a forward time, central finite differencing scheme, Equations 6 and 7 can be combined to calculate the temperature at the next time iteration: 


$$
T^{\prime}=T+\frac{\Delta t(\nabla \cdot(k \nabla T)+Q)}{\left(\rho_{T} C_{p} T^{n}+\rho C_{p_{T}} T+\rho C_{p}+\rho_{T} L+\rho L_{T}\right)}
$$

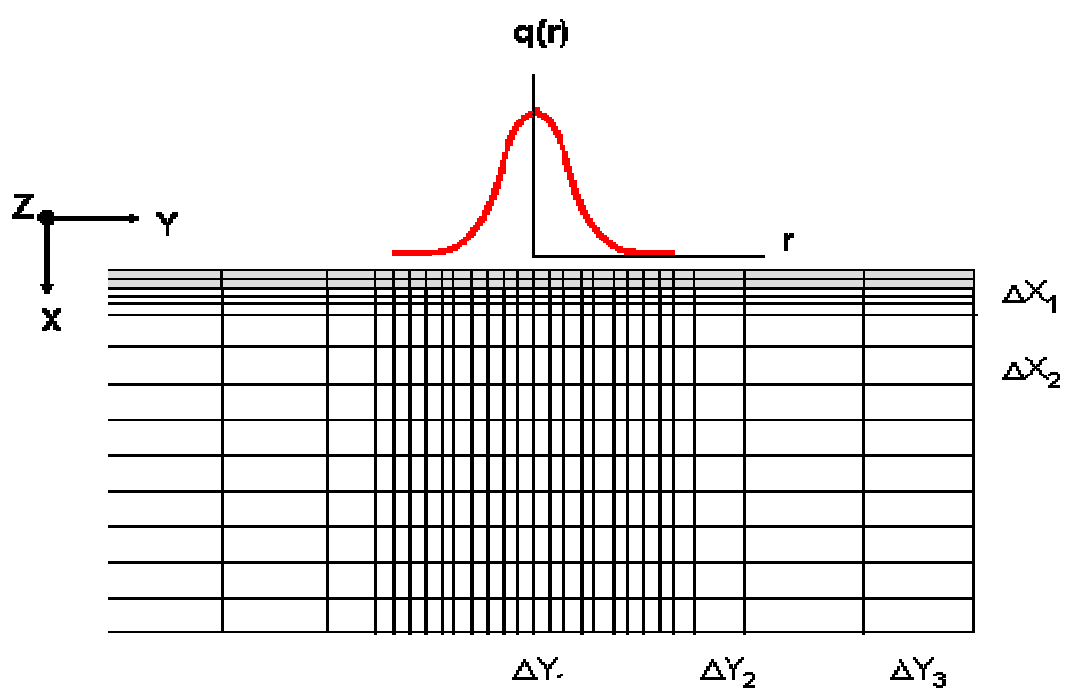

Figure 17 - Grid spacing used in finite differencing scheme with laser distribution, $q(r)$, shown at the surface.

The temperature at each node, T', is calculated based on Equation 8 for each time iteration. The discretization error is minimized by ensuring the time iteration is less than the stability criteria to ensure convergence of the numerical solution. The stability criteria is based on the thermal diffusivity and computational grid spacing [30]. The numerator in Equation 8 is simply the conduction equation and is the sum of the partial derivatives in each direction away from the computational element [31]. In the denominator; density $(\rho)$, specific heat $\left(C_{p}\right)$, and latent heat of fusion $(\mathrm{L})$ are shown as temperature dependant parameters. In the model, latent heat is defined as a function of temperature within the melting range of the material in the same form as thermal conductivity. The total amount of energy that is absorbed or released by the change in phase is equal to the latent heat of fusion of the material divided by the specific heat. The latent heat of vaporization is applied to the model in much the same way as the latent heat of fusion. The main difference between vaporization and melting is that the 
solidus and liquidus are known for the melting range, but the corresponding values in the vaporization region are not widely defined. In order to determine the temperature where both liquid and vapor are present, a generic phase diagram was utilized, as shown in Figure 18. The upper and lower phase boundaries were estimated, based on the vaporization points of the two principal species in the system, which provided an approximation of the temperatures of interest during vaporization at a certain concentration, $Z_{\mathrm{A}}$. The upper curve is modeled using [32]:

$$
T_{V}=T_{B}-\left(T_{B}-T_{A}\right) \cdot Z_{A}^{2}
$$

and the lower curve by:

$$
T_{L}=T_{B}-\left(T_{B}-T_{A}\right) \cdot Z_{A}\left(2-Z_{A}\right)
$$

where $T_{B}$ and $T_{A}$ are the vaporization points of the two main components of the alloy system. Thus, for a given concentration of an alloy, the upper and lower bounds of the temperature can be determined and the latent heat of vaporization may be estimated.

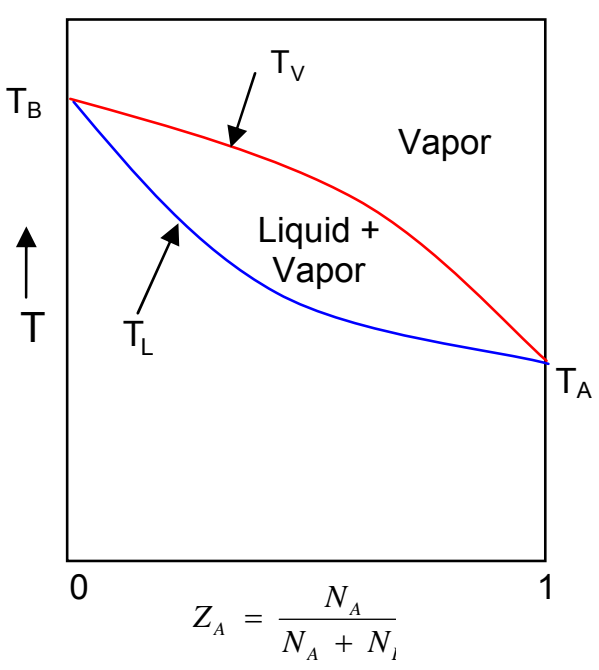

Figure 18 - Generic binary liquid-vapor phase diagram. 
Thermal properties below the vaporization temperature are considered to be independent of temperature except in the melting range, where there is a change in phase. With changes in phase, the thermal properties are designed to change linearly. Within the melting range, the thermal conductivity increases from a calculated value for loose powder to the value for the consolidated (melted and solidified) powder, as shown in Figure 19.

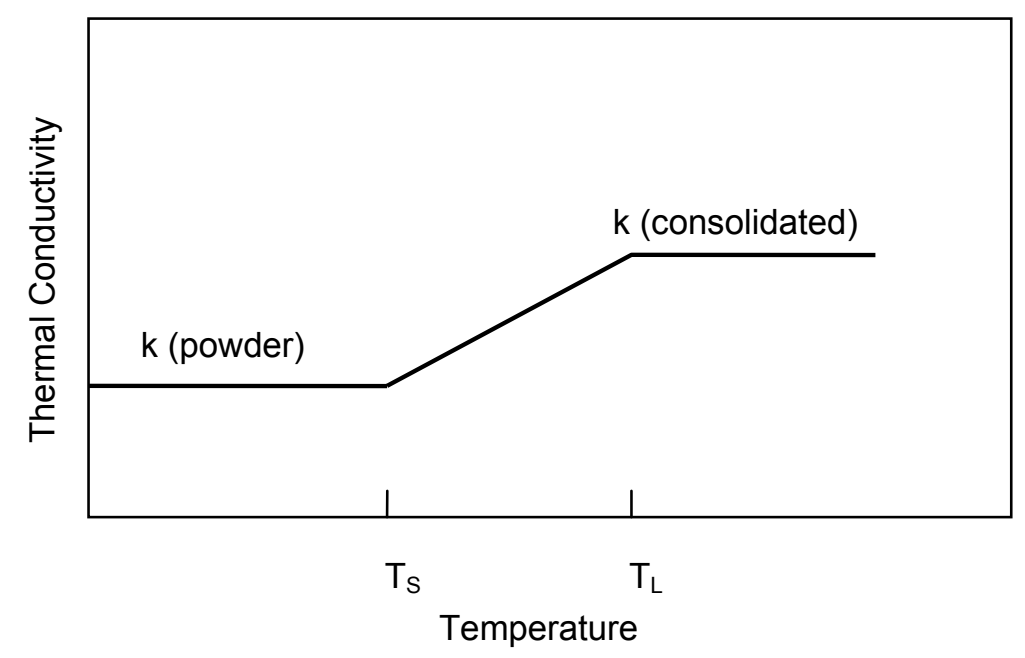

Figure 19 - Change in thermal conductivity of powder upon melting.

The thermal conductivity in the powdered layer is significantly lowered due to voids and imperfect packing within the layer. The thermal conductivity is calculated based on the type of packing of the powder, which also defines the volume of voids between the particles. The fluid within the interstitial areas can be any gas with thermal conductivity k. Several different equations representing the effective conductivity of the powder layer are available. [33,34]:

$$
\mathrm{k}=\frac{2 \mathrm{k}_{\text {air }}}{1-\left(\mathrm{k}_{\text {air }} / \mathrm{k}_{\text {powder }}\right)}\left[\frac{\ln \left(\mathrm{k}_{\text {powder }} / \mathrm{k}_{\text {air }}\right)}{1-\left(\mathrm{k}_{\text {air }} / \mathrm{k}_{\text {powder }}\right)}-1\right]
$$




$$
\begin{gathered}
\log \left(\frac{\mathrm{k}}{\mathrm{k}_{\text {air }}}\right)=\left(0.280-0.757 \log (\alpha)-0.057 \log \left(\frac{\mathrm{k}_{\text {powder }}}{\mathrm{k}_{\text {air }}}\right)\right) * \log \left(\frac{\mathrm{k}_{\text {powder }}}{\mathrm{k}_{\text {air }}}\right) \\
\frac{\mathrm{k}}{\mathrm{k}_{\text {air }}}=\mathrm{V}_{\mathrm{s}} \mathrm{N}_{\mathrm{c}} * 2 \ln \left(\frac{\mathrm{k}_{\text {powder }}}{\mathrm{k}_{\text {air }}}\right)
\end{gathered}
$$

In all three relationships, an effective conductivity, $k$, which accounts for the porous nature of the powder in some way, is calculated. In these relationships it is also assumed that $\mathrm{k}_{\text {air }}$ is the thermal conductivity of air, and $\mathrm{k}_{\text {powder }}$ is the theoretical conductivity of the powder material in its solid state. In Equation 13, $V_{s}$ is volume fraction of the particles and $N_{c}$ is the coordination number of the powder. Figure 20 shows calculated values for effective conductivity of the powder layer against the theoretical value of the powder material for the above equations. As illustrated, the thermal conductivity of powder is significantly lower than the thermal conductivity in the bulk state $\left(k_{p}\right)$. Based upon available data and the characteristics of typical powders used for laser deposition, it was determined that Equation 11 would best represent the powder layer.

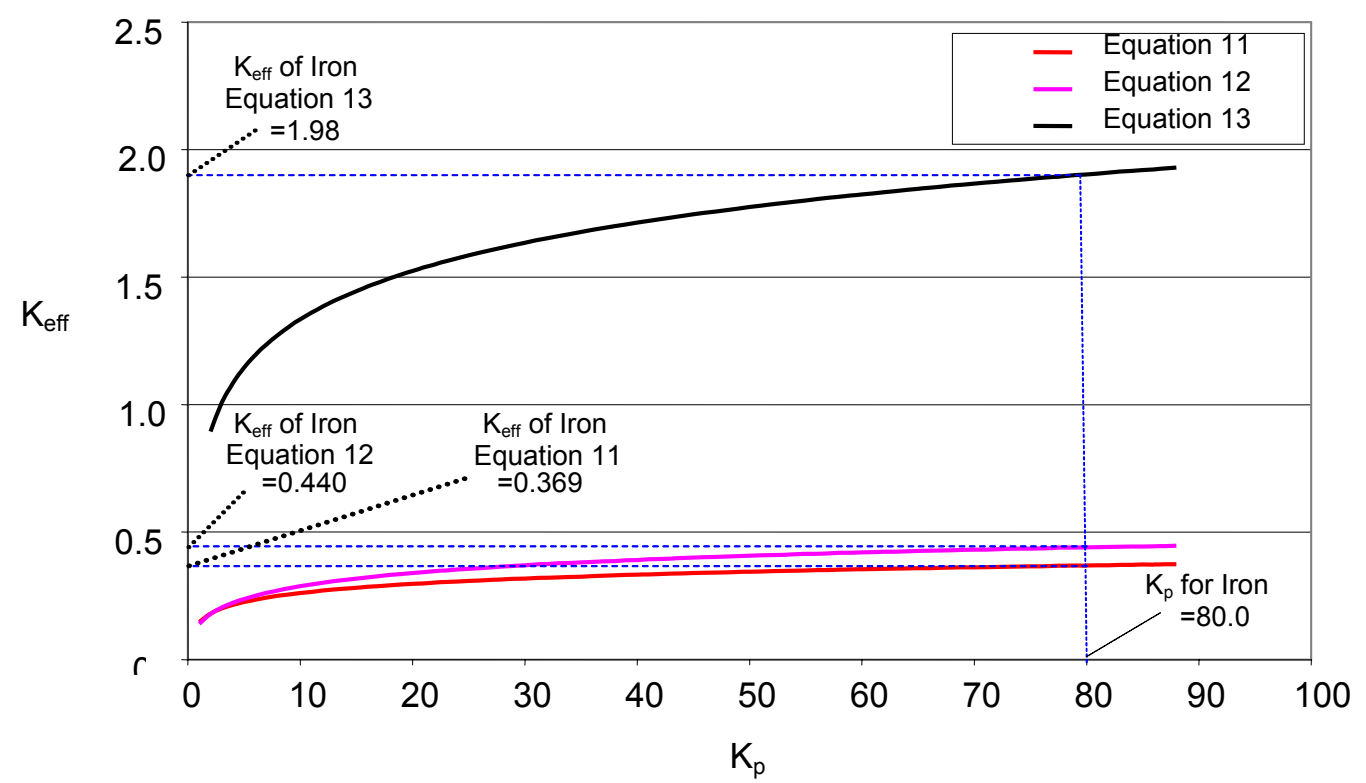

Figure 20 - Effective conductivity of the powder material vs. conductivity in solid state for pure iron ( $\mathrm{K}_{\text {eff }}$ and $\mathrm{K}_{\mathrm{p}}$ in $\left.\mathrm{W} / \mathrm{m} \mathrm{K}\right)$. 
The extremely low conductivity of the powder creates an instability within the differencing equations at the substrate/powder interface [35]. Because of the vastly different thermal conductivities and diffusivities of the powder layer and the substrate, a unique differencing equation must be employed across the boundary, and is based on maintaining conservation of energy at this interface. Specifically, the heat flux entering the interface must be equal to the heat flux leaving the interface:

$$
\mathrm{k}_{1}\left(\frac{\partial \mathrm{T}}{\mathrm{dx}}\right)_{\mathrm{j} 1}=\mathrm{k}_{2}\left(\frac{\partial \mathrm{T}}{\mathrm{dx}}\right)_{\mathrm{j} 2}
$$

If $\mathrm{j}$ is the node on the boundary between the powder (material 1) and the substrate (material 2), then from Taylor's expansion it may be shown:

$$
\begin{gathered}
\left(\frac{\partial^{2} T}{d x^{2}}\right)_{j 1}=\frac{2}{(\Delta x)^{2}}\left[T_{j-1}-T_{j}+\Delta x\left(\frac{\partial T}{d x}\right)_{j 1}\right] \\
\left(\frac{\partial T}{\partial t}\right)_{j 1}=\frac{T_{j}^{\prime}-T_{j}}{\Delta t}
\end{gathered}
$$

where $T^{\prime}$ is the temperature at node $\mathrm{j}$ at the next time iteration. Substituting Equations 15 and 16 into Fourier's governing relationship (Equation 8), a relationship is established for the derivative of temperature with respect to distance:

$$
\Delta x\left(\frac{\partial T}{d x}\right)_{j 1}=\frac{T_{j}^{\prime}-T_{j}}{2 \lambda \alpha_{1}}+\left(T_{j}-T_{j-1}\right)
$$

where $\lambda$ is defined as $\Delta t /(\Delta x)^{2}$. A similar equation can be derived for material 2 . 


$$
-\Delta x\left(\frac{\partial T}{d x}\right)_{j 2}=\frac{T_{j}^{\prime}-T_{j}}{2 \lambda \alpha_{2}}+\left(T_{j}-T_{j-1}\right)
$$

Now, an expression can be obtained by inserting Equations 17 and 18 into the conservation of energy equation (Equation 14), and solving for T' [36]:

$$
\mathrm{T}_{\mathrm{j}}^{\prime}=\mathrm{T}_{\mathrm{j}}+\left[\frac{2 \lambda \alpha_{1}}{\frac{\alpha_{1}}{\alpha_{2}}+\frac{\mathrm{k}_{1}}{\mathrm{k}_{2}}}\right]\left[\mathrm{T}_{\mathrm{j}+1}-\left(1+\frac{\mathrm{k}_{1}}{\mathrm{k}_{2}}\right) \mathrm{T}_{\mathrm{j}}+\frac{\mathrm{k}_{1}}{\mathrm{k}_{2}} \mathrm{~T}_{\mathrm{j}-1}\right]
$$

Hence, Equation 19 describes the temperature across the boundary, which incorporates the vastly different properties of the powder and substrate. It can be shown that if there is no interface present, or $\alpha_{1}=\alpha_{2}$ and $k_{1}=k_{2}$, then Equation 19 reduces to the normal finite differencing equation:

$$
\mathrm{T}_{\mathrm{j}}^{\prime}=\mathrm{T}_{\mathrm{j}}+\alpha_{1} \Delta \mathrm{t}\left[\frac{\mathrm{T}_{\mathrm{j}+1}-2 \mathrm{~T}_{\mathrm{j}}+\mathrm{T}_{\mathrm{j}-1}}{(\Delta \mathrm{x})^{2}}\right]
$$

The magnitude of the effect that the interface imposes on the temperature at that boundary can be observed by plotting $T^{\prime}$ against $k_{1} / k_{2}$. This is shown in Figure 21 , which was produced by assuming the conductivity of the substrate is constant at $70 \mathrm{~W} / \mathrm{m}-\mathrm{K}$ and the conductivity of the powder varies from 0.5 to 70 $\mathrm{W} / \mathrm{m}-\mathrm{k}$. Also, an initial temperature of $1500 \mathrm{~K}$ is assumed.

As illustrated in the figure, and based on the above assumptions, there is only a $25 \mathrm{~K}$ difference in temperature at the interface based on the application of the adapted equation (Equation $19, \mathrm{k}_{\text {pow }} / \mathrm{k}_{\text {sub }}=.02$ ) and using the normal differencing equation (Equation 20). However, it should be mentioned that this calculation would only represent one iteration and is compounded during the normal calculation scheme. It is also important to note that in the simulation the effective 
conductivity is only applied to temperatures below the solidus temperature. After the solidus temperature is reached, a linear relationship is utilized to define the conductivity between the solidus and liquidus temperatures. Upon complete melting, i.e. exceeding the liquidus, the conductivity is assumed to be constant.

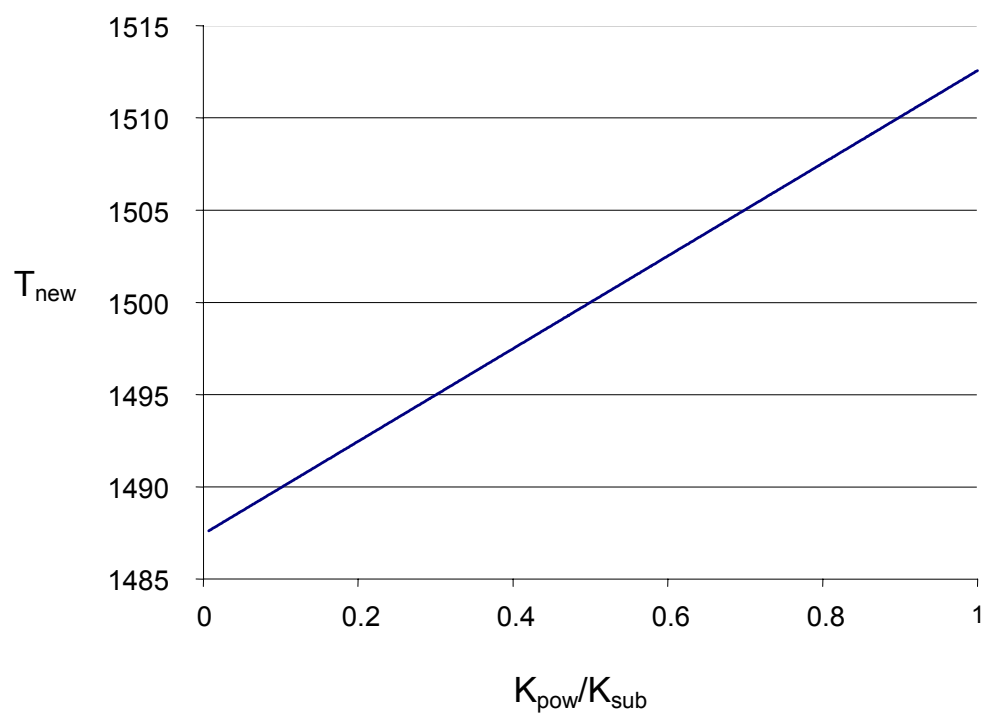

Figure 21 - Modification to calculated interface temperature $\left(T_{\text {new }}\right)$ based on the variation of the thermal conductivities of the powder and substrate materials.

For all surface points, radiation and convection determine energy losses at the surface. The general formula for the flow of heat due to convection is given as Equation 21, where $\mathrm{h}$ is the convective heat transfer coefficient.

$$
q=h\left(T-T_{\infty}\right)
$$

This equation becomes useful when determining an effective heat transfer coefficient $\left(\mathrm{h}_{\text {eff }}\right)$ that may account for both radiation and convection. Equation 22 expresses a relationship between the two, where $h_{c}$ is the convective heat transfer coefficient, $e$ is the emissivity, and $\sigma$ is the Stefan-Boltzman constant [37]. 


$$
\mathrm{h}_{\text {eff }}=\mathrm{h}_{\mathrm{c}}+\sigma \mathrm{e}\left(\mathrm{T}^{3}+\mathrm{T}^{2} \mathrm{~T}_{\infty}+\mathrm{TT}_{\infty}^{2}+\mathrm{T}_{\infty}^{3}\right)
$$

Assuming free convection and constant ambient temperature, the coefficient $\left(\mathrm{h}_{\mathrm{c}}\right)$ can be determined according to Equations (23) and (24):

$$
\begin{gathered}
\mathrm{Nu}=\frac{8 \mathrm{Pr}^{\frac{1}{2}} \mathrm{Gr}^{\frac{1}{4}}}{3(336(\operatorname{Pr}+0.556))^{\frac{1}{4}}} \\
\mathrm{~h}_{\mathrm{c}}=\frac{\mathrm{Nuk}}{\mathrm{L}}
\end{gathered}
$$

Where Pr and Gr are the Prandtl and Grashof numbers, respectively, and are calculated using values for air at $300 \mathrm{~K}$.

\subsubsection{Representation of Laser Energy Absorption}

The absorption of laser energy is dependent upon the surface characteristics of the absorbing material. A permeable powder layer will then absorb photons and will be more effective at absorbing laser energy as compared to a flat metallic surface. The powder layer creates pathways for the incident laser beam to penetrate through the powder and be absorbed internally through scattering. The absorption of laser radiation is essentially an energy exchange between a photon and an electron and is tersely described by Hagg et. al. [38]. This exchange begins with an electromagnetic wave passing over a small charged particle, such as an electron, which will set the particle in motion and initiate a forced vibration. The charged particle in this case is an electron, either free or bound. As the particle vibrates it will either generate heat due to the restraint by lattice phonons, or reradiate this energy. The result of irradiation is an initial increase in absorbed energy within the powder; however, as the particles melt to form a liquid pool, reflection of energy increases as absorption is again confined 
to a region near the top surface of the molten pool. In addition to reradiating electromagnetic energy, the excited elementary charges may transform part of the incident energy into other forms, for example thermal energy, i.e. absorption. Hence, scattering and absorption are not mutually exclusive processes [39].

The penetration of the beam within the powder layer occurs by scattering, or the production of secondary radiation, through the thickness. This phenomenon is illustrated in the schematic of Figure 22 [40]. The scattering or secondary radiation can occur by:

(i) changing the path of the photon, without ever colliding with the particle, by diffraction,

(ii) altering the direction of the photon by reflection, and/or

(iii) the photon may penetrate into the particle and change direction due to refraction [41].

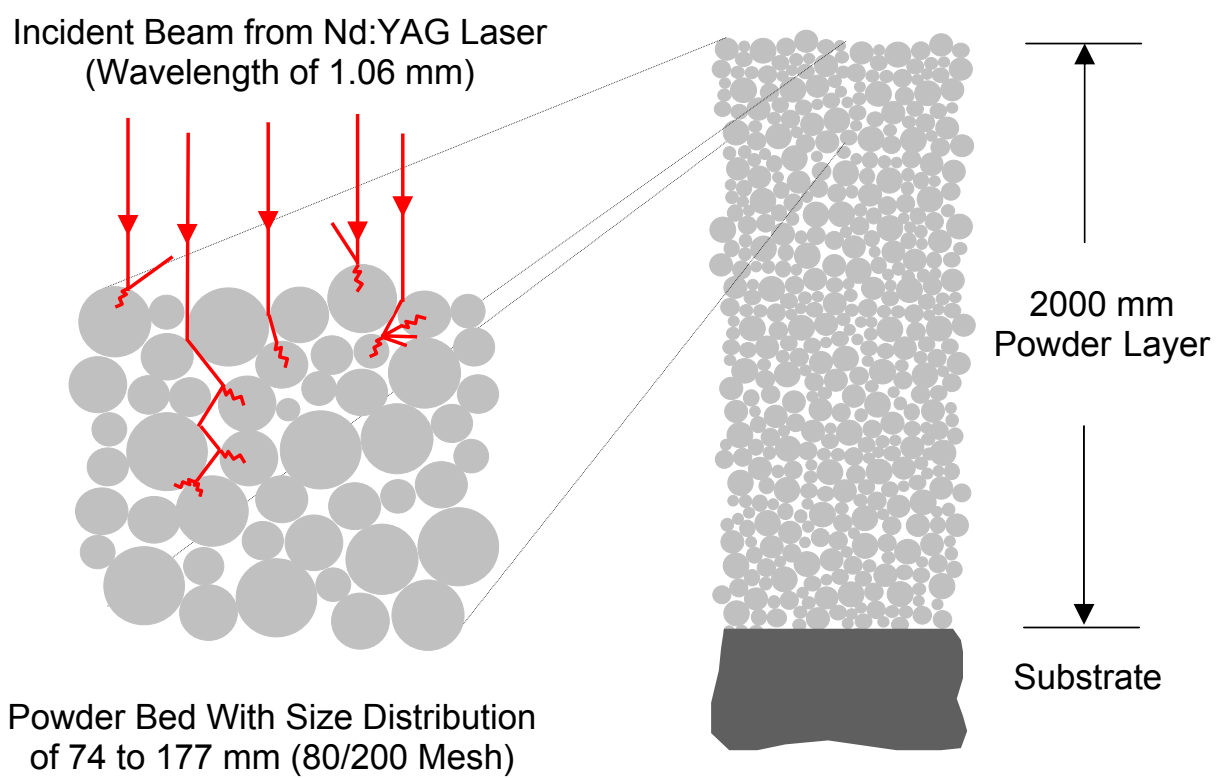

Figure 22 - Schematic of laser irradiation of a powder layer showing scattering within the porous powder [13].

If it is assumed that irradiation that is not reflected from the surface is absorbed in a finite layer of the powder, the decrease of laser intensity or attenuation that 
occurs within this layer may be described as an exponential decay or BeerLambert type relationship [42]:

$$
\mathrm{I}(\mathrm{z})=\beta \cdot \mathrm{I}_{0} \exp (-\gamma z)
$$

where $I(z)$ is the intensity of the beam at depth $z, \beta$ is the surface absorption, $I_{0}$ is the initial intensity of the incident beam, and $\gamma$ is the attenuation coefficient or absorbance, which describes beam penetration within the powder. It may also be shown that Equation 25 may be manipulated to the form:

$$
I(z)=I_{0} \exp (-\gamma z+k)
$$

Where the constant k may be shown, under the conditions described above, to be equal to $\ln (\beta)$.

The use of the above relationships assumes that the interparticle spacing is relatively large compared to the wavelength such that a certain degree of independent scattering is operative within the powder layer. If this condition is met, Equation 26 may be used to represent absorption through the depth of the powder layer in terms of an exponential decay.

In many instances, such as with lasers displaying a $T E M_{00}$, the beam intensity on the surface $\left(\mathrm{I}_{\circ}\right)$ may be described as circular having a Gaussian radial distribution [43]:

$$
\mathrm{I}_{\mathrm{o}}=\frac{3 \mathrm{Q}_{\mathrm{in}}}{\pi \mathrm{r}_{\mathrm{o}}^{2}} \exp \left(-\frac{3 \mathrm{r}^{2}}{\mathrm{r}_{\mathrm{o}}^{2}}\right)
$$

where $Q_{\text {in }}$ is the beam power, and $r_{0}$ is the effective radius associated with $95 \%$ of the beam energy, and $r$ is the distance from the center of the energy source. 
The total energy absorbed within the powder layer may be determined by integrating the energy intensity over the volume of the powder affected by the beam:

$$
Q_{a b s}=\iiint c \cdot \beta \cdot \frac{3 Q_{i n}}{\pi r_{0}^{2}} \exp \left(\frac{-3 \cdot r^{2}}{r_{o}^{2}}\right) \cdot \exp (-\gamma z) \cdot d V
$$

where $\mathrm{C}$ is a scaling factor and $\mathrm{V}$ describes the volume of the powder under consideration. Equation 28 assumes that the total amount of energy that entered the powder layer was completely absorbed within the layer. The integral of Equation 28 may be evaluated by defining a generic surface and volume having a range:

$$
\begin{aligned}
& r: 0 \rightarrow r_{0} \\
& \theta: 0 \rightarrow 2 \pi \\
& z: 0 \rightarrow t
\end{aligned}
$$

where $r$ is integrated from zero to the effective radius of the beam $\left(r_{0}\right)$, for all angles within the circular spot $(2 \pi)$, and through a depth of the powder layer $(t)$, or:

$$
Q_{a b s}=\int_{0}^{t} \int_{0}^{2 \pi r_{0}} \int_{0} C \cdot \beta \frac{3 Q_{\text {in }}}{\pi r_{0}^{2}} \exp \left(\frac{-3 r^{2}}{r_{0}^{2}}\right) \exp (-\gamma z) r d r d \theta d z
$$

The integration of Equation 30 using the method of substitution yields:

$$
Q_{a b s}=-\beta Q_{\text {in }}(\exp (-3)-1) C\left[\frac{-\exp (-\gamma \cdot t)+1}{\gamma}\right]
$$


where the constant $\mathrm{C}$ in the above equation may be determined by evoking conservation of energy for the total energy flux at the top surface being equal to the total energy absorbed within the powder, or:

$$
\iint \frac{3 \beta Q_{i n}}{\pi r_{0}^{2}} \exp \left(\frac{-3 r^{2}}{r_{o}^{2}}\right) \cdot \hat{n} d A=\iiint C \frac{3 \beta Q_{i n}}{\pi r_{0}^{2}} \exp \left(\frac{-3 r^{2}}{r_{o}^{2}}\right) \exp (-\gamma z) d V
$$

The right side of Equation 32 had been evaluated previously and a similar approach is utilized to integrate the expression on the left. This yields:

$$
-\beta Q_{\text {in }}(\exp (-3)-1)=-\beta Q_{\text {in }}(\exp (-3)-1) C\left[\frac{1-\exp (-\gamma \mathrm{t})}{\gamma}\right]
$$

The constant may now be determined:

$$
C=\frac{Y}{1-\exp (-\gamma t)}
$$

and upon substitution into Equation 31 yields:

$$
Q_{a b s}(r, z)=\left[\frac{\gamma}{1-\exp (-\gamma t)}\right] \frac{3 \beta \cdot Q_{i n}}{\pi r_{0}^{2}} \exp \left(\frac{-3 r^{2}}{r_{0}^{2}}\right) \exp (-\gamma z)
$$

Hence, Equation 35 defines the absorbed laser energy $\left(Q_{a b s}\right)$ for a circular beam of radius $r_{o}$ displaying a Gaussian energy distribution within a powder layer having a depth $t$, provided that the bulk absorption and attenuation coefficient ( $\beta$ and $\mathrm{y}$, respectively) are known.

Similar analyses may be conducted for beams having other shapes and energy distributions. If the "top hat" beam profile associated with a fiber delivered 
$\mathrm{Nd}$ :YAG is assumed to have a relatively uniform distribution, the incident beam may be described as:

$$
I_{o}=\frac{Q_{i n}}{\pi r_{o}^{2}}
$$

In which case the internal absorption for a circular spot having a uniform energy distribution may be defined as:

$$
Q_{a b s}(r, z)=\left[\frac{\gamma}{1-\exp (-\gamma \cdot t)}\right] \cdot \frac{\beta \cdot Q_{\text {in }}}{\pi \cdot r_{0}^{2}} \cdot \exp (-\gamma \cdot z)
$$

Following this method, if the beam of a direct diode laser is rectangular and approximated as having a relatively uniform energy distribution, the absorption relationship becomes:

$$
I(r, x)=\left[\frac{\gamma}{1-\exp (-\gamma \cdot t)}\right] \cdot \frac{\beta \cdot Q_{i n}}{A \cdot B} \cdot \exp (-\gamma \cdot x)
$$

where $A$ and $B$ describe the spatial dimensions of the rectangular spot.

Hence, Equations 35, 37, and 38 may be used with the appropriate bulk absorption and attenuation coefficient to describe absorption laser irradiation within the powder layer, based upon the shape and energy distribution of the incident beam. The following section describes the determination of the attenuation coefficient, with bulk absorption being determined previously [44]. It should also be noted that both of these parameters, the attenuation coefficient and bulk absorption, are dependent upon the wavelength of the laser radiation, the optical properties of the material, and the nature of the porous powder layer, i.e. particle size and packing density. 


\subsubsection{Experimental Determination of Laser Attenuation}

Experiments were conducted on pure iron and copper powders to determine the attenuation coefficients associated with $\mathrm{CO}_{2}(\lambda=10.6 \mu \mathrm{m})$ and Nd:YAG $(\lambda=1.06$ $\mu \mathrm{m})$ irradiation. These materials were chosen because of the significant interest in iron-based depositions and their contrast in optical and thermal properties. The experiments were designed to determine attenuation of $\mathrm{CO}_{2}$ and $\mathrm{Nd}$ :YAG irradiation within powder layers of different thickness by employing a sphere integrator to directly measure reflected and transmitted energy.

Both powder materials were $99.9 \%$ pure and represented a procured size distribution of between 44 and $149 \mu \mathrm{m}(-100 /+325$ mesh size). The as-received powders were characterized using a Horiba Instruments LA920 Laser Diffraction Particle Size Analyzer and the results of these measurements indicated that the actual size distributions, based on $90 \%$ of the powder, were between 10 and 150 $\mu \mathrm{m}$ for the copper powder and between 12 and $240 \mu \mathrm{m}$ for the iron powder. This information was then used to select two additional size distributions, representing powder having smaller and larger particles. The as-received powders were then separated into the two additional size distributions using a row tap sieve machine using a 140 mesh (106 $\mu \mathrm{m}$ opening) for the larger powder size and a 325 mesh $(45 \mu \mathrm{m})$ for the smaller powder size. This resulted in two additional distributions being 14 to $100 \mu \mathrm{m}$ and 106 to $210 \mu \mathrm{m}$ for the copper powder and 14 to $105 \mu \mathrm{m}$ and 106 to $300 \mu \mathrm{m}$ for the iron powder, based on $90 \%$ of the powder. The smaller particles were characterized with the same Diffraction Particle Size Analyzer, and the larger particles were characterized with an Olympus SZH 10 stereoscope and camera, and image analysis, using specialized software created for particle characterization. The apparent densities were then measured for all of the distributions using an Arnold Meter for the iron powders and a graduated cylinder for the copper powders since the amount of copper powder was limited. The porosity was calculated from the apparent and solid densities of the materials, and the powder shapes were characterized using a Nikon model SMZ- 
2T light microscope. Table 1 provides the results of characterization for the powders used during the experiment.

Table 1 - Size, density, and porosity of powders used during the experiment.

\begin{tabular}{|c|c|c|c|c|c|}
\hline $\begin{array}{c}\text { Powder } \\
\text { Composition }\end{array}$ & $\begin{array}{c}\text { Measured } \\
\text { Size Range } \\
(\mu \mathrm{m})\end{array}$ & $\begin{array}{c}\text { Powder Size of } \\
\text { Procured Powder and } \\
\text { after Sieving } \\
(\text { mesh) }\end{array}$ & $\begin{array}{c}\text { Apparent } \\
\text { Density } \\
\left(\mathrm{g} / \mathrm{cm}^{3}\right)\end{array}$ & $\begin{array}{c}\text { Solid } \\
\text { Density } \\
\left(\mathrm{g} / \mathrm{cm}^{3}\right)\end{array}$ & Porosity \\
\hline $\mathrm{Cu}(99.9 \%)$ & $10-150$ & $-100 /+325$ & 4.80 & 8.96 & 0.46 \\
\hline $\mathrm{Cu}(99.9 \%)$ & $106-210$ & -140 & 4.98 & 8.96 & 0.44 \\
\hline $\mathrm{Cu}(99.9 \%)$ & $14-100$ & +325 & 4.20 & 8.96 & 0.53 \\
\hline $\mathrm{Fe}(99.9 \%)$ & $12-240$ & $-100 /+325$ & 2.60 & 7.90 & 0.67 \\
\hline $\mathrm{Fe}(99.9 \%)$ & $106-300$ & -140 & 2.34 & 7.90 & 0.70 \\
\hline $\mathrm{Fe}(99.9 \%)$ & $14-105$ & +325 & 2.82 & 7.90 & 0.64 \\
\hline
\end{tabular}

The laser systems used in these experiments were a $2.2 \mathrm{~kW}$ fast axial flow $\mathrm{CO}_{2}$ laser from PRC and a $4.5 \mathrm{~kW}$ diode-pumped Nd:YAG laser from Trumpf, Incorporated. Although these systems are capable of operating at their full output power, this experiment required low power levels as to not induce significant melting. Power levels of interest were between 8 and 12 Watts with an unfocused spot size of $0.5 \mathrm{~cm}$ diameter, corresponding to 40.7 and 61.1 $\mathrm{W} / \mathrm{cm}^{2}$ power densities, respectively. To allow the lasers to operate at higher levels having greater stability, 90/10 Reflectance/Transmittance plate beam splitters were used to transmit only $10 \%$ of the lasers' output power to the powder layers. The unwanted power $(90 \%)$ was dumped to a graphite block. A $\mathrm{ZnSe}$ beam splitter was used for the $\mathrm{CO}_{2}$ laser beam and a fused silica beam splitter was used for the Nd:YAG. Fiber delivered lasers can contain a secondary intensity when operated far from focus; therefore, a $5 \mathrm{~mm}$ diameter aperture was included after the beam splitter to ensure greater uniformity of the irradiated energy. The aperture was machined as a conic section from $2 \mathrm{~mm}$ thick aluminum alloy to reduce diffraction.

A Labsphere ${ }^{\circledR}$ Model RTC-060-IG integrating sphere was employed to integrate 
the laser energy obtained during transmission through, or reflectance from, the powder layer. The internal coating provides 0.933 reflectivity at the $1.064 \mu \mathrm{m}$ wavelength (Nd:YAG) and greater than 0.940 reflectance for the $10.6 \mu \mathrm{m}$ wavelength $\left(\mathrm{CO}_{2}\right)$ [45], traceable to the U.S. National Institute of Standards and Technology. A Dexter Research Model 6M thermopile detector, in conjunction with a Dexter Research Model 1010 Low Noise Amplifier, was incorporated into the integrating sphere. This arrangement provided a linear signal output of from $10^{-6}$ to $0.1 \mathrm{~W} / \mathrm{cm}^{2}$ over the wavelengths of interest.

A specially designed sample holder was constructed to enable reproducible placement of powder layers having various thickness. The stainless steel holder utilized fused silica and $\mathrm{ZnSe}$ cover glass during $\mathrm{Nd}$ :YAG and $\mathrm{CO}_{2}$ laser irradiation, respectively, as a transparent coupling media between the powder and the integrating sphere. The holder employed an annular ring that could be raised above the cover glass using precision shim stock to allow accurate thickness of the powder layer to be obtained by "scraping" the powder layer across the ring. The design allowed the sample holder to fit easily into the 3.2 $\mathrm{cm}$ diameter ports found at the top or bottom of the integrating sphere. The holder was placed in the top port for the transmissive experiments and at the bottom port for the reflective experiments. A schematic showing the experimental arrangement for both conditions is shown in Figure 23.

Initial calibration runs were performed to determine the optimal oscilloscope voltage and irradiation time for the thermopile detector, and to verify spot size on the sample. Based on these results, a beam power of $100 \mathrm{~W}$ for 5 seconds of irradiation was established as process parameters, and resulted in approximately $10 \mathrm{~W}$ being provided to the powder specimens. The thermopile output as a function of intensity measured by the detector was found to be linear, which allowed direct determination of power transmitted through the powder layer and measured in the sphere. 
Material was then added to the system for depths ranging from 75 to 675 microns, with new powder material being used for each measurement. These steps were carried out for the six powders outlined in Table 1. Throughout the transmissive experiments, power measurements were made of the incident beam and transmitted power recorded from the sphere calorimeter throughout the range of powder depths, as shown in Figure 23a. The irradiation time for each test was 5 seconds. Reflective data was also obtained using the Nd:YAG laser and the original iron and copper powder size distributions using the arrangement shown in Figure 23b. This data indicated that the reflected Nd:YAG radiation from the powder was nearly constant for each material at selected powder depths. The reflectance for the iron powder was found to be 0.26 , whereas the measured reflectance of the copper powder was 0.58 . Measurements of the incident beam were taken randomly during the experiments and were found to be between 9.4 and $9.8 \mathrm{~W}$ for all tests. Shown in Figure 24 are photographs of representative powder specimens for the pure iron and pure copper after $\mathrm{Nd}$ :YAG irradiation.

The results of the transmissive experiments are shown in Figure 25 and Figure 26 for the pure iron and pure copper powder, respectively. The data represents the power transmitted through the iron and copper powders as a function of powder layer thickness, and hence, defines the intensity present and available for absorption within the powder at progressively greater depths. The data is shown for the three size distributions of the two powder materials. The data of Figures 25 and 26 was also plotted in a form that allows the attenuation of the beam within the powder to be explored in terms of a Beer-Lambert type relationship. This is shown in Figure 27 and Figure 28 for the iron powder for the $\mathrm{Nd}$ :YAG and $\mathrm{CO}_{2}$ laser irradiation, respectively, and Figure 29 and Figure 30 for the copper powder for the $\mathrm{Nd}: Y A G$ and $\mathrm{CO}_{2}$ laser irradiation, respectively. These graphs represent the natural log plot of the ratio of the measured intensity to the initial intensity as a function of powder depth. 


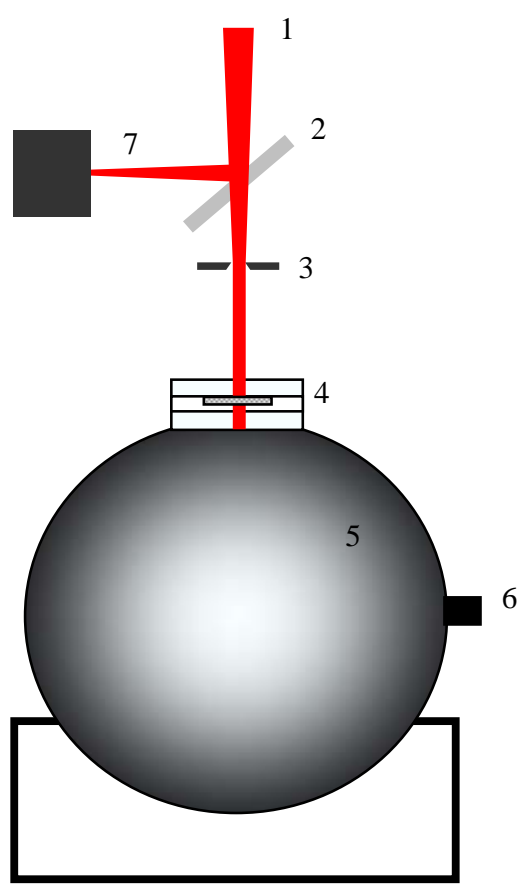

(a)

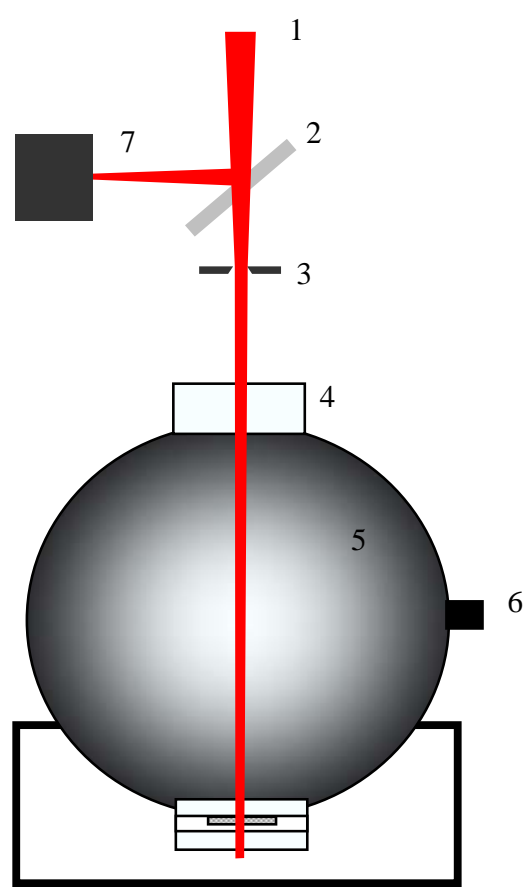

(b)

Figure 23 - Schematic of sphere integrator arrangement for experiments to measure (a) transmitted and (b) reflected irradiation from powder layers (1: incoming beam, 2: beam splitter, 3: aperture, 4: powder sample holder, 5: integrating sphere, 6: thermopile detector, 7: beam dump).

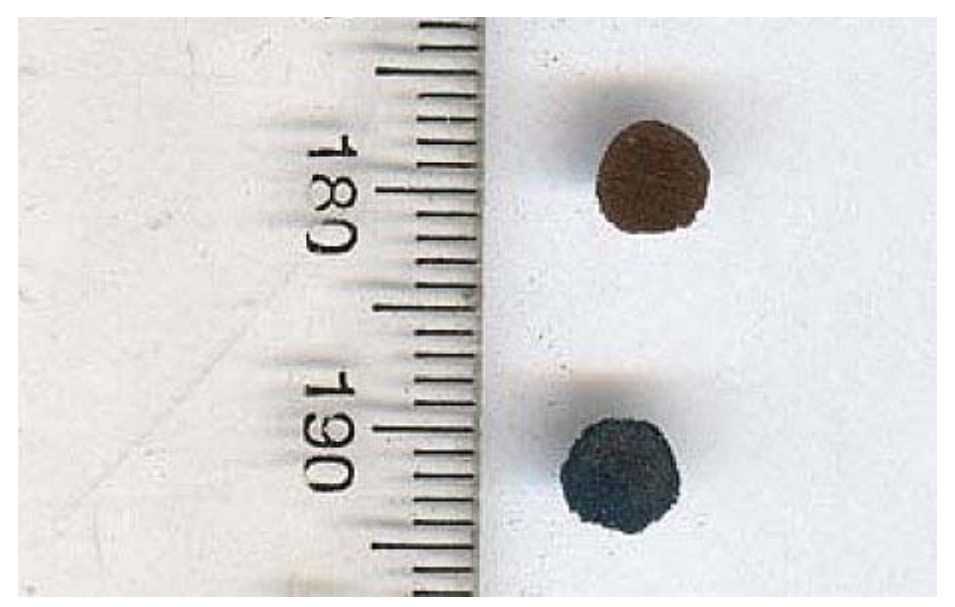

Figure 24 - Photographs of the pure copper powder (top) and pure iron powder (bottom) after Nd:YAG irradiation of approximately $10 \mathrm{~W}$ for 5 seconds (scale on left in $\mathrm{mm}$ ). 
Reflecting on Equation 26, it may be shown that depiction of the data in the above form allows a linear fit of the data to be used to estimate the attenuation coefficient, $\gamma$, as the slope of the fit. The $y$-intercepts representing the Nd:YAG data, used in Figures 27 and 29, were based on the bulk absorption $(\ln (\beta))$ estimated from the reflectance data $(\beta=1-R)$ determined experimentally, which was 0.74 for the iron powder and 0.42 for the copper powder. The bulk absorption data for $\mathrm{Nd}$ :YAG irradiation obtained from the reflectance experiments is in good agreement with earlier calorimetry experiments [40]. The bulk absorption data for the $\mathrm{CO}_{2}$ laser irradiation used in Figures 28 and 30 was obtained from the literature, which were 0.45 for the iron powder and 0.35 for the copper powder [38,40,].

The linear fits, obtained by the least-squares method while constraining the fit through $\ln (\beta)$ on the y axis, are also included in the plots of Figures 27 through 30. Table 2 lists the estimated attenuation coefficients obtained in this manner for the powders and wavelengths evaluated, along with the $R^{2}$ value that indicates the suitability of the fit. The closer the $R^{2}$ value is to unity, the better the linear fit of the data.

The data of Figures 27 through 30 and Table 2 may be viewed qualitatively, as well as quantitatively in several instances. In all cases, there is a trend in the experimental data for the initial size distribution of the powders to be bounded by the distributions representing the fine and course powders, with the attenuation coefficient decreasing as the particle size of the powder increases. Utilizing the data representing the initial size distributions of the iron and copper powder, there is also an inclination for the attenuation coefficient to decrease with the lower wavelength of the $\mathrm{Nd}$ :YAG laser when compared to the $\mathrm{CO}_{2}$ laser, as well as with the copper powder when compared to the iron powder. The lower attenuation coefficient would indicate greater penetration of the powder bed with the Nd:YAG laser and the copper powder. 


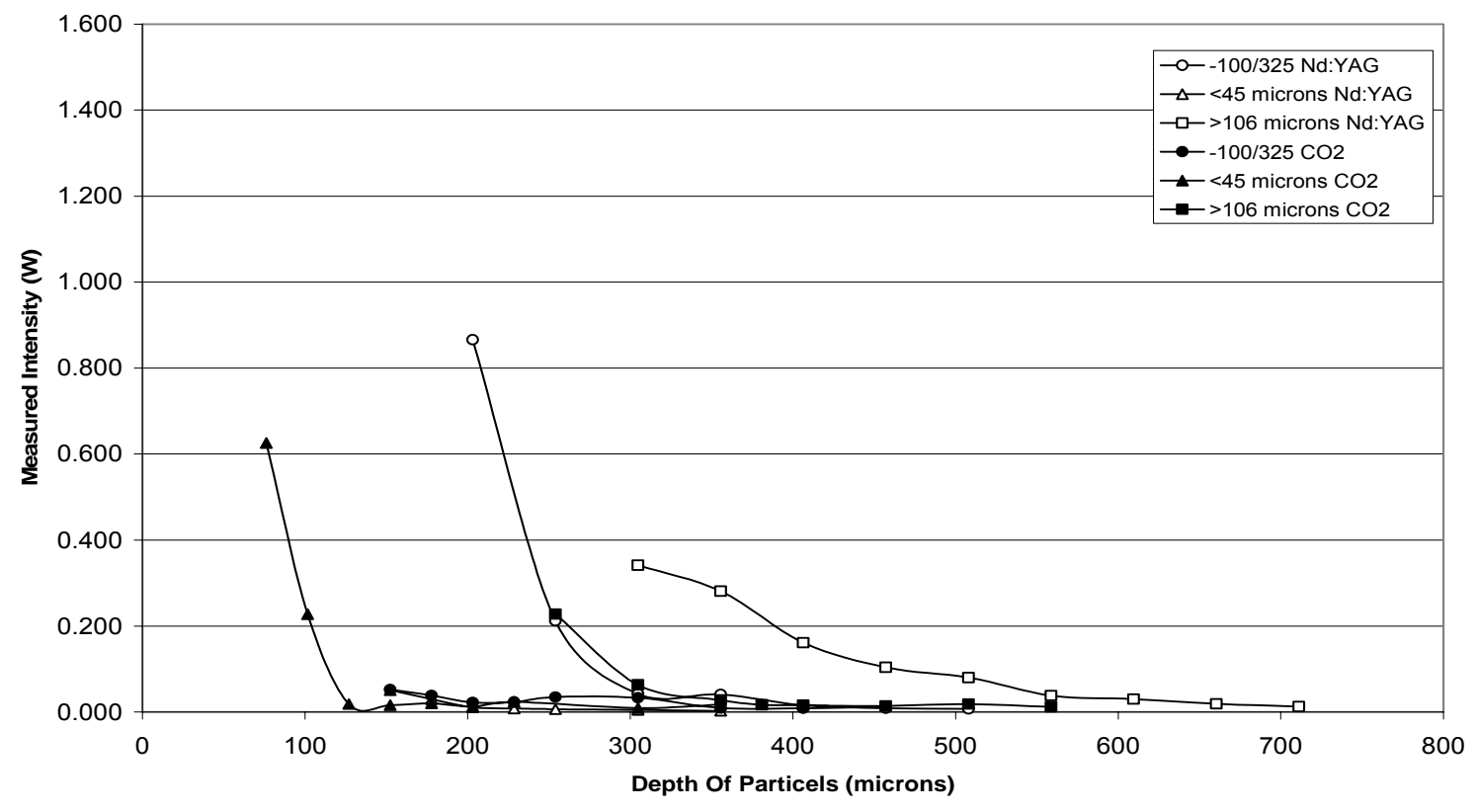

Figure 25 - Experimental data showing transmittance versus powder depth for iron irradiated by $\mathrm{CO}_{2}(\lambda=10.6 \mu \mathrm{m})$ and $\mathrm{Nd}$ :YAG $(\lambda=1.06 \mu \mathrm{m})$ lasers.

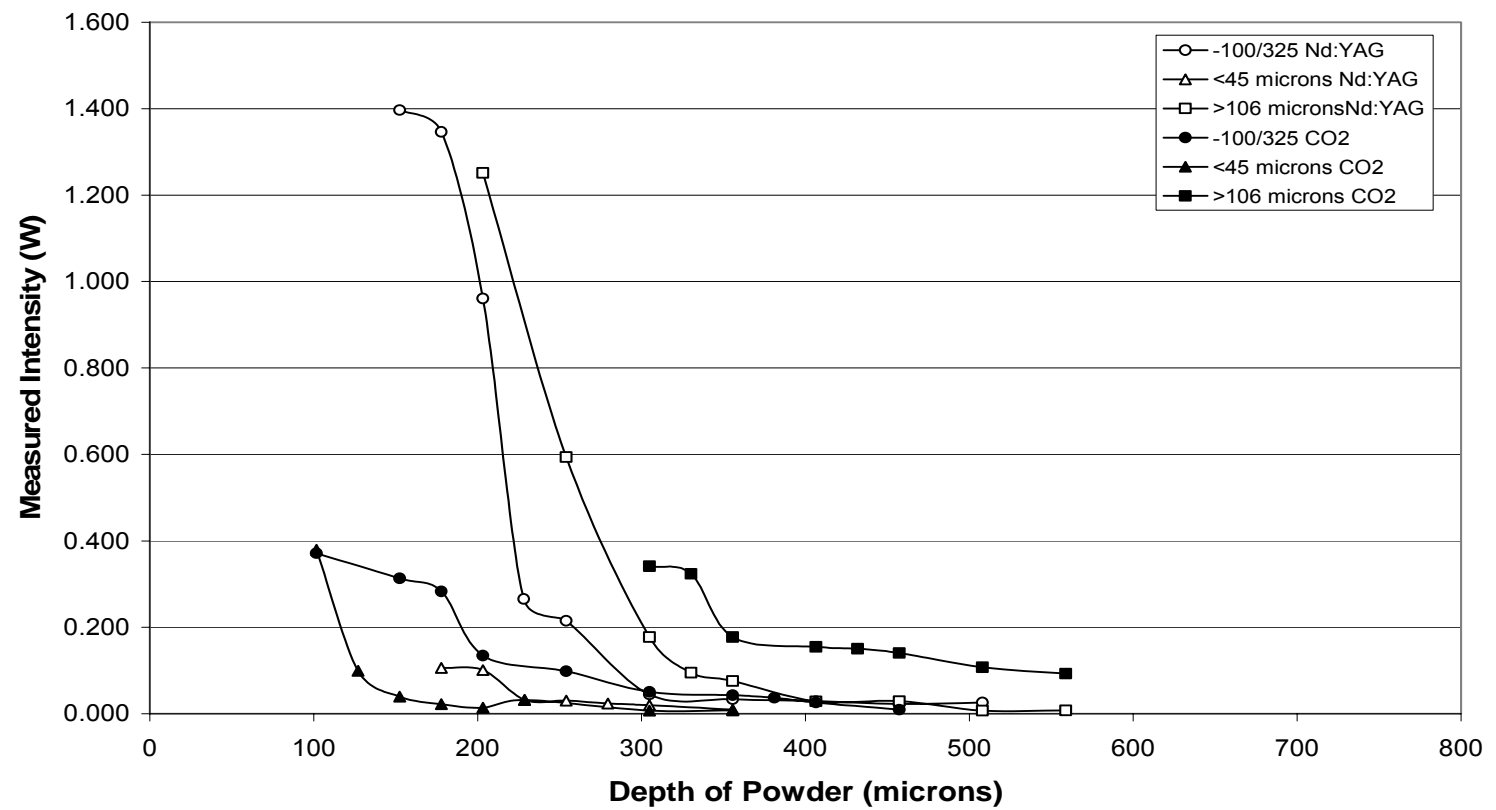

Figure 26 - Experimental data showing transmittance versus powder depth for copper irradiated by $\mathrm{CO}_{2}(\lambda=10.6 \mu \mathrm{m})$ and Nd:YAG $(\lambda=1.06 \mu \mathrm{m})$ lasers. 


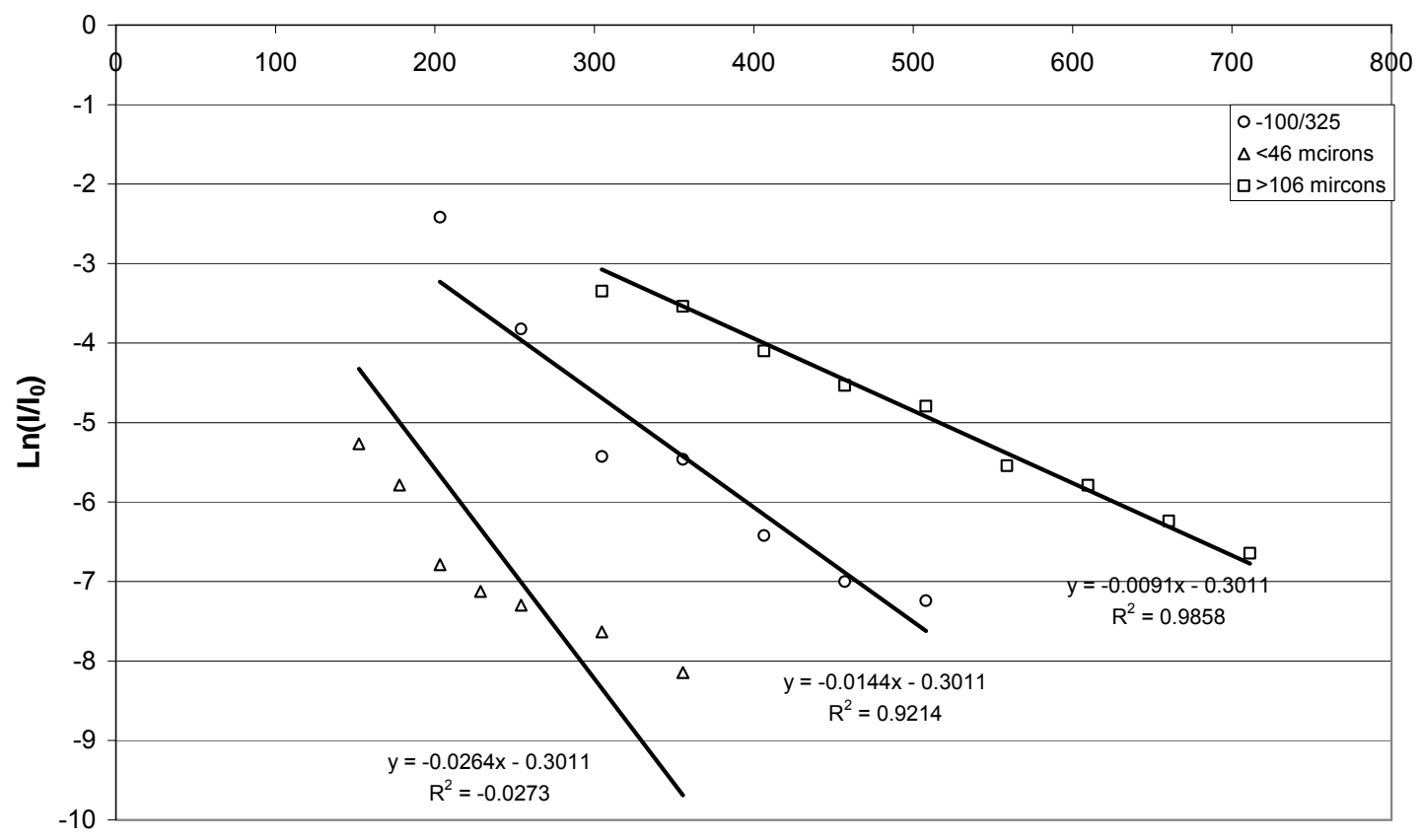

Depth of Powder (microns)

Figure 27 - Ratio of measured intensity to initial intensity as a function of powder depth for Nd:YAG laser irradiation with iron powder.

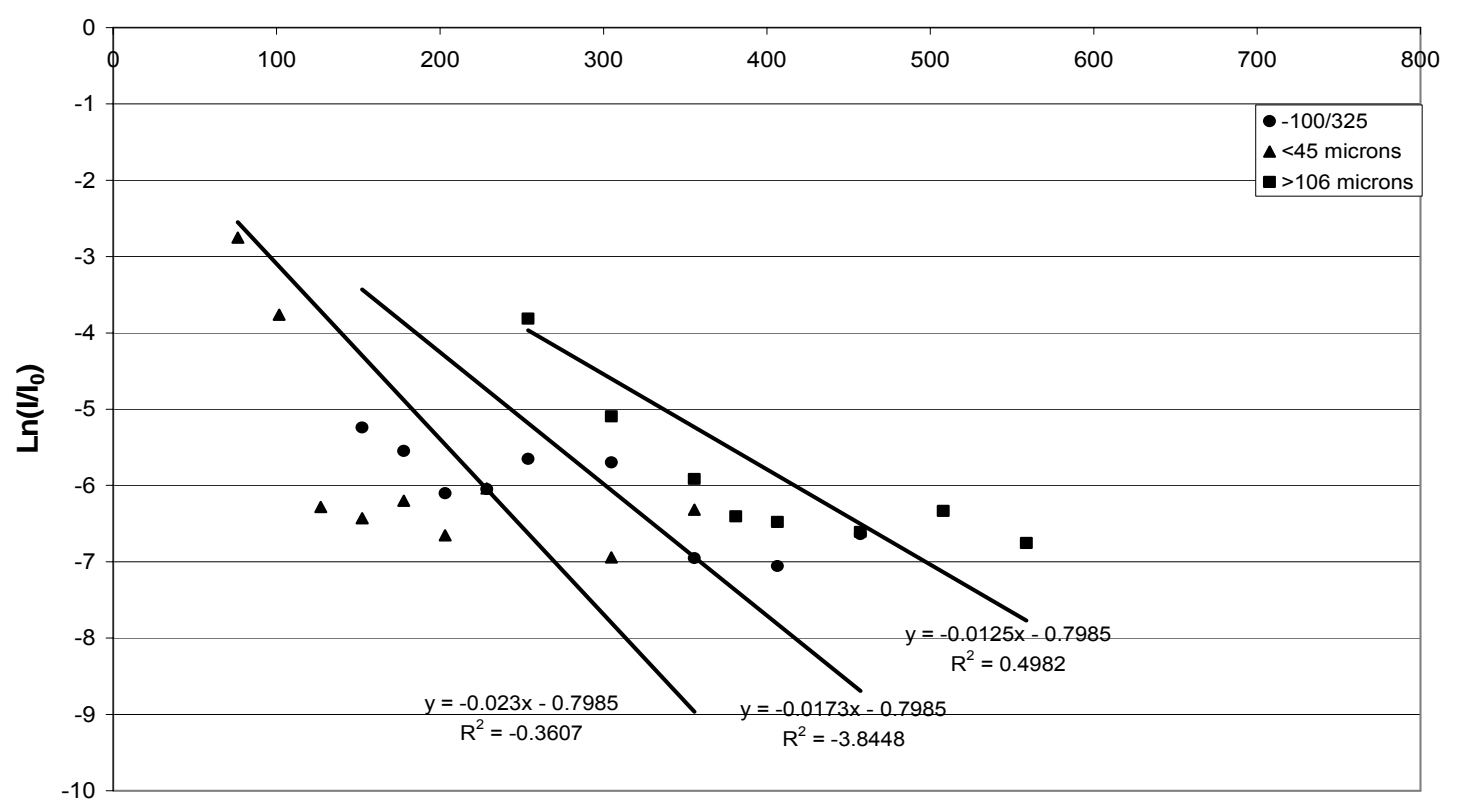

Depth of Powder (microns)

Figure 28 - Ratio of measured intensity to initial intensity as a function of powder depth for $\mathrm{CO}_{2}$ laser irradiation with iron powder. 


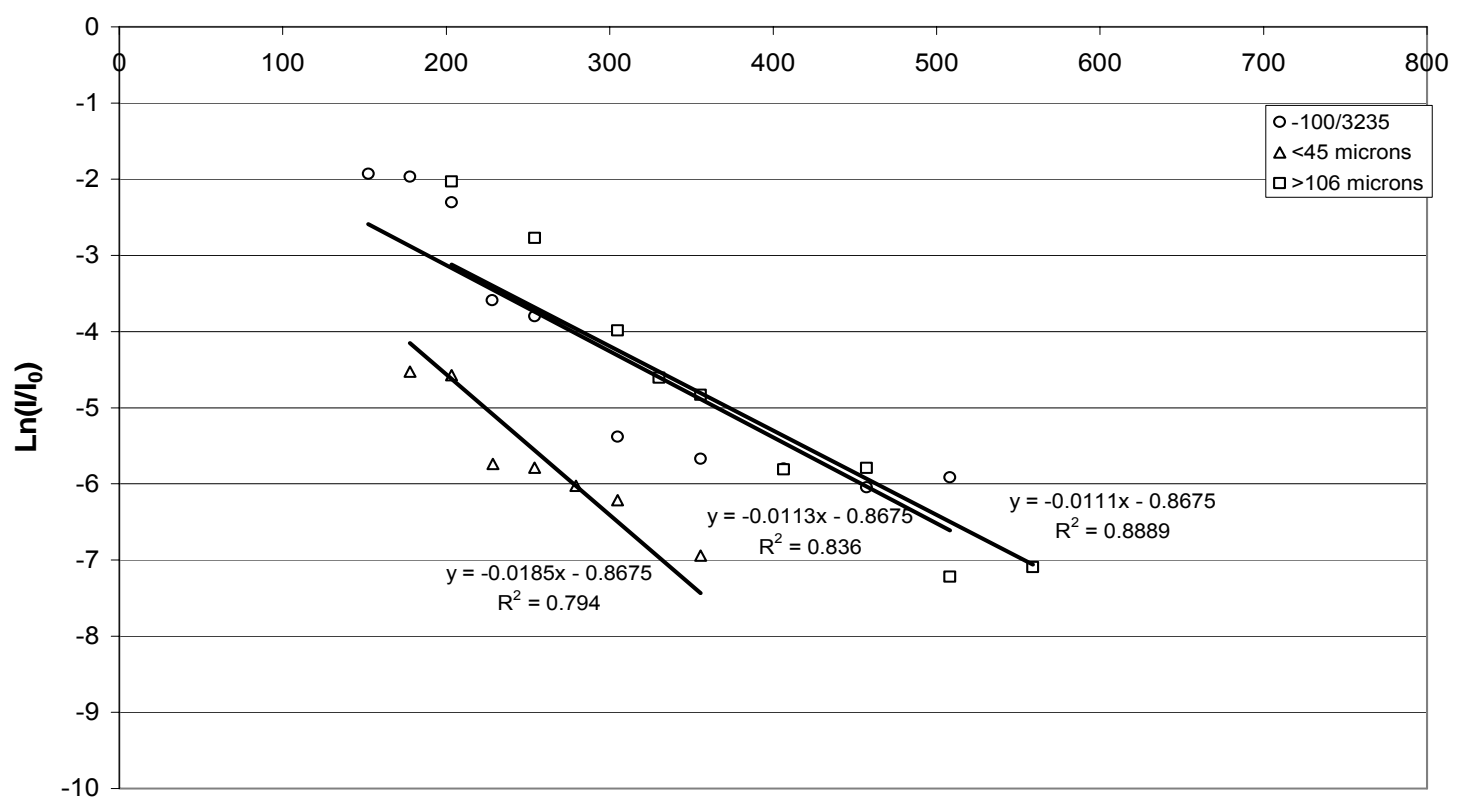

Depth of Powder (microns)

Figure 29 - Ratio of measured intensity to initial intensity as a function of powder depth for Nd:YAG laser irradiation with copper powder.

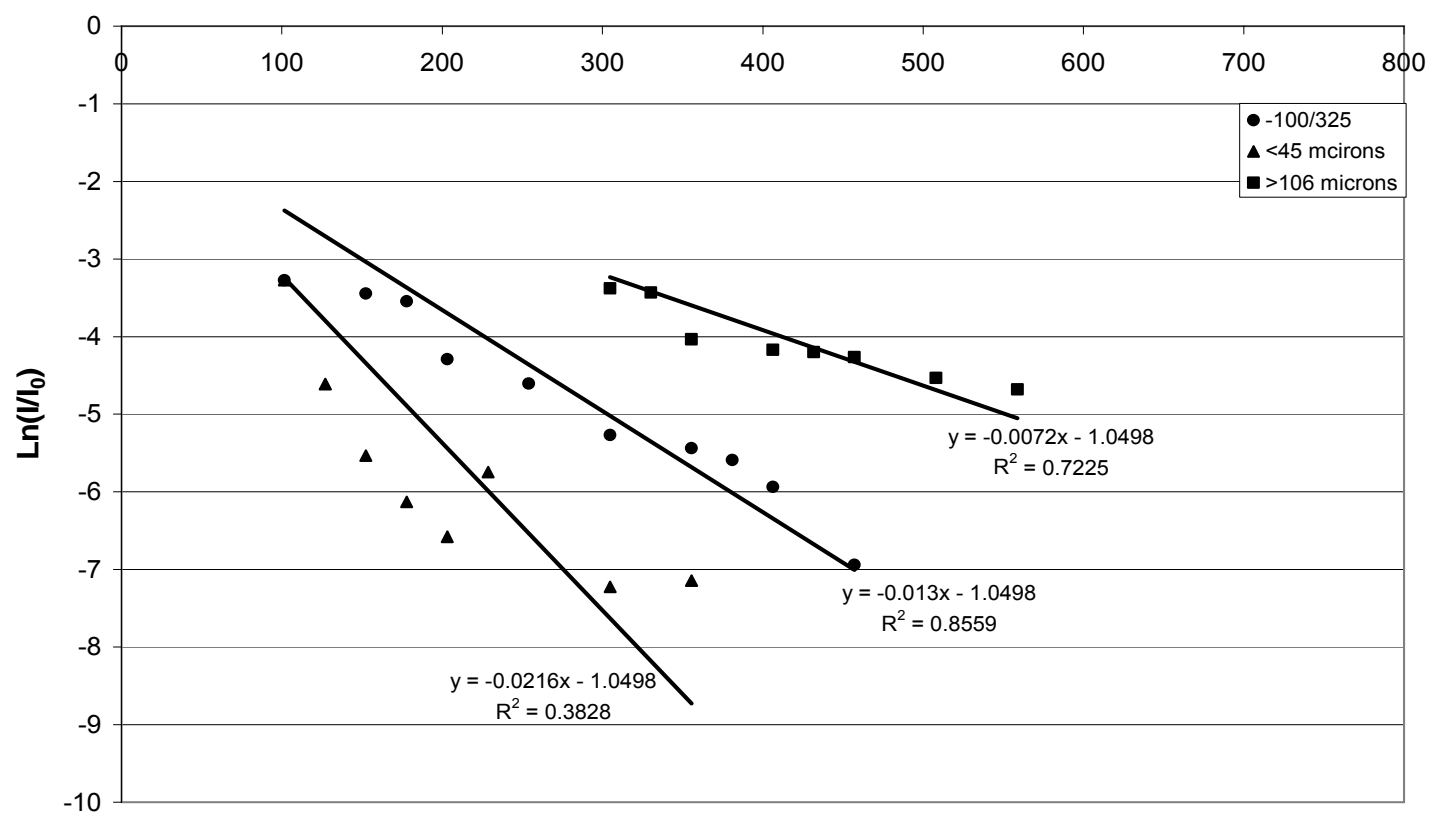

Depth of Powder (microns)

Figure 30 - Ratio of measured intensity to initial intensity as a function of powder depth for $\mathrm{CO}_{2}$ laser irradiation with copper powder. 
Table 2 - Estimated attenuation coefficients obtained from the absorption experiments.

\begin{tabular}{|c|c|c|c|c|}
\hline Powder Type & $\begin{array}{c}\text { Laser } \\
\text { Wavelength } \\
(\mu \mathrm{m})\end{array}$ & $\begin{array}{c}\text { Measured Size } \\
\text { Range } \\
(\mu \mathrm{m})\end{array}$ & $\begin{array}{c}\text { Estimate of } \\
\text { Attenuation } \\
\text { Coefficient } \\
\left(\mu \mathrm{m}^{-1}\right)\end{array}$ & $\begin{array}{c}\mathrm{R}^{2} \text { Value } \\
\text { Indicating Fit }\end{array}$ \\
\hline $\mathrm{Cu}(99.9 \%)$ & 1.06 & $10-150$ & 0.0113 & 0.836 \\
\hline $\mathrm{Cu}(99.9 \%)$ & 1.06 & $14-100$ & 0.0111 & 0.794 \\
\hline $\mathrm{Cu}(99.9 \%)$ & 1.06 & $106-210$ & 0.0185 & 0.889 \\
\hline $\mathrm{Cu}(99.9 \%)$ & 10.6 & $10-150$ & 0.013 & 0.856 \\
\hline $\mathrm{Cu}(99.9 \%)$ & 10.6 & $14-100$ & 0.216 & 0.383 \\
\hline $\mathrm{Cu}(99.9 \%)$ & 10.6 & $106-210$ & 0.0072 & 0.7225 \\
\hline $\mathrm{Fe}(99.9 \%)$ & 1.06 & $12-240$ & 0.0144 & 0.921 \\
\hline $\mathrm{Fe}(99.9 \%)$ & 1.06 & $14-105$ & 0.0264 & -0.027 \\
\hline $\mathrm{Fe}(99.9 \%)$ & 1.06 & $106-300$ & 0.0091 & 0.986 \\
\hline $\mathrm{Fe}(99.9 \%)$ & 10.6 & $12-240$ & 0.0173 & -3.844 \\
\hline $\mathrm{Fe}(99.9 \%)$ & 10.6 & $14-105$ & 0.0230 & -0.361 \\
\hline $\mathrm{Fe}(99.9 \%)$ & 10.6 & $106-300$ & 0.0125 & 0.498 \\
\hline
\end{tabular}

Selective values for the attenuation coefficient in Table 2 may also be used in a quantitative manner; however, this requires further discrimination of the experimental results of Figures 27 through 30 pertaining to the correctness of the data. It has been stated that the distributions representing the fine powder showed a marked departure from linearity, and this was most apparent with the fine powder and $\mathrm{CO}_{2}$ laser irradiation (Figures 28 and 30). In these cases, the wavelength of the laser radiation approaches the size and interparticle spacing of the powder, and probably involves multiple scattering effects, in both the forward and backward direction to the incident beam. Hence, data representing the fine distributions cannot be described by exponential decay of a Beer-Lambert type relationship. However, the larger powder distributions, and especially with $\mathrm{Nd}$ :YAG irradiation, appear to fit this description. It must also be noted that the typical powder size normally available for laser deposition is $-100 /+325$ mesh (44 to $149 \mu \mathrm{m}$ ), which may be described fairly well by the experimental data. 
The $R^{2}$ values of Table 2, which defines the suitability of the linear fit of the experimental data, reinforces the above discussion. The $\mathrm{R}^{2}$ values for the experimental data representing the original and coarse powder distributions that was irradiated with the Nd:YAG laser consistently approached unity, indicating the appropriateness of a linear relationship. Therefore, the quantitative discussion of the attenuation coefficients is confined to the original size distributions for the iron and copper powder and Nd:YAG irradiation. As mentioned, the original size distribution is well represented by commercial powders used for laser deposition. The estimated attenuation coefficients under these conditions are $0.0144 \mu \mathrm{m}^{-1}$ for the iron powder and $0.0113 \mu \mathrm{m}^{-1}$ for the copper powder. A comparison of these values to those of the materials in the solid state indicate that the attenuation coefficients of the powders to be four orders of magnitude less [46], which reveals the significant effect of the penetration of the Nd:YAG beam into the powder layer as opposed to surface absorption in solid metals.

The attenuation coefficients for iron and copper powder under Nd:YAG irradiation may be utilized to describe internal energy absorption using the relationships derived earlier. The use of the absorption relationship in the thermal model, along with the experimentally derived coefficients, enables a greater degree of accuracy for simulating laser deposition of the pre-placed powder process. Depending upon the shape and energy distribution of the beam, Equations 35, 37 , or 38 , may be used to define the internal energy associated with scattering of the beam within the powder layer. Figure 31 illustrates the energy density within the powder layer during Nd:YAG irradiation on iron and copper powder for a Gaussian energy source (Equation 35), and Figure 32 shows the energy density within the powders for a uniform energy source (Equation 37). The attenuation coefficients $(\gamma)$ for the absorption relationships of Figures 31 and 32 are those obtained from these experiments for the original powder size distributions and the bulk absorption values $(\beta)$ were those obtained from the reflectance data as defined previously. The units in Figure 31 and 32 are in $W / \mu \mathrm{m}^{3}$, and the figures 
demonstrate the degree of absorption occurring at substantial depths within the powder layer during irradiation. The figures also illustrate the effects of bulk absorption near the surface and attenuation within the powder layer. Although the energy density near the surface for copper is lower than for the iron, owing to the lower bulk absorption, the greater attenuation of copper results in similar energy densities at higher depths within the powder layer.

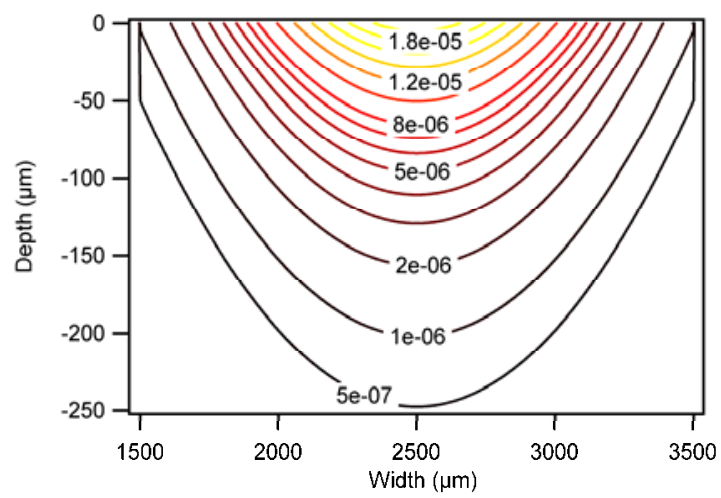

(a)

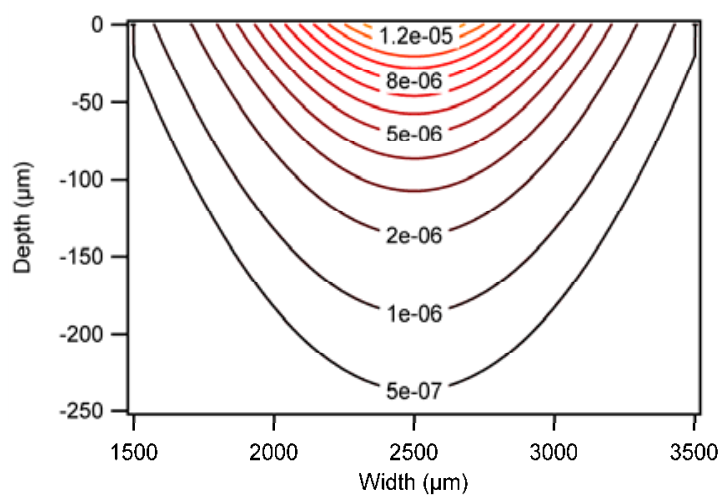

(b)

Figure 31 - Internal energy density within the powder layer during Nd:YAG irradiation with a Gaussian energy source for (a) iron and (b) copper powders (units in $W / \mu m^{3}$ ).

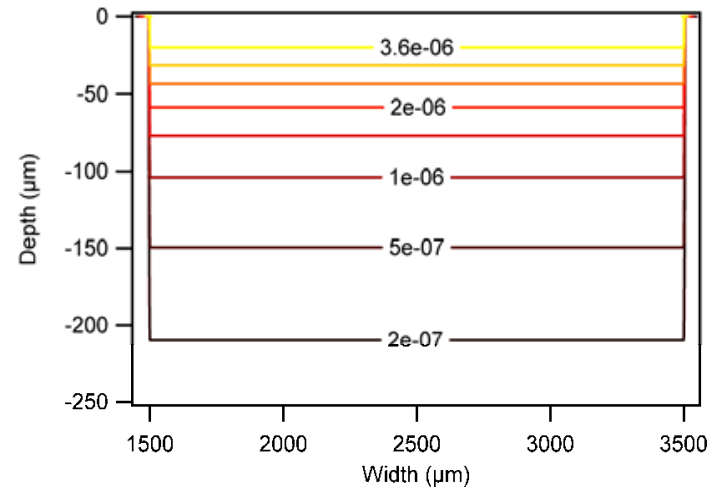

(a)

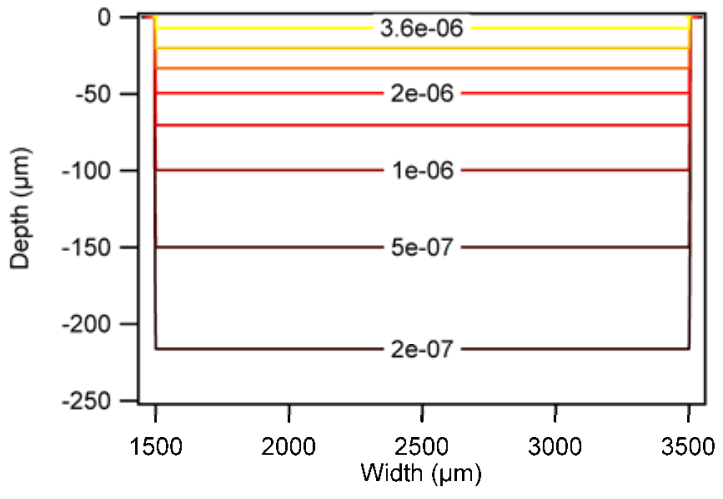

(b)

Figure 32 - Internal energy density within the powder layer during Nd:YAG irradiation with a uniform energy source for (a) iron and (b) copper powders (units in $W / \mu \mathrm{m}^{3}$ ). 


\subsubsection{Implementation of the Thermal Model}

The techniques, parameters, and data established above were utilized to construct a numerical model capable of simulating heat transfer of the laser surface modification processes. The model is termed Computational Analysis of Laser Cladding and Surface Modification (CALC+SM) and provides several features, such as window-based input, a limited data library of material thermal properties, graphical output capabilities, and operable on a personal computer, that enable it to be utilized by engineers not versed in numerical modeling.

In order to begin calculations with the model, input from the user must be made to four different menu windows. These input menu windows are:

- dimensions menu - allows the user to specify the substrate thickness, width and length, and the powder thickness and width

- parameters menu - allows the user to specify the clad position, which is the distance from the front left corner of the substrate, laser velocity, laser power supplied to the substrate, bulk absorption of the powder and substrate, if known, initial temperature of the substrate, ambient temperature, and type of heat source, which can be either Gaussian or a line source.

- materials menu - provides a selection of properties required for calculations for typical substrate and powder materials used for laser deposition. If a material is not on the list, a new material and properties may be added.

- output menu - defines the cross-sectional plane of interest along the length of the substrate that is viewed for isotherms of maximum temperature or time-dependent temperatures at various depths within the coating and substrate.

While the calculations are being conducted, a transient time versus temperature graph is displayed for temperatures on the top surface and at the interface between the powder layer and substrate for the plane specified. Additional data is stored in a file that contains temperatures throughout the plane of interest for various times during processing. 


\subsection{Experimental Validation of Process Model}

In order to compare results of the thermal model to experiments, simulations were conducted and compared to experiments performed using identical parameters. Thermocouple measurements and macrogrpahic analysis was used to compare measured and predicted temperatures and profiles. The material system chosen for the simulations and experiments were Inconel 625 powder and a mild steel substrate, since these materials are common for laser deposition.

Although all attempts were made to utilize similar parameters, two conditions were slightly different for the simulations and the experiments. In order to decrease the run time of the model, the simulations used a substrate that was one-fourth the length of that used for the experiment. Also, because the attenuation coefficient, $\gamma$, is not known for Inconel 625 , it was estimated. The estimation was performed by realizing that there was a distinct relationship between the absorption coefficient and the attenuation coefficient for the powders that were previously tested, that is, the higher the absorption coefficient for a certain wavelength, the higher the attenuation coefficient. Assuming the absorption coefficient of Inconel 625 is similar to that of nickel, it was then compared to iron and copper. After comparing these absorption coefficients, it was estimated that the attenuation coefficient of Inconel 625 powder to be 0.0152 $\mu \mathrm{m}^{-1}$ for Nd:YAG irradiation and $0.0192 \mu \mathrm{m}^{-1}$ for $\mathrm{CO}_{2}$ irradiation. Tables 3 and 4 outline the constants and parameters used for the $\mathrm{CO}_{2}$ and $\mathrm{Nd}$ :YAG laser deposition simulations. It should be noted that, as described previously, density and conductivity within the model vary linearly with temperature for the powder material when in the melting range, between $\rho_{\text {pow }}$ and $\rho_{\text {eff }}$ and $k_{\text {pow }}$ and $k_{\text {eff, }}$ respectively. After melting, density, thermal conductivity, absorption, and the attenuation coefficients represent the consolidated material. 
Table 3 - Various model parameters used for the $\mathrm{CO}_{2}$ and $\mathrm{Nd}$ :YAG laser deposition simulations.

\begin{tabular}{|l|l|l|}
\hline Parameter & Symbol & Value \\
\hline Substrate Material & & AISI 1020 Steel \\
\hline Substrate Length $(\mathrm{mm})$ & Ls & 76.0 \\
\hline Substrate Width $(\mathrm{mm})$ & Ws & 40.0 \\
\hline Substrate Depth $(\mathrm{mm})$ & Ts & 13.0 \\
\hline Powder Material & & Inconel 625 \\
\hline Powder Width $(\mathrm{mm})$ & Wpow & 5 \\
\hline Powder Depth $(\mathrm{mm})$ & Tpow & 2 \\
\hline Laser Power $(\mathrm{W})$ & $\mathrm{P}$ & 2000 \\
\hline Laser Diameter $(\mathrm{mm})$ & $\mathrm{d}$ & 5 \\
\hline Laser Speed $(\mathrm{mm} / \mathrm{s})$ & $\mathrm{V}$ & 2.5 \\
\hline Density of Substrate $\left(\mathrm{g} / \mathrm{cm}^{3}\right)$ & $\rho_{\mathrm{s}}$ & 7.87 \\
\hline Effective Density of Powder $\left(\mathrm{g} / \mathrm{cm}^{3}\right)$ & $\rho_{\text {eff }}$ & 2.53 \\
\hline Density of Consolidated Powder $\left(\mathrm{g} / \mathrm{cm}{ }^{3}\right)$ & $\rho_{\text {pow }}$ & 8.44 \\
\hline Specific Heat of Substrate $(\mathrm{J} / \mathrm{g}-\mathrm{K})$ & $\mathrm{C}_{\mathrm{ps}}$ & 486 \\
\hline Specific Heat of Powder $(\mathrm{J} / \mathrm{g}-\mathrm{K})$ & $\mathrm{C}_{\mathrm{p} \text { pow }}$ & 410 \\
\hline Thermal Conductivity of Substrate $(\mathrm{W} / \mathrm{m}-\mathrm{K})$ & $\mathrm{k}_{\mathrm{sub}}$ & 51.9 \\
\hline Effective Conductivity of Powder $(\mathrm{W} / \mathrm{m}-\mathrm{K})$ & $\mathrm{k}_{\text {eff }}$ & 0.0813 \\
\hline Consolidated Conductivity of Powder $(\mathrm{W} / \mathrm{m}-\mathrm{K})$ & $\mathrm{k}_{\mathrm{pow}}$ & 9.1 \\
\hline Liquidus of Substrate $(\mathrm{K})$ & $\mathrm{T}_{\mathrm{Is}}$ & 1803 \\
\hline Solidus of Substrate $(\mathrm{K})$ & $\mathrm{T}_{\mathrm{ss}}$ & 1763 \\
\hline Liquidus of Powder $(\mathrm{K})$ & $\mathrm{T}_{\mathrm{Ip}}$ & 1623 \\
\hline Solidus of Powder $(\mathrm{K})$ & $\mathrm{T}_{\mathrm{sp}}$ & 1563 \\
\hline
\end{tabular}

Table 4 - Beam and powder material interaction parameters used for the $\mathrm{CO}_{2}$ and $\mathrm{Nd}$ :YAG laser deposition simulations.

\begin{tabular}{|l|l|l|l|}
\hline Parameter & \multicolumn{1}{|c|}{ Symbol } & \multicolumn{1}{c|}{$\begin{array}{c}\mathrm{CO}_{2} \\
\text { irradiation }\end{array}$} & $\begin{array}{c}\text { Nd:YAG } \\
\text { irradiation }\end{array}$ \\
\hline Bulk Absorption in Powder & $\mathrm{abs}_{\text {eff }}$ & 0.42 & 0.64 \\
\hline Bulk Absorption Consolidated & $\mathrm{abs}_{\text {pow }}$ & 0.10 & 0.25 \\
\hline Attenuation Coefficient Powder $\left(\mu \mathrm{m}^{-1}\right)$ & $\gamma_{\text {pow }}$ & $1.55 \times 10^{-2}$ & $1.83 \times 10^{-2}$ \\
\hline Attenuation Coefficient Liquid $\left(\mu \mathrm{m}^{-1}\right)$ & $\gamma_{\text {liq }}$ & $1.00 \times 10^{1}$ & $4.00 \times 10^{1}$ \\
\hline
\end{tabular}


After performing the simulations, measured temperature profiles obtained by the thermocouples were compared to the results of the simulations. Figures 33 and 34 show the comparison between the experimental data obtained by the thermocouples and the simulated temperature profiles. The temperatures shown in the figure represent thermocouple positions and simulation locations at the mid-plane of the substrate and the edge of the deposition, displaying the highest peak temperature, and positions at 8 and $16 \mathrm{~mm}$ from the edge of the deposition, which show progressively lower peak temperatures.

Direct comparison of the simulation and experimentally measured temperatures at the three positions indicate that the simulated peak temperatures are in relative agreement with the experimentally derived temperatures. However, cooling rates from the peak temperature that are associated with the simulations are seen to be much greater than those observed by experiment. In order to explain the difference in cooling rates between the model and the experiment, the boundary conditions on the surface were closely examined, especially the convection coefficient. In theory, the cladding substrate can be thought of as a horizontal plate, having a much larger surface area on the top and bottom than on the sides. Also, since there is little or no air flow, it should be assumed that free convection is the cause of any heat loss due to convection. This loss is due to the fact that the heated metal surface will heat the air around it, creating a convective flow of the surrounding gas. Assuming, that the temperature of the substrate is $200 \mathrm{~K}$ higher then the surrounding air, the convection coefficients were estimated using accepted relationships, and these values were compared to the relationship for surface heat losses utilized within the model. At a comparable specimen size and with the same temperature difference, the convection coefficient for the model is $16.67 \mathrm{~W} / \mathrm{m}^{2} \mathrm{~K}$. This is significantly higher than that of the horizontal plate assumption, almost tripling the theoretical coefficient, and may explain the high cooling rates exhibited by the simulations. The model is currently undergoing modifications to the surface heat loss function to rectify the high convective term. 


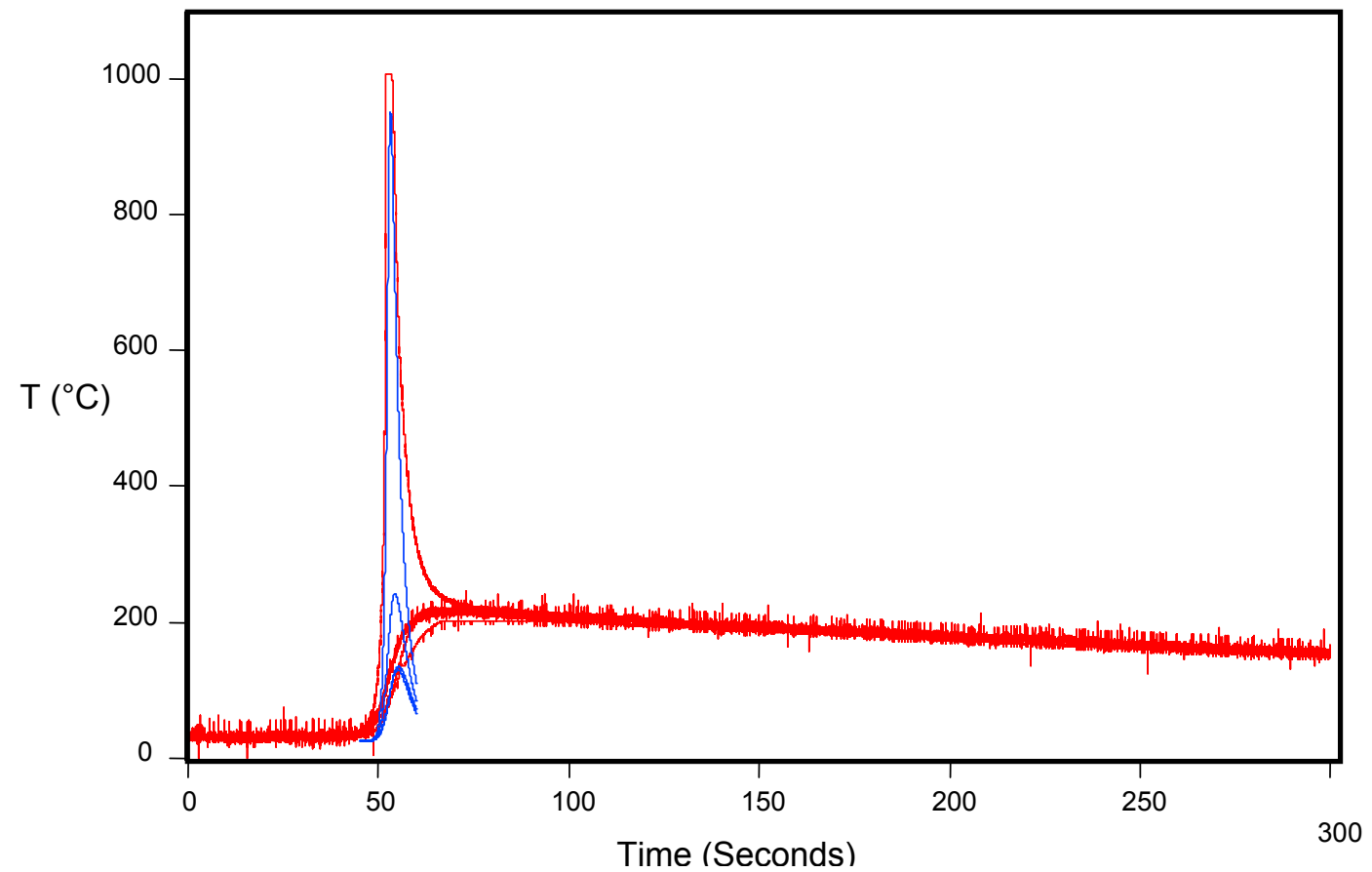

Figure 33 - Comparison of experimental (red) to simulation (blue) data for laser deposition using a Nd:YAG laser (highest peak temperatures at the edge of the deposition followed by progressively lower peak temperatures for 8 and $16 \mathrm{~mm}$ from the edge).

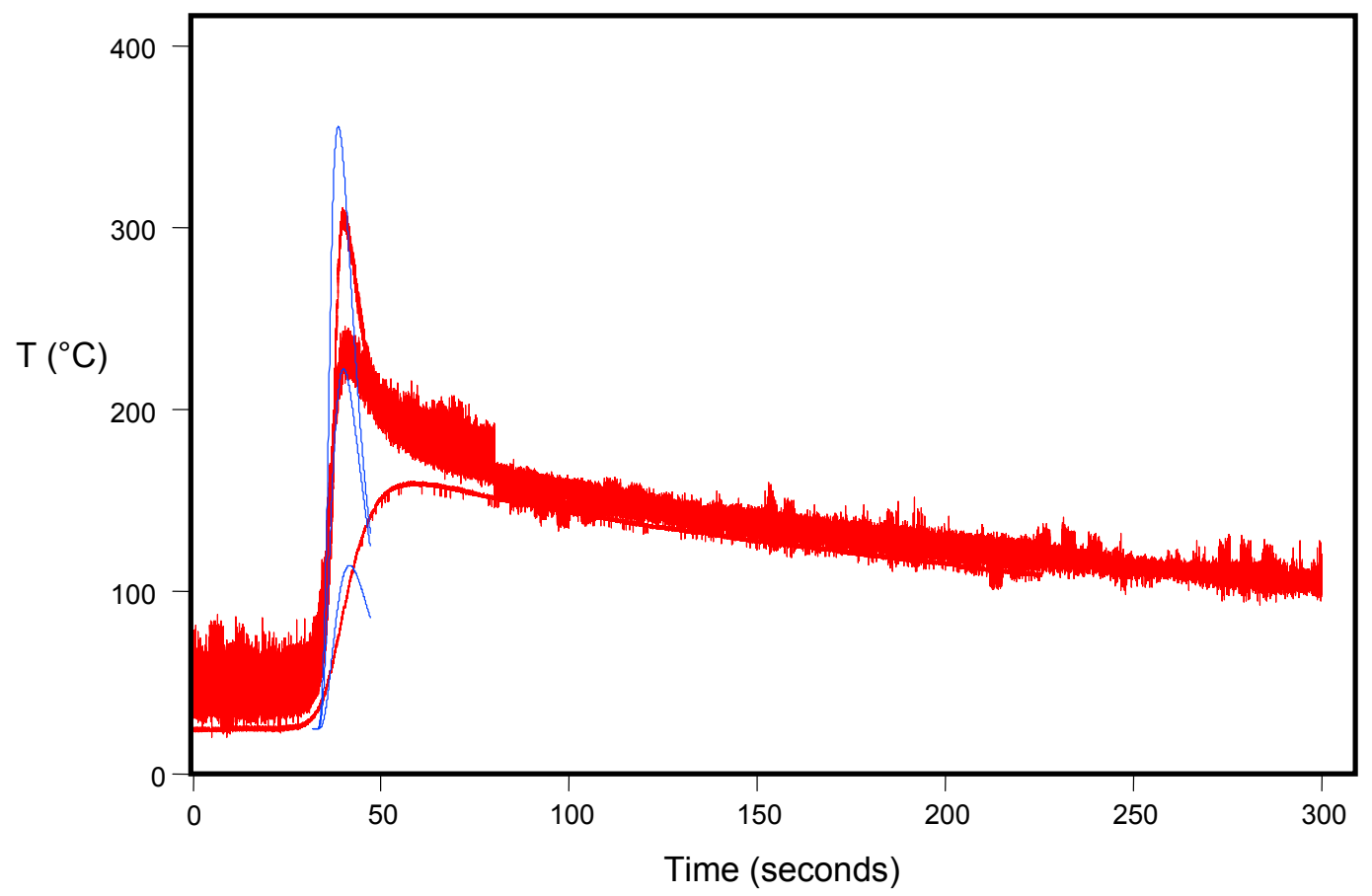

Figure 34 - Comparison of experimental (red) to simulation (blue) data for laser deposition using a $\mathrm{CO}_{2}$ laser (highest peak temperatures at the edge of the deposition followed by progressively lower peak temperatures for 8 and $16 \mathrm{~mm}$ from the edge). 
Figures 35 and 36 show the cross-sectional views of isotherms representing maximum penetration from the simulations for the $\mathrm{Nd}: \mathrm{YAG}$ and $\mathrm{CO}_{2}$ lasers, respectively. In the figures, the powder layer is $2 \mathrm{~mm}$ deep and is centered at 20 $\mathrm{mm}$. The black areas adjacent to the deposition are artifacts of the graphics program and represent unmelted powder. The lightest area corresponds to the region that is melted, so the maximum penetration into the substrate is clearly defined. Figure 35 shows that there is penetration in the substrate up to a depth of about $1.4 \mathrm{~mm}$ for the Nd:YAG, and Figure 36 shows negligible melting of the substrate. Note, that the model does not include fluid flow within the molten pool, such that the resultant profile of the simulated deposition is only due to thermal considerations.

These figures were then compared to cross-sectional macrographs obtained from the experimental clads. Figures 37 and 38 show macrographic crosssections obtained from the experiments conducted with the Nd:YAG and $\mathrm{CO}_{2}$ lasers, respectively. Figure 37 indicates that there is approximately $0.5 \mathrm{~mm}$ of penetration into the substrate associated with the deposition produced using the $\mathrm{Nd}$ :YAG laser, and Figure 38 shows negligible penetration associated with the $\mathrm{CO}_{2}$ laser deposition.

Comparison of the experimental data and the results of the numerical simulations indicate that the model provides relatively good agreement of peak temperatures; however, the cooling rates predicted by the model are much greater than those measured experimentally. This anomaly is believed to be due to the estimation of surface heat losses and is currently being evaluated. The model provides adequate predictive capabilities for the amount of powder melted and the penetration into the substrate. The model has also been found to be sensitive to conditions that effect melting at the powder and substrate interface, i.e. laser power and travel velocity. This is an important consideration in determining processing parameters for laser-based deposition for surface modification and near net shape processing. 


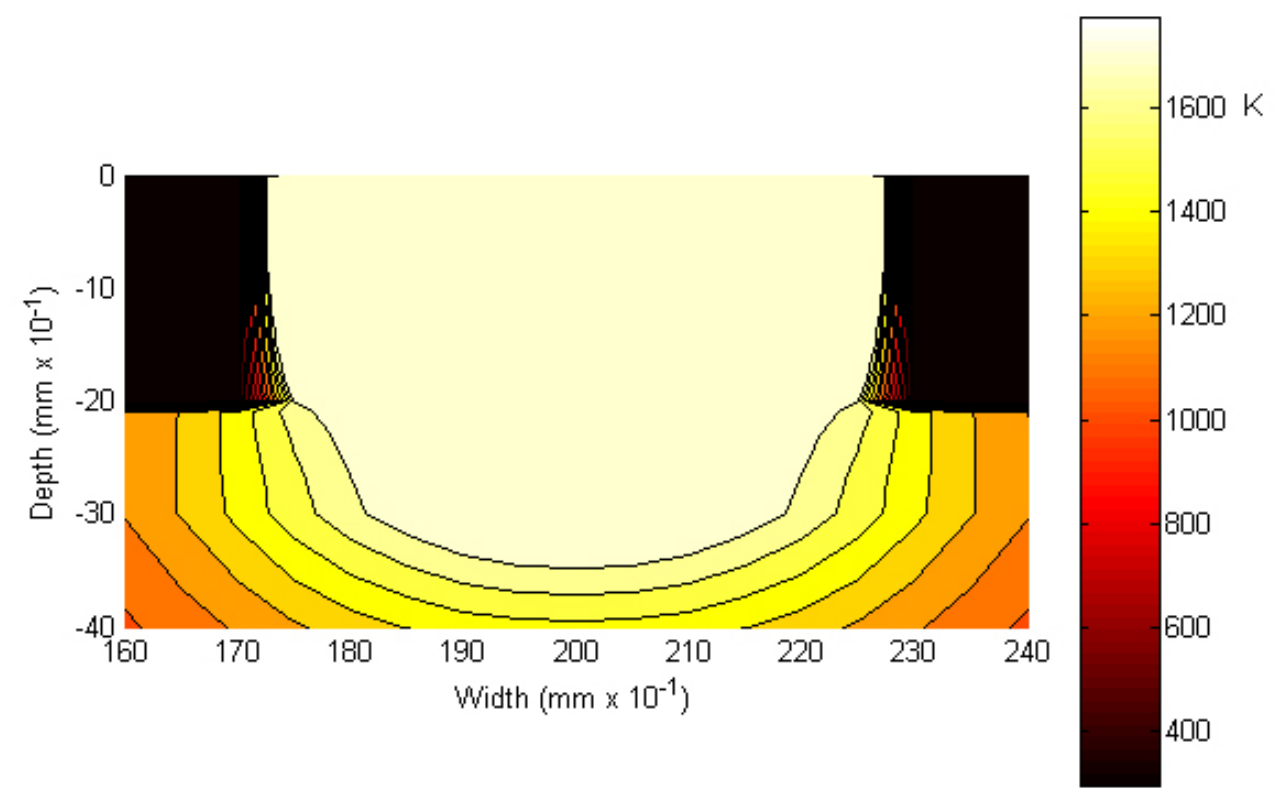

Figure 35 - Cross-sectional view from model of max penetration into substrate for $\mathrm{Nd}$ :YAG irradiation.

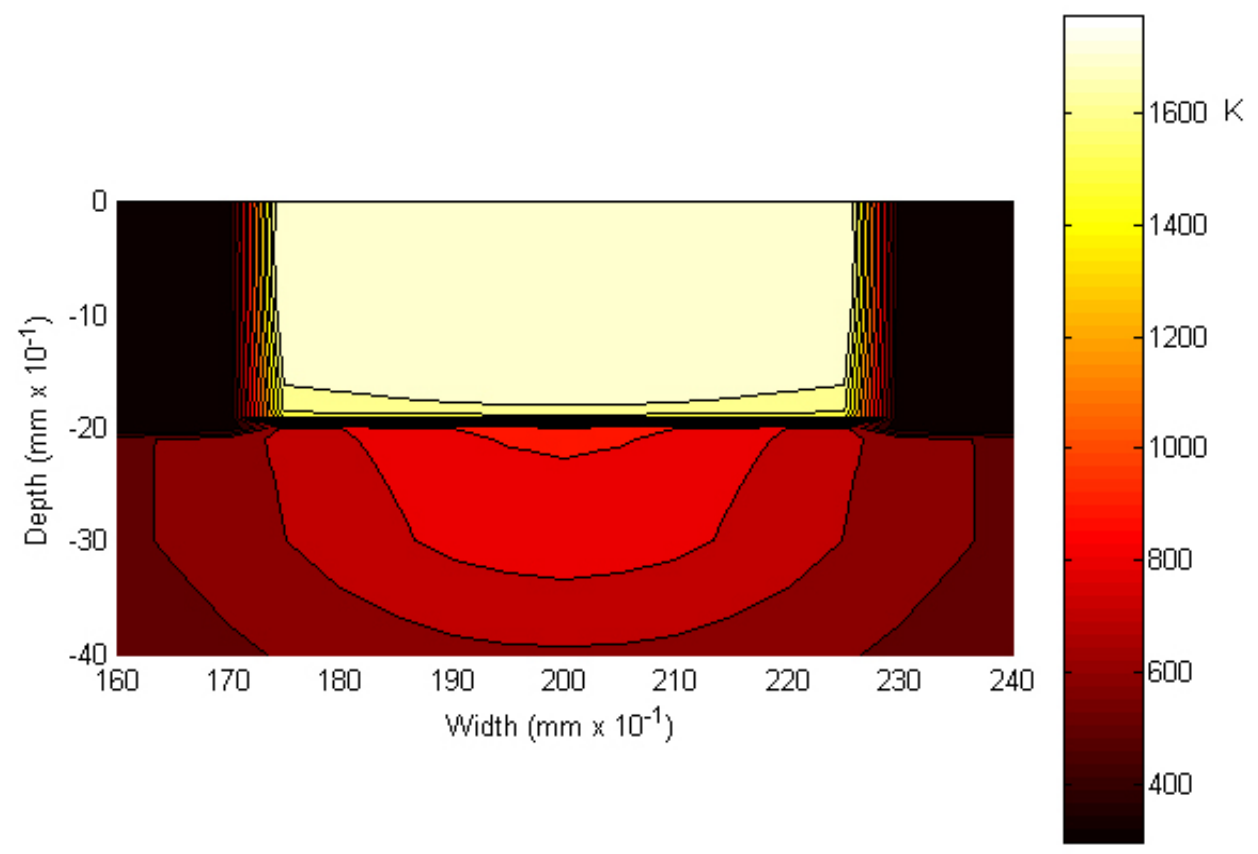

Figure 36 - Cross-sectional view from model of max penetration into substrate for $\mathrm{CO}_{2}$ irradiation. 


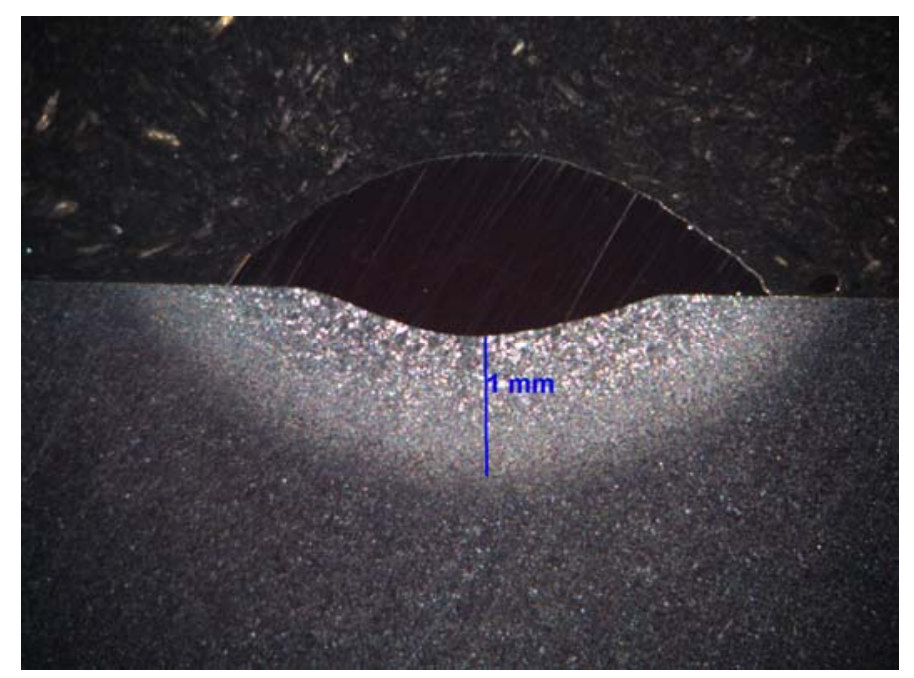

Figure 37 - Macrograph of Nd:YAG laser deposition of Inconel 625 on a mild steel substrate using a $2 \mathrm{~mm}$ thick preplaced powder layer.

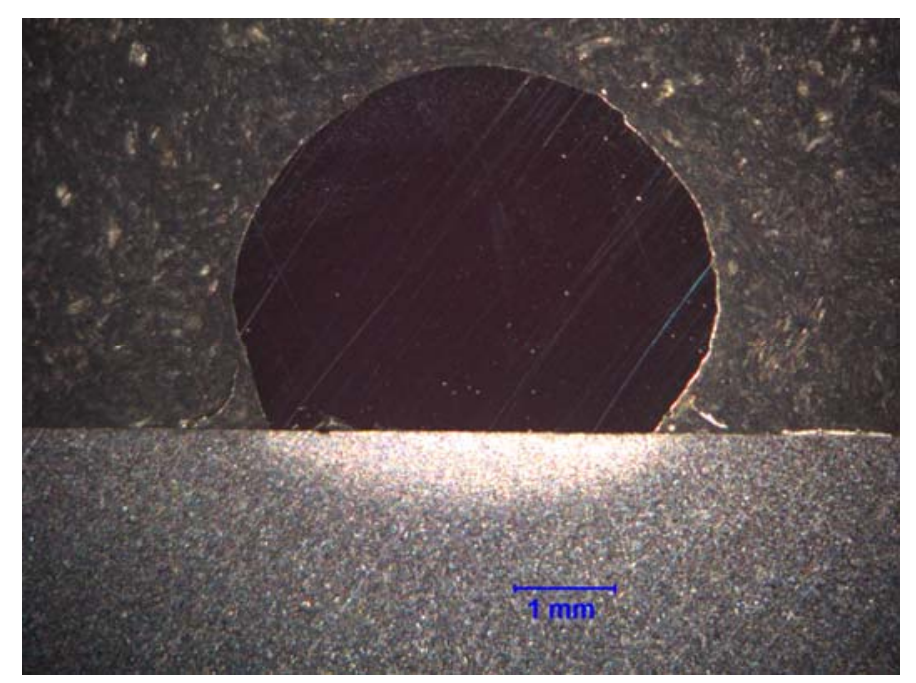

Figure 38 - Macrograph of $\mathrm{CO}_{2}$ laser deposition of Inconel 625 on a mild steel substrate using a $2 \mathrm{~mm}$ thick preplaced powder layer.

\subsection{Laser Deposition Analysis and Experiments}

The positive results obtained during the earlier portion of this research, i.e. the development of materials and process simulation techniques, were utilized to identify and corroborate material systems that would achieve beneficial coating characteristics using the laser surface modification process. This resulted in a 
selection of several hard particles, WC, TiC, and TiN, and a cost-effective matrix material representing a martensitic-grade of stainless steel (alloy 431) powder, having a nominal composition of $\mathrm{Fe}-0.2 \mathrm{C}-1 \mathrm{Si}-1 \mathrm{Mn}-16 \mathrm{Cr}$, being evaluated. Although the material simulation techniques offered guidance for material selection, it also provided insight into the possibility of active shielding gas during the laser surface modification process, and hence, this was also evaluated.

Shown in Figure 39 is the thermodynamic stability diagram and solid volume fraction during cooling for a system represented by titanium or tungsten with carbon in stainless steel alloy 431 . The greater stability, based on composition, associated with TiC in the stainless steel alloy 431 when compared to WC is clearly seen in the figure. Although it was shown previously that WC displayed a greater tendency for dissolution within Fe when compared to $\mathrm{Ni}$, the potential for retaining WC within a matrix of alloy 431 was of interest. This improvement was not observed based on the thermodynamic analysis; therefore, further analysis was limited to the TiC and TiN in alloy 431 , as well as the potential for $\mathrm{N}_{2}$ shielding gas as an active participant in controlling the resultant microstructures of the laser deposition.

To design the material compositions that allow for the formation of $\mathrm{Ti}(\mathrm{CN})$, the stability diagram of the Fe-Ti-C-N system was calculated using the ThermoCalc software with the solid solution and substance database. The stability diagram for $1800 \mathrm{~K}$ is shown in Figure 40 . The calculations considered different extents of dissolved nitrogen as a function of titanium and carbon concentrations in liquid iron. Since the TiC, TiN and Ti(CN) have face centered cubic (FCC) based crystal structure, in thermodynamic calculations the three phases are denoted as MX. The first set of calculations was performed in a simple Fe-C-T-N system with no dissolved nitrogen. The calculations showed a limited stability MX phase as shown by the shaded region. However, with increase in nitrogen concentration to $0.003 \mathrm{wt} . \%$, the calculations showed increased stability of MX phase indicating that the $\mathrm{MX}$ phase is progressively changing from $\mathrm{TiC}$ to $\mathrm{Ti}(\mathrm{CN})$. 
At high concentrations of nitrogen, the calculations showed that the MX phase is stable even with low-carbon concentrations. This showed that by combined additions of titanium, carbon and nitrogen you can stabilize the MX particles in the Fe-rich laser melts.
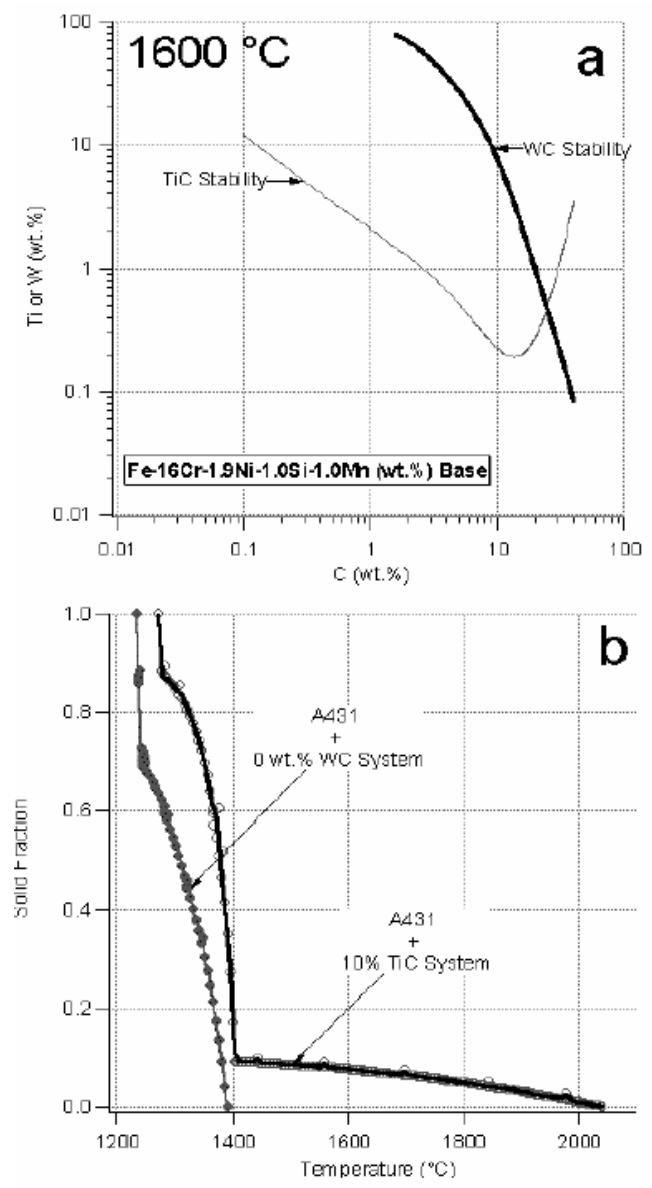

Figure 39 - Thermodynamic stability diagram (top) and solid volume fraction during cooling (bottom) for a system represented by titanium or tungsten with carbon in stainless steel alloy 431.

In the next set of calculations, the stability of MX phases in the martensitic stainless steel composition was considered with a net addition of $0.03 \mathrm{wt} . \% \mathrm{~N}$. The calculations showed that the addition of $\mathrm{Si}, \mathrm{Mn}, \mathrm{Ni}$ and $\mathrm{Cr}$ would not lead to any significant changes in the stability of MX phases, and therefore, suggested 
that the MX phases, even in a highly-alloyed iron liquid melt, can be retained. The potential use of an active shielding gas was also verified. Although, the calculations indicated that addition of nitrogen promotes the MX phases, the method of adding nitrogen to the liquid metal would need to be considered. In this analysis, the addition of nitrogen to the liquid steel is assumed to be performed by laser surface alloying with $100 \%$ nitrogen shielding. However, It is important to note these calcualtions do not consider the formation of a gas.
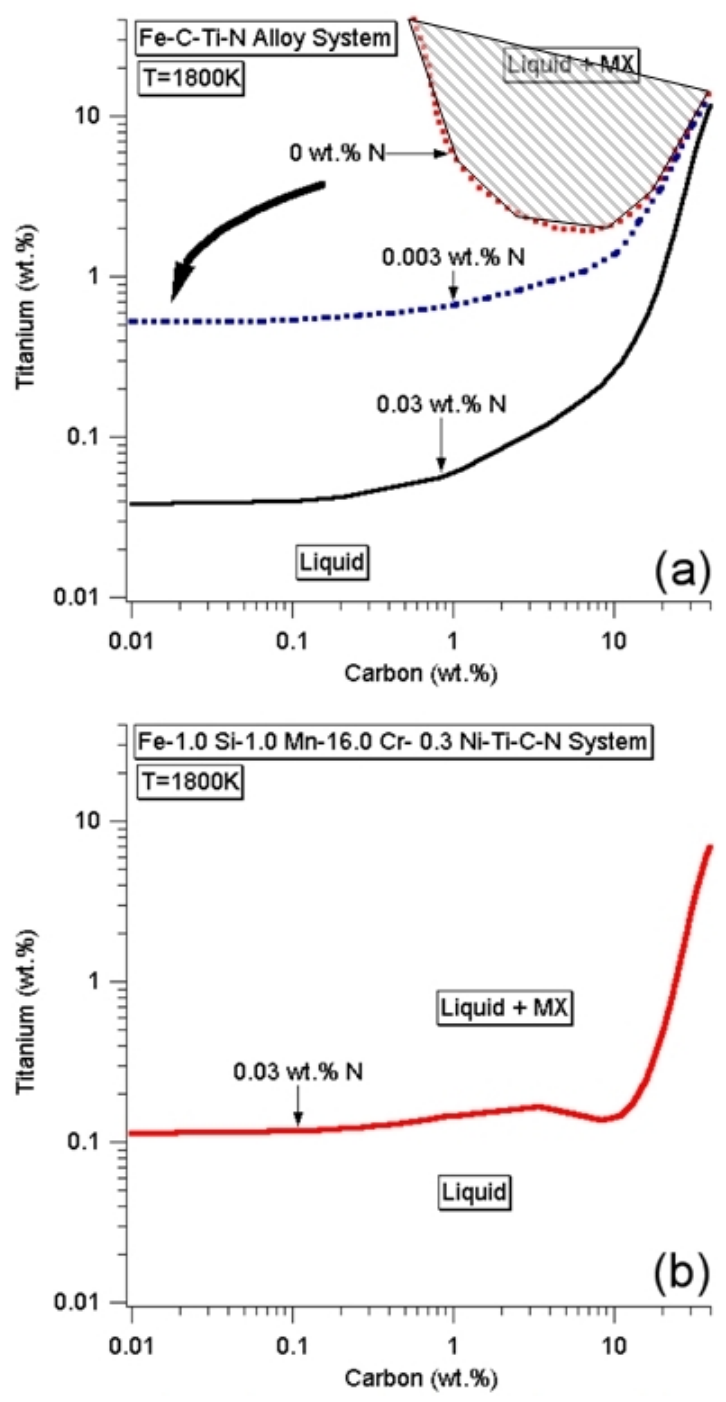

Figure 40 - Thermodynamic calculations of MX stability as a function of carbon and nitrogen for (a) simple Fe-based and (b) complex Fe-base alloy. 
Based on the above analysis, various laser deposition experiments were conducted to verify the ability to obtain or reform hard particles, in the form of TiC or $\mathrm{Ti}(\mathrm{C}, \mathrm{N})$, in a matrix representing the martensitic stainless steel alloy. In all instances, a commercially pure 431 steel powder (Sulzer-Metco $42 \mathrm{C}$ powder) was used as the matrix material. The nominal composition of the 431 steel was Fe-0.2C-1Si-1Mn-16Cr (wt.\%). Three experiments were performed and are described below.

\section{Experiment with $431+\mathrm{TiC}+\mathrm{N}_{2}$ Shielding}

A commercially pure 431 steel powder (Sulzer-Metco $42 \mathrm{C}$ powder) was used as the matrix material. The nominal composition of the 431 steel was $\mathrm{Fe}-0.2 \mathrm{C}-1 \mathrm{Si}$ $1 \mathrm{Mn}-16 \mathrm{Cr}$ (wt.\%). A TiC powder of $99 \%$ purity was obtained from AEE Corporation. In this experiment, 80 wt. $\% 431$ steel powder was mixed with 20 wt.\% TiC powder and pre-placed to a thickness of $2 \mathrm{~mm}$ on a 1020-mild steel substrate having a nominal composition Fe-0.2C-0.5Mn (wt.\%). Laser deposition experiments were conducted using a $3.0 \mathrm{~kW}$ Nd-YAG laser with fiber optic beam delivery and $\mathrm{f} 16$ focus optics. The majority of these experiments were conducted at a travel velocity of $2.12 \mathrm{~mm} / \mathrm{s}$; however, limited experiments were also conducted at $6.35 \mathrm{~mm} / \mathrm{s}$. The beam diameter was $5 \mathrm{~mm}$ and the angle of the laser source was $15^{\circ}$ rear angle. A laser power of $2430 \mathrm{~W}$ was used in these experiments. To allow for different extents of nitrogen dissolution, different extents of nitrogen gas were mixed with argon were used for shielding. In all the experiments, the powder material to be melted by the laser process was premixed and preplaced on the substrate surface. The width of the preplaced powder layer was approximately $1.5 \mathrm{~cm}$. Shielding gases were delivered to the laser surface processing region through a $9.5 \mathrm{~mm}$ inside diameter copper nozzle at $30^{\circ}$ reverse angle from the direction of processing. Processing parameters used during these experiments are shown in Table 5. 
Table 5 - Powder and shielding gas parameters used for laser deposition experiments for evaluating $\mathrm{TiC}$ in a 431 stainless steel matrix.

\begin{tabular}{|l|c|c|c|c|c|c|}
\hline ID & \multicolumn{2}{|c|}{$\begin{array}{c}\text { Powder Mixture } \\
\text { Wt.\% }\end{array}$} & Speed & \multicolumn{2}{|c|}{$\begin{array}{c}\text { Shielding gas flow rate } \\
\text { (cfh) }\end{array}$} & Remarks \\
\hline & 431 & $\mathrm{TiC}$ & $\mathrm{mm} / \mathrm{s}$ & $\mathrm{Ar}$ & $\mathrm{N}_{2}$ & \\
\hline Ar100 & $80 \%$ & $20 \%$ & 2.12 & 20 & -- & \\
\hline Ar90N10 & $80 \%$ & $20 \%$ & 2.12 & 18 & 2 & \\
\hline Air & $80 \%$ & $20 \%$ & 2.12 & -- & -- & Under air \\
\hline N100 & $80 \%$ & $20 \%$ & 2.12 & -- & 20 & \\
\hline
\end{tabular}

${ }^{1} \mathrm{cfh}=$ cubic-feet per hour; 1 cubic-feet $=0.0283168 \mathrm{~m}^{3}$.

Macrographs from representative Nd:YAG laser deposits produced using various combinations of 431 and TiC powder and shielding gas are compared in Figure 41. The comparison of the outlines from all laser beads are shown in Figure $41 \mathrm{f}$ and shows the effect of gradually increasing nitrogen content in the shielding. With increase in nitrogen content, the weld pool shape became smaller and smaller. The results also show that one can modify the bead shape by controlling the nitrogen content in the shielding gases.

The microstructures obtained for these conditions are shown in Figure 42. The microstructure of the deposit produced using the 431 powder with argon shielding gas at 20cfh did not contain any carbide and showed only a martensite matrix (see Figure 42a). The microstructures of the deposits produced using 431 and TiC powder with various shielding gas combinations (see Figures $42 \mathrm{~b}$, $42 \mathrm{c}, 42 \mathrm{~d}$, and $42 \mathrm{e}$ ) showed the presence of fine carbides in the form of particles and dendrites. The microstructure of the deposit produced using 431 and TiC powder with a shielding gas of argon at 20cfh and nitrogen at $2 \mathrm{cfh}$ (see Figure 42c) showed the remnants of the original TiC used in the experiment. 


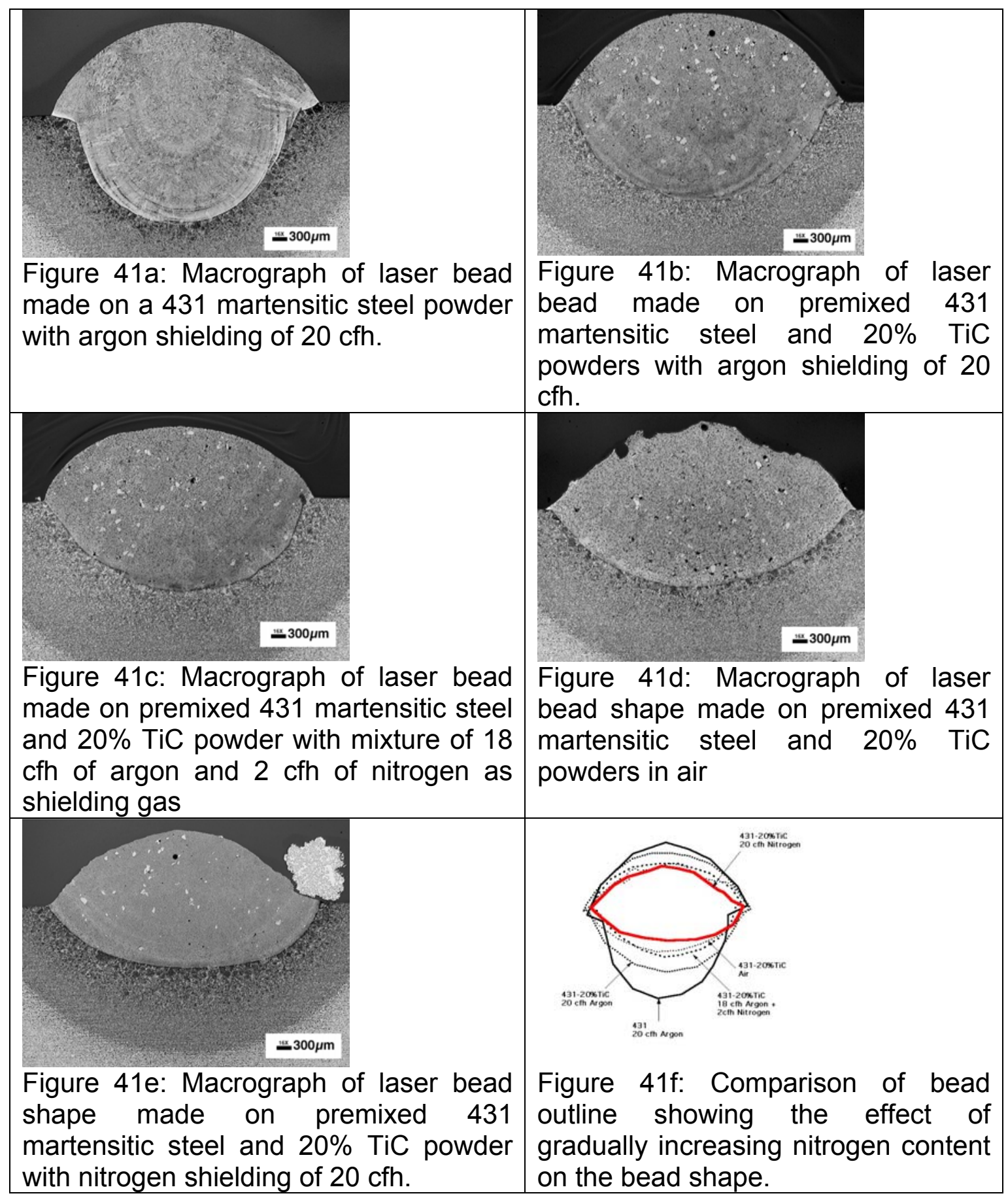

Figure 41 - Macrographs of representative Nd:YAG laser deposits made using various combinations of 431 and TiC powder and shielding gas.. 


\begin{tabular}{|c|c|}
\hline 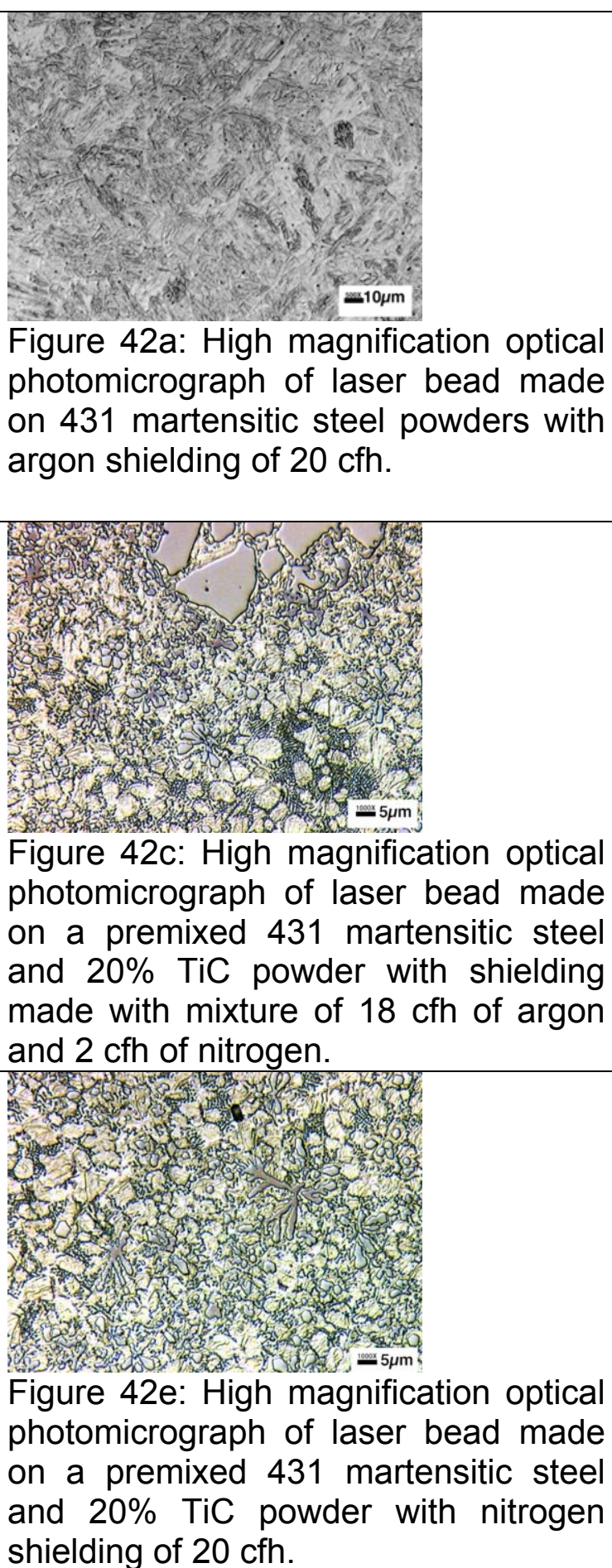 & 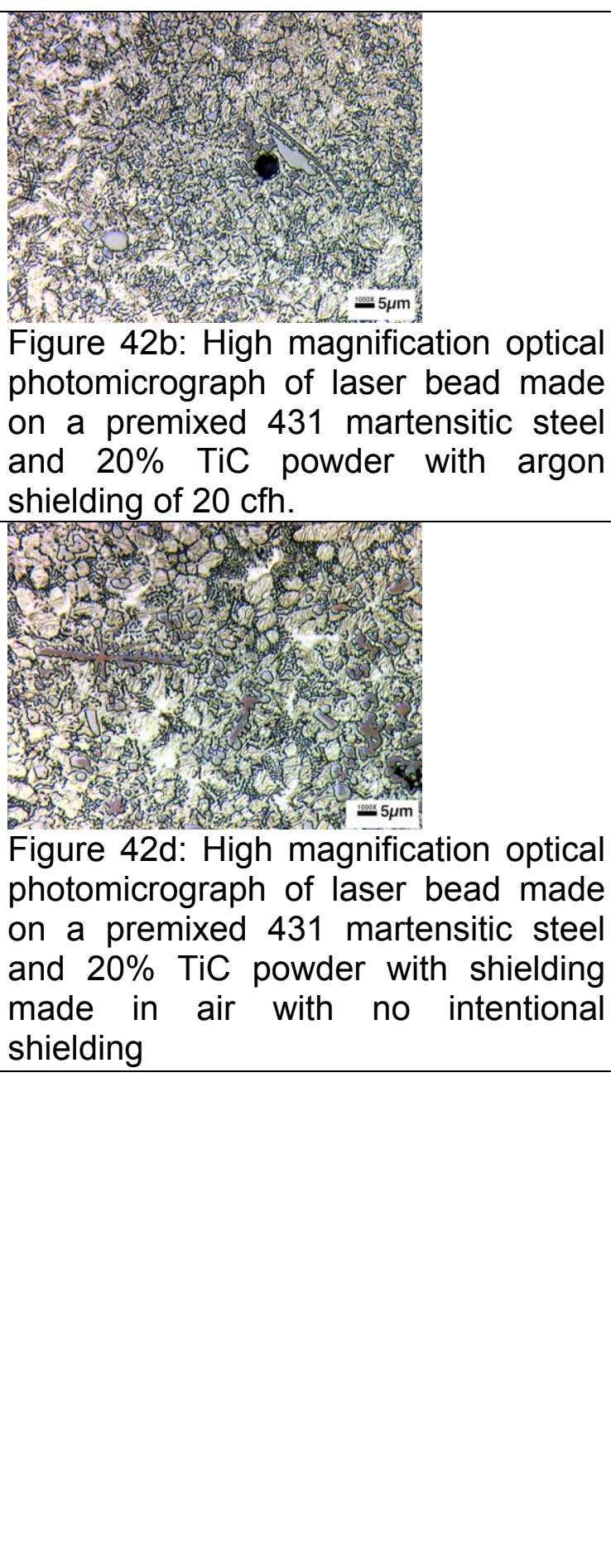 \\
\hline
\end{tabular}

Figure 42 - Microstructures of representative Nd:YAG laser deposits made using various combinations of 431 and TiC powder and shielding gas. 
The presence of fine particles smaller than the original particle size indicates that most of the original TiC powders dissolve in the liquid steel. On dissolution, the supersaturation of titanium and carbon increases, as well as, the nitrogen due to dissolution from the shielding environment. Then, during cooling from high temperature, the dissolved titanium, carbon and nitrogen react to precipitate as titanium carbonitride [Ti(CN)]. The presence of dendritic shaped $\mathrm{Ti}(\mathrm{CN})$ particles indicates these precipitates are forming much before the primary solidification of iron matrix. The carbides obtained with the nitrogen shielding gas at $20 \mathrm{cfh}$ (see Figure 42e) were much finer and is attributed to the higher supersaturation of nitrogen. Also, faster cooling rates in the deposit due to smaller bead shape may also have been partly responsible for the evolution of these observed microstructures.

Scanning electron microscopy (SEM) was also conducted on the deposit produced using the $80 \% 431$ and $20 \%$ TiC powder blend with $100 \%$ nitrogen shielding, and the results indicated that the laser surface alloyed region showed three kinds of $\mathrm{Ti}(\mathrm{CN})$ particles namely, the un-dissolved coarse particles, the dendritic particles that form first from the liquid and the fine interdendritic particles. The microstructure from scanning electron microscopy of the deposit produced with $100 \%$ nitrogen is illustrated in Figure 43 , and indicates that during laser surface alloying the $\mathrm{TiC}$ particles that are present in the powder dissolve to a greater extent. Nevertheless, some of these particles do survive and get trapped as large particles. The dissolution leads to super saturation of titanium and carbon in the liquid steel. Further dissolution of nitrogen from the shielding gas occurred which then lead to copious nucleation of $\mathrm{Ti}(\mathrm{CN})$ which subsequently grows into coarse primary dendrites. With continued cooling, solidification to austenite is expected around these primary dendrites. With continued solidification, the liquid metal continues to enrich in titanium, carbon and nitrogen which then leads to the formation of interdendritic $\mathrm{Ti}(\mathrm{CN})$. 


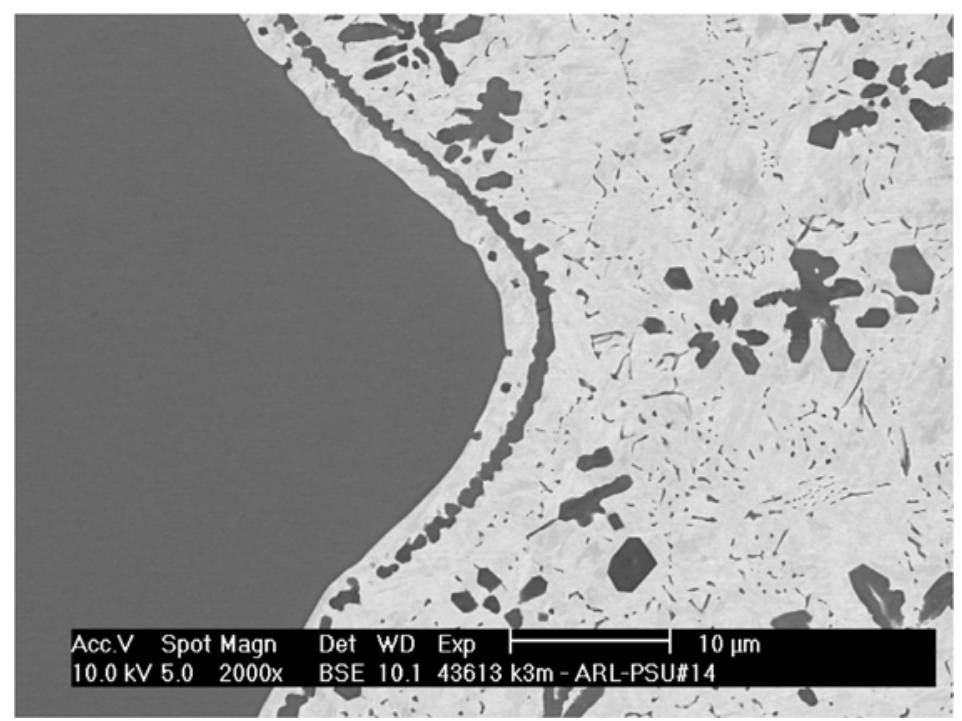

Figure 43 - Scanning electron micrograph images show coarse original $\mathrm{Ti}(\mathrm{CN})$, dendritic $\mathrm{Ti}(\mathrm{CN})$ and secondary $\mathrm{Ti}(\mathrm{CN})$ in the interdendritic region.

Further evaluation of the microstructure obtained using 100\% nitrogen shielding was performed using orientational imaging microscopy, which is shown in Figure 44. The orientational imaging microscopy was performed in a FEI XL-30 field emission gun scanning electron microscopy. In this method, the distribution of both FCC and BCC crystal structures were analyzed. The measurements from a region containing the primary dendritic and secondary interdendritic particles are also shown in the fugure, as well as the distribution of FCC phases. Here the FCC phase corresponds to $\mathrm{Ti}(\mathrm{CN})$ phases. The data clearly shows the presence of coarse dendrites growing in different directions. Since the plane of cross section is not along the primitive [001] zone axis, the shape of these dendrites are not symmetrical. The measurements also show the presence of very fine $\mathrm{Ti}(\mathrm{CN})$, approximately at half the distance between the primary coarse dendritic particles, indicating that these are interdendritic particles forming during the late stages of solidification.

Corresponding BCC grain misorientation distributions for this deposit are shown in Figure 45. Here the BCC crystal structure corresponds to ferrite grains. The different colored lines in the fugure delinate the extent of crystallographic 
misorientations between the ferrite grains. The average fraction of the ferrite grain boundaries that have mis-orientations greater than 10 degrees is approximately $73 \%$. This is indeed an interesting observation, since the sample is in the as-welded condition. In principle, as-cast structure of the laser surface alloyed region may not lead to such a fine distribution of grains. This is tentatively attributed to the low-temperature decomposition of the austenite that forms during solidification while cooling to room temperature.

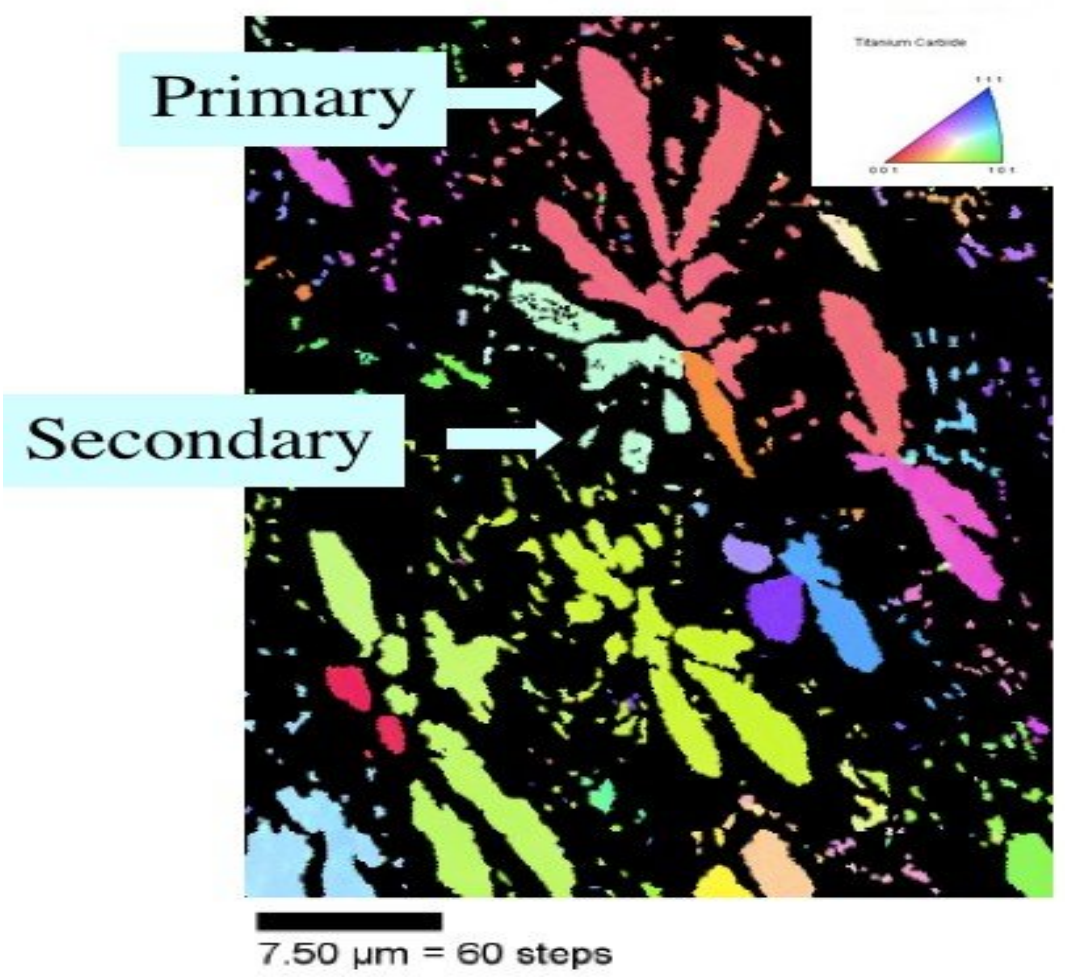

Figure 44 - Orientational imaging microscopy analysis showing distribution of FCC crystal strucuture. The color codes correpsond to relative orientation of different grains in a diffraction trinangle shown in the inset. 


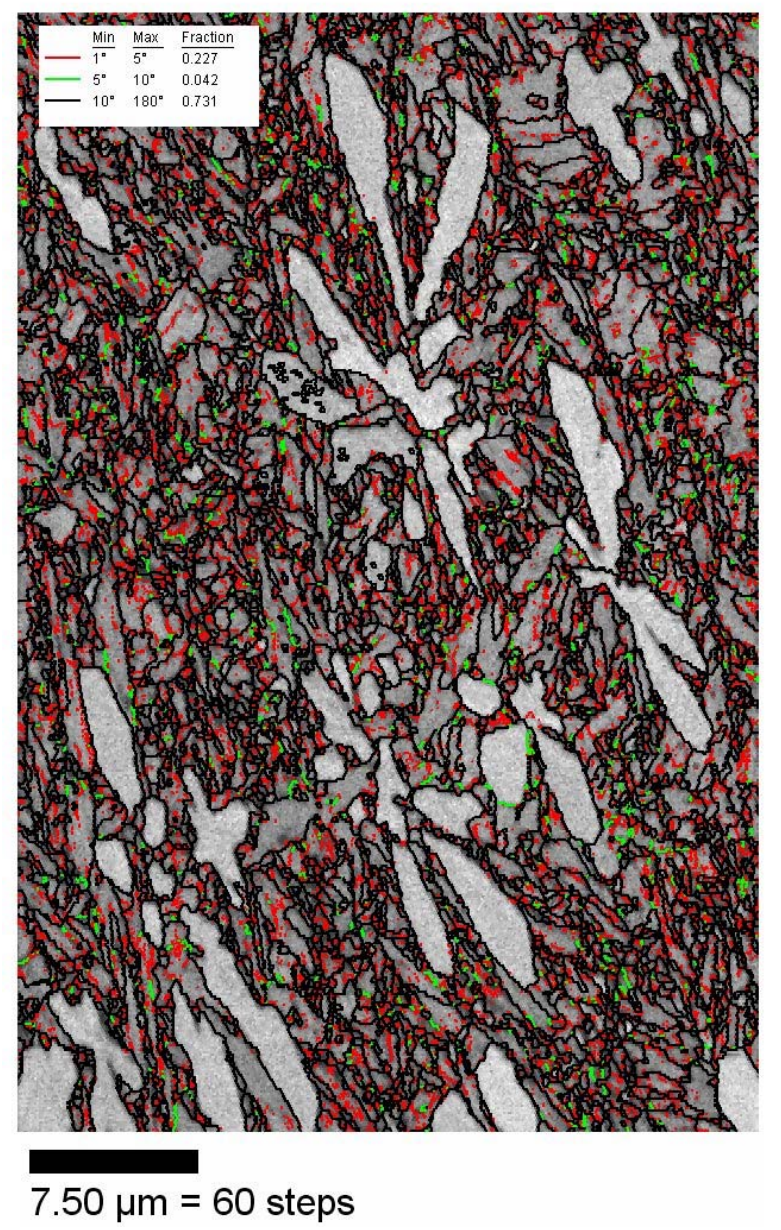

Figure 45 - Orientational imaging microscopy analysis of BCC grains showing the presence of predominantly fine ferrite grain size with misorientations above 10 degrees. The grey regions are the FCC regions where there is absence of BCC diffraction.

The hardness distribution images for these deposits are compared in Figure 46. The hardness distributions were obtained from one-half of the cross sections shown in Figure 41. The hardness values in these images were measured at a spatial resolution of 200 micro-meters $(\mu \mathrm{m})$. The distributions are shown in a gray scale image format. The darker contrast indicates higher hardness and lighter contrast shows low hardness. Qualitative overview of the images showed that the condition representing $100 \%$ nitrogen shielding attained the highest hardness. 
The hardness distributions are compared in Figure 47. The results reinforce the prior observation that the deposit made with 431 steel powder with $20 \% \mathrm{TiC}$ under $20 \mathrm{cfh}$ nitrogen shielding produced the maximum hardness. This result shows that by increasing the nitrogen content in the shielding the hardness of the coating can be increased.

The average hardness of the deposits was calculated by assuming a Gaussian distribution of the data from Figure 47 . The values obtained from this analysis are compared in Table 6 . The maximum hardness in the coating was occasionally above $1000 \mathrm{HV}$ (see Table 6). This is attributed to sampling of coarse carbides present in the coating by the hardness indenter. Therefore, for true representation of coating performance, the average hardness is evaluated further. The average substrate hardness close to the coating exhibited minor changes for all conditions. A maximum hardness of 280 to $300 \mathrm{HV}$ in the substrate is related to the formation of martensite in the regions close to the laser bead due to rapid cooling from the single-phase austenite region.

The average hardness of the deposit produced using the 431 powder and the argon shielding was $438 \mathrm{HV}$. On adding $20 \% \mathrm{TiC}$ to the 431 lead to an increase in average hardness to $574 \mathrm{HV}$. This $31 \%$ increase in hardness is attributed to the addition of $\mathrm{TiC}$ to the deposit. The average hardness of deposit produced using the blend of $80 \% 431$ and $20 \%$ TiC powder with the $18 \mathrm{cfh}$ argon and $2 \mathrm{cfh}$ nitrogen shielding gas was $621 \mathrm{HV}$. This $8 \%$ increase in hardness was attributed to increasing levels of dissolved nitrogen, as well as, the hard $\mathrm{Ti}(\mathrm{CN})$ compound that is expected to form by the reaction with dissolved titanium and carbon. The average hardness of the deposit produced using the blend of $80 \% 431$ and $20 \%$ TiC powder with only air shielding was $637 \mathrm{HV}$. This represents only a $2 \%$ increase in hardness over the deposit produced using the blend of $80 \% 431$ and $20 \% \mathrm{TiC}$ powder with the $18 \mathrm{cfh}$ argon and $2 \mathrm{cfh}$ nitrogen shielding gas. Although one would expect higher levels of nitrogen dissolution in the deposit produced using the blend of $80 \% 431$ and $20 \%$ TiC powder with only air 
shielding, the hardness increase was only $2 \%$. This is attributed to deleterious effects of possible oxygen contamination. The average hardness of the deposit produced using the blend of $80 \% 431$ and $20 \%$ TiC powder with nitrogen shielding was $724 \mathrm{HV}$. This shows that a 13\% increase in hardness, compared to the $431 / \mathrm{TiC}$ deposit produced using air, can be achieved by $100 \%$ nitrogen shielding. An increase in hardness of $65 \%$, when compared to the deposit produced using the 431 powder with argon shielding, was achieved using the 431/TiC powder and nitrogen shielding. The hardness data conclusively proved that by combining laser metal deposition of 431 steel powder, with the addition of $\mathrm{TiC}$, and while employing $100 \%$ nitrogen shielding gas, surface hardness of laser deposits can be significantly increased.

A comparison of hardness measurements obtained within these deposits is shown in graphically in Figure 48. This data also strongly suggests the synergistic effect of materials and gas composition of the process. As described earlier, the use of $\mathrm{TiC}$ in combination with nitrogen shielding gas provided the highest hardness within the laser deposit. The hardness obtained in the laser deposit produced using $\mathrm{TiC}$ and 431 alloy powder with nitrogen shielding gas is approximately $60 \%$ greater than the deposit produced using only the 431 powder. This is significant, since the martensitic grades of stainless steel, which alloy 431 represents, is associated with high hardness coatings. 


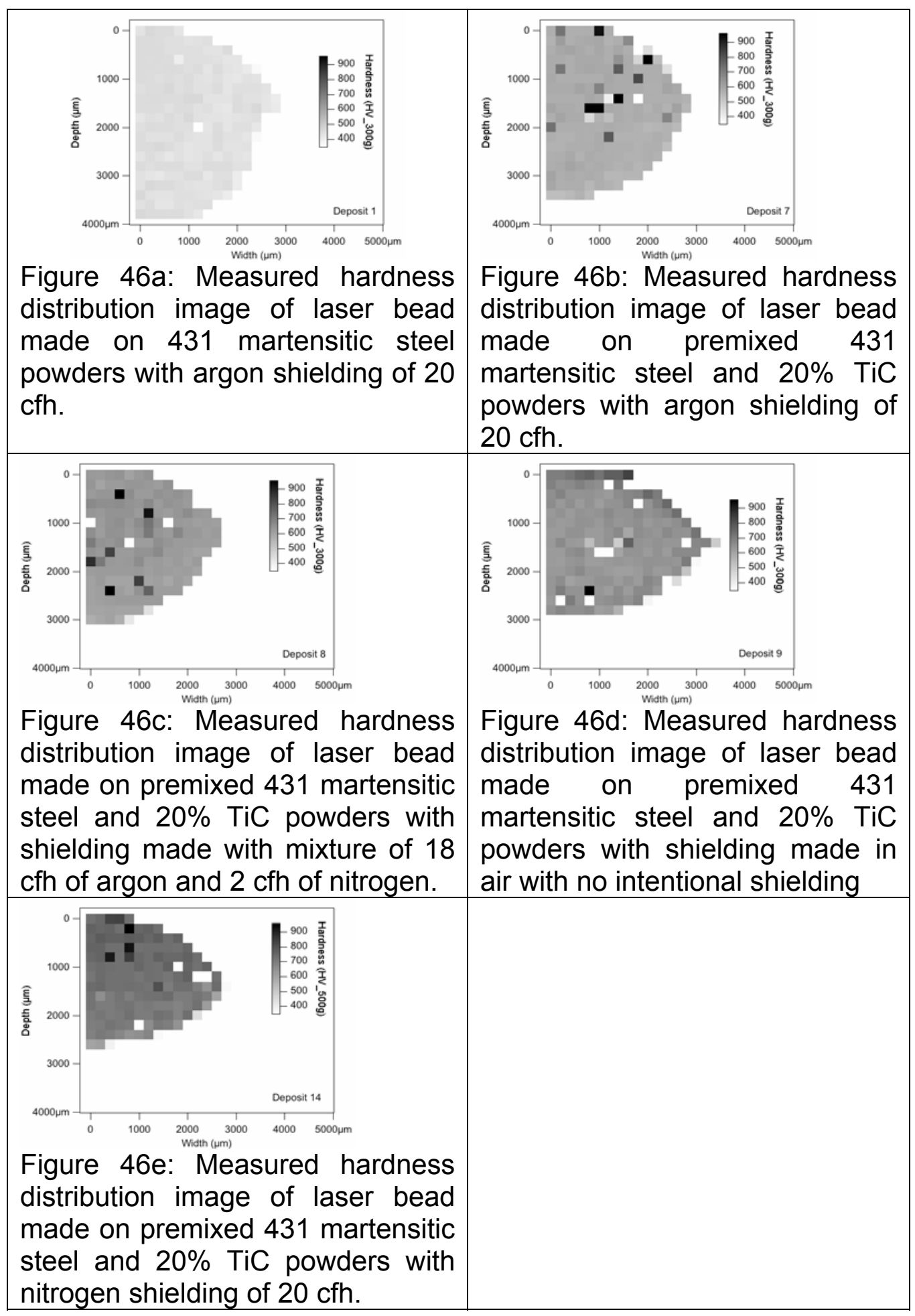

Figure 46 - Hardness distributions for Nd:YAG laser deposits made using various combinations of 431 and TiC powder and shielding gas. 


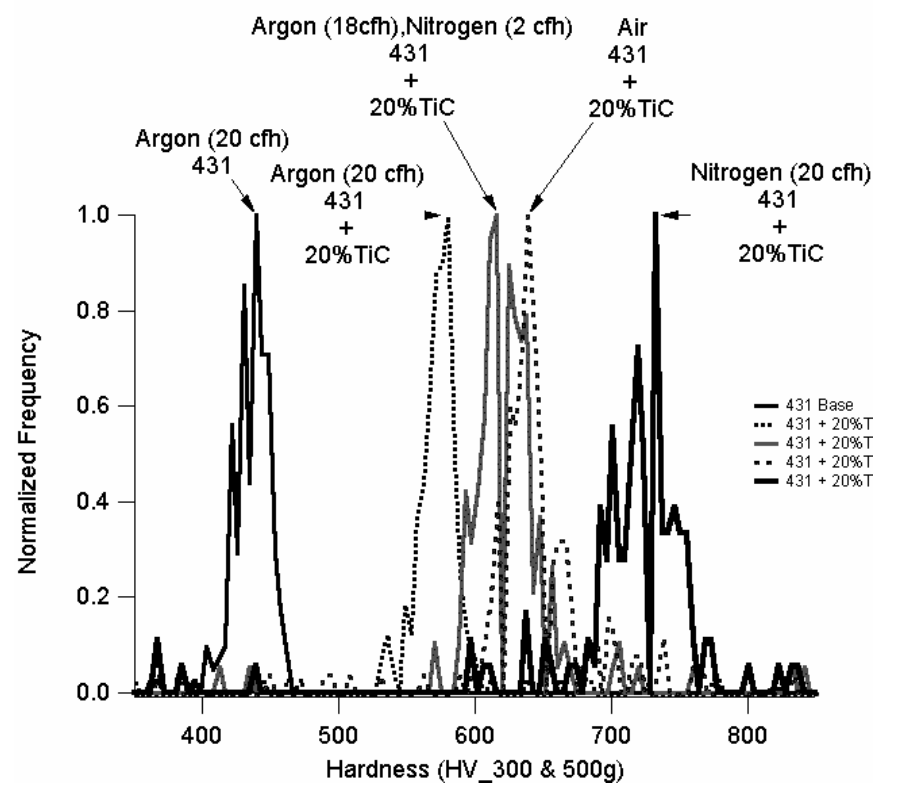

Figure 47 - Comparison of hardness distributions of the Nd:YAG laser deposits made using various combinations of 431 and TiC powder and shielding gas.

Table 6 - Measured Hardness Data in the substrate and the coatings produced using the different conditions.

\begin{tabular}{|c|c|c|c|c|c|c|}
\hline Powder & $\begin{array}{c}\text { Shielding } \\
\text { Gas }\end{array}$ & $\begin{array}{c}\text { Minimum } \\
\text { Substrate } \\
\text { Hardness } \\
(\mathrm{HV})\end{array}$ & $\begin{array}{c}\text { Maximum } \\
\text { Substrate } \\
\text { Hardness } \\
(\mathrm{HV})\end{array}$ & $\begin{array}{c}\text { Minimum } \\
\text { Coating } \\
\text { Hardness } \\
(\mathrm{HV})\end{array}$ & $\begin{array}{c}\text { Maximum } \\
\text { Coating } \\
\text { Hardness } \\
(\mathrm{HV})\end{array}$ & $\begin{array}{c}\text { Average } \\
\text { Coating } \\
\text { Hardness } \\
(\mathrm{HV})\end{array}$ \\
\hline 431 & $\mathrm{Ar}$ & 141 & 285 & 394 & 462 & 438 \\
\hline $431 / \mathrm{TiC}$ & $\mathrm{Ar}$ & 136 & 249 & 530 & 1835 & 574 \\
\hline $431 / \mathrm{TiC}$ & $\mathrm{Ar} / \mathrm{Ni}$ & 172 & 245 & 579 & 1378 & 621 \\
\hline $431 / \mathrm{TiC}$ & $\mathrm{Air}$ & 154 & 258 & 602 & 1007 & 637 \\
\hline $431 / \mathrm{TiC}$ & $\mathrm{Ni}$ & 168 & 299 & 652 & 1104 & 724 \\
\hline
\end{tabular}




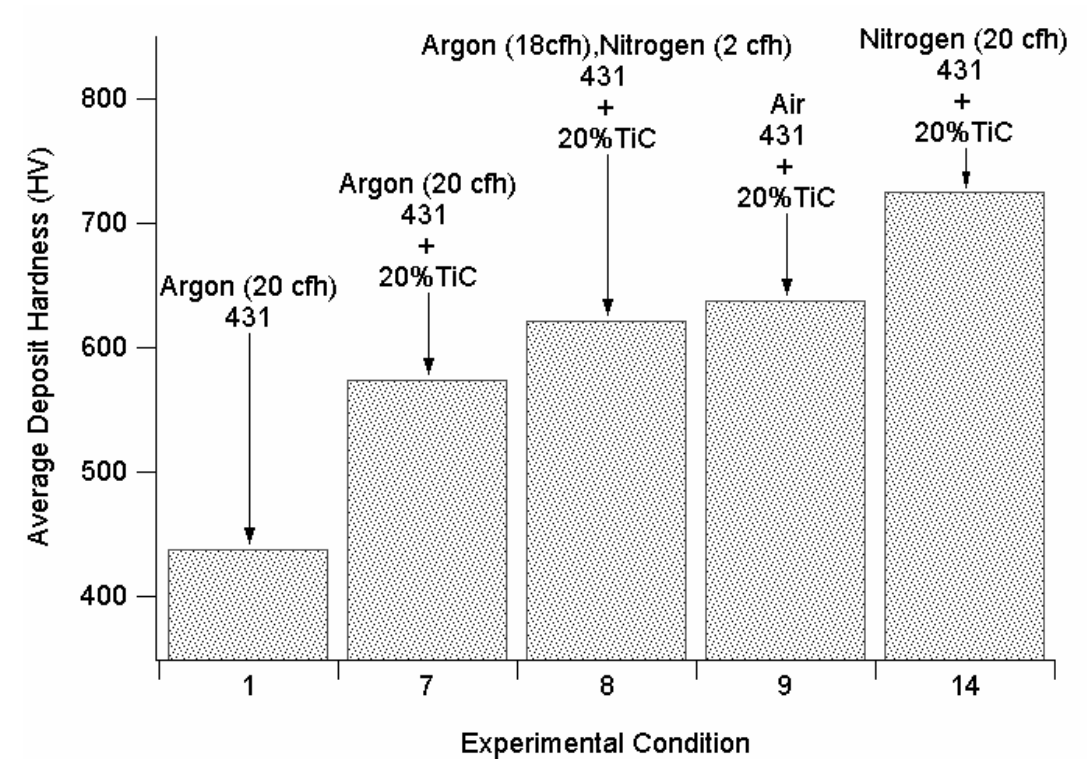

Figure 48 - Comparison of average hardness of the laser deposits using 431 and $\mathrm{TiC}$ powder that were evaluated.

\section{Experiment with $431+\mathrm{FeTi}+\mathrm{N}_{2}$}

Since the calculations showed that it is possible to form MX phases even with low carbon concentrations, additional experiments were performed with 431 martensitic steel powders with only addition of $20 \mathrm{wt}$ \% Fe-Ti. The calculations suggested that the precipitation of TiN must occur even in this condition.

In the previous section, the supersaturation of liquid steel was attained by premixing with 431 martensitic steel powders with TiC powders and subsequent dissolution of the same during laser surface alloying. Based on the results from the previous section, it was hypothesized that the supersaturation of the liquid can also be attained from their elemental form and allowing for in-situ reaction during laser surface alloying. This may be able to reduce the cost of the raw material used for these processes.

To evaluate the hypothesis, the tendency to form TiN was considered first. The 431 martensitic steel powders were mixed with $20 \mathrm{wt} . \%$ ferro-titanium and was pre-placed on a 1020 mild steel block. The laser surface alloying was performed 
with $100 \%$ nitrogen shielding. The optical microscopy of the samples made at a scanning speed of $2.11 \mathrm{~mm} / \mathrm{s}$ is shown in Figure 49 . It is important to note that in the current experiments we cannot delineate the extent of carbon dilution in these deposits since there is no intentional addition of carbon except for the residual carbon from 431 martensitic steel powders.

Three distinct microstructural features were observed in Figure 49. First, large slender elongated dendrites were observed. These particles were identified as $\mathrm{Ti}(\mathrm{CN})$ with FCC structure. The fraction of these primary $\mathrm{Ti}(\mathrm{CN})$ dendrites was less than that of previous experiments with TiC addition. Secondly, an equiaxed but dendritic ferrite grain structure was observed. The average grain size of these ferrite grains were in the order of 5 to $10 \mu \mathrm{m}$. Third, a fine, interdendritic, dark, eutectic microstructure was observed.

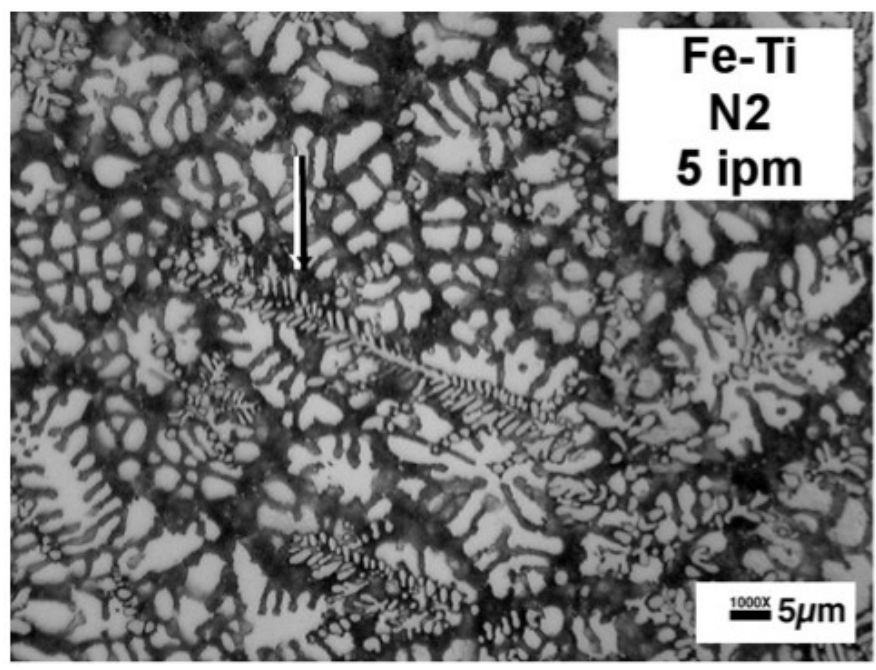

Figure 49 - Optical mcirograph of laser surface alloyed region showing fine TiCN dendrites with a small dendritic ferrite grain size in the back ground. In addition, dark interdendritic regions were also observed.

Further analysis of the microstructure was performed with orientational imaging microscopy. The distribution of both $\mathrm{Ti}(\mathrm{CN})$ and Ferrite crystal structure are mapped and are shown in Figure 50. The maps clearly show that these two 
phases are interspersed with each other. The ferrite maps show that the all the primary ferrite dendrite arms have similar orientation in space. Interestingly, the ferrite veins in the eutectic regions appear to be extension of the primary dendrite grain. The primary coarse dendritic $\mathrm{Ti}(\mathrm{CN})$ and the interdendritic $\mathrm{Ti}(\mathrm{CN})$ can also be seen in the figure. It is interesting to note that the interdendritic $\mathrm{Ti}(\mathrm{CN})$ all have similar orientation in space. This suggests that there may be preferred crystallographic orientation relationship between $\mathrm{Ti}(\mathrm{CN})$ and ferrite. Detailed study is underway to evaluate the relative orientation between primary $\mathrm{Ti}(\mathrm{CN})$, ferrite and interdendritic $\mathrm{Ti}(\mathrm{CN})$.

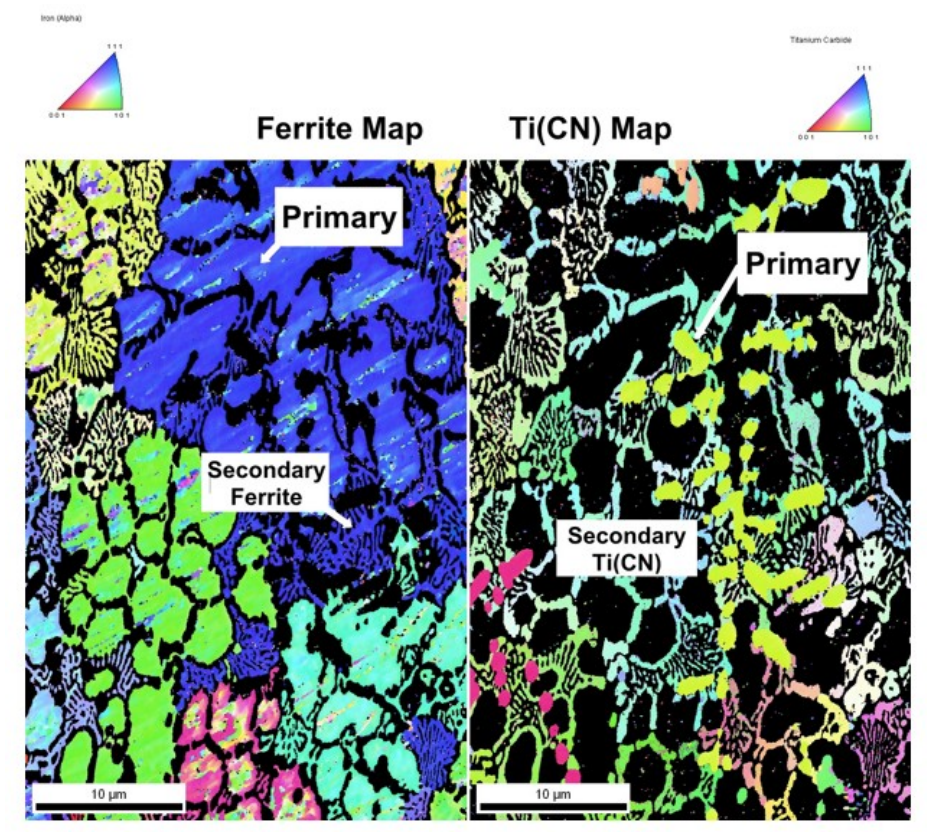

Figure 50 - Orientational imaging microscopy maps showing the distributions of ferrite (BCC) and TiCN (FCC) crystal structure showing fine inter-twinning microstructure.

Preliminary microstructural observations showed that the hardening within the deposit, which was measured to be approximately $250 \mathrm{HV}$, is not as extensive as that of previous experiments. This is partly attributed to a lack of high volume fraction of primary $\mathrm{Ti}(\mathrm{CN})$ in this microstructure. Although it has been shown that 
there is a potential to form in-situ $\mathrm{Ti}(\mathrm{CN})$ with lower cost powder blends, further work would be required to increase the fraction of hard particles in these alloys.

These results indicated that the path for microstructural evolution from the liquid during cooling included primary dendritic $\mathrm{Ti}(\mathrm{CN})$ formation, primary dendritic ferrite formation, and finally interdendritic eutectic decomposition of liquid to ferrite and $\mathrm{Ti}(\mathrm{CN})$. This path was evaluated with theoretically utilizing thermodynamic calculations using the Scheil additivity rule. The composition of the overall steel for these calculations was taken as $\mathrm{Fe}-0.18 \mathrm{C}-0.9 \mathrm{Si}-0.8 \mathrm{Mn}$ $12.8 \mathrm{Cr}-8 \mathrm{Ti}-0.047 \mathrm{~N}(\mathrm{wt} . \%)$. The calculated solid fraction versus temperature is shown in Figure 51. The calculations indicate the first phase to form in the liquid steel at high temperature would be $\mathrm{Ti}(\mathrm{CN})$ and as the deposit cools, the primary ferrite phase will form at a lower temperature. With continued cooling, extensive solidification occurs by the formation of the ferrite phase. In the final stages of solidification, the calculations predict eutectic decomposition of the liquid. These calculations qualitatively support the experimentally observed microstructural results obtained during the evaluation.

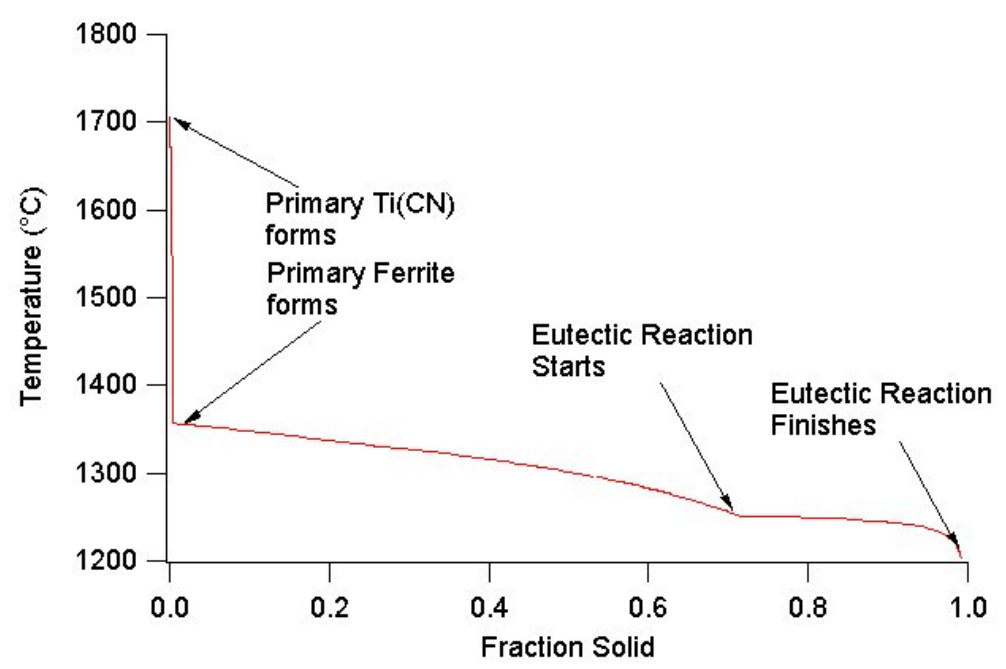

Figure 51 - Predicted variation of solid fraction versus temperature during solidification is shown with different phase regions. The calculations assume Scheil additivity conditions. 


\section{Experiment Using a Direct Diode Laser}

The goal of the last experiment was to determine the effectiveness of using active shielding gas with a laser source more suited to high deposition processes for producing a composite microstructure. In this case, a Nuvonyx Corporation $4,000 \mathrm{~W}$ direct diode laser was used to produce overlapping deposits. The spot size produced by the direct diode laser was approximately $12 \mathrm{~mm}$ by $0.8 \mathrm{~mm}$ and was presented to the work-piece perpendicular to the direction of travel. A travel velocity of $4.2 \mathrm{~mm} / \mathrm{s}$ was used while feeding the powder to the front of the interaction area through an ancillary nozzle. The powder blend of $80 \% 431$ and $20 \% \mathrm{TiC}$ was fed at a rate of $25 \mathrm{~g} / \mathrm{min}$. The shielding gas, both argon and nitrogen were evaluated, was provided at a flow rate of $19 \mathrm{l} / \mathrm{min}$. (40 cfh) from both sides of the deposition. The overlap of each pass was set at $6 \mathrm{~mm}$.

The macrograph of three laser deposits made using argon and nitrogen shielding gas with the overlap is shown in Figure 52. Preliminary analysis showed that both deposits were shallower compared to that of Nd:YAG laser deposits, probably due to the heat distribution of the laser source, as well as increase in scanning velocity. Interestingly, the shape of the nitrogen-shielded deposit was slightly wider and shallower than that of argon-shielded deposit, which is in agreement with earlier results.

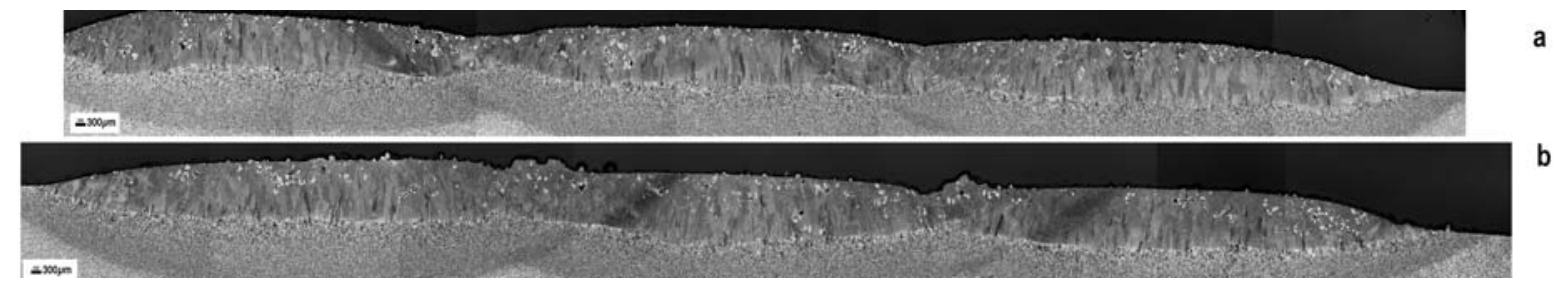

Figure 52 - Comparison of overlapping bead shapes made with diode laser source made with (a) argon shielding and (b) nitrogen shielding.

The optical microstructures from these two deposits are compared in Figure 48. The microstructures show a fine distribution of carbides in both deposits. 
However, the dendritic structures of carbides are well established in the case of deposits made with nitrogen shielding, as shown by arrows in Figure 53. This result indicates that the observed microstructural evolution is generic to all laser sources.

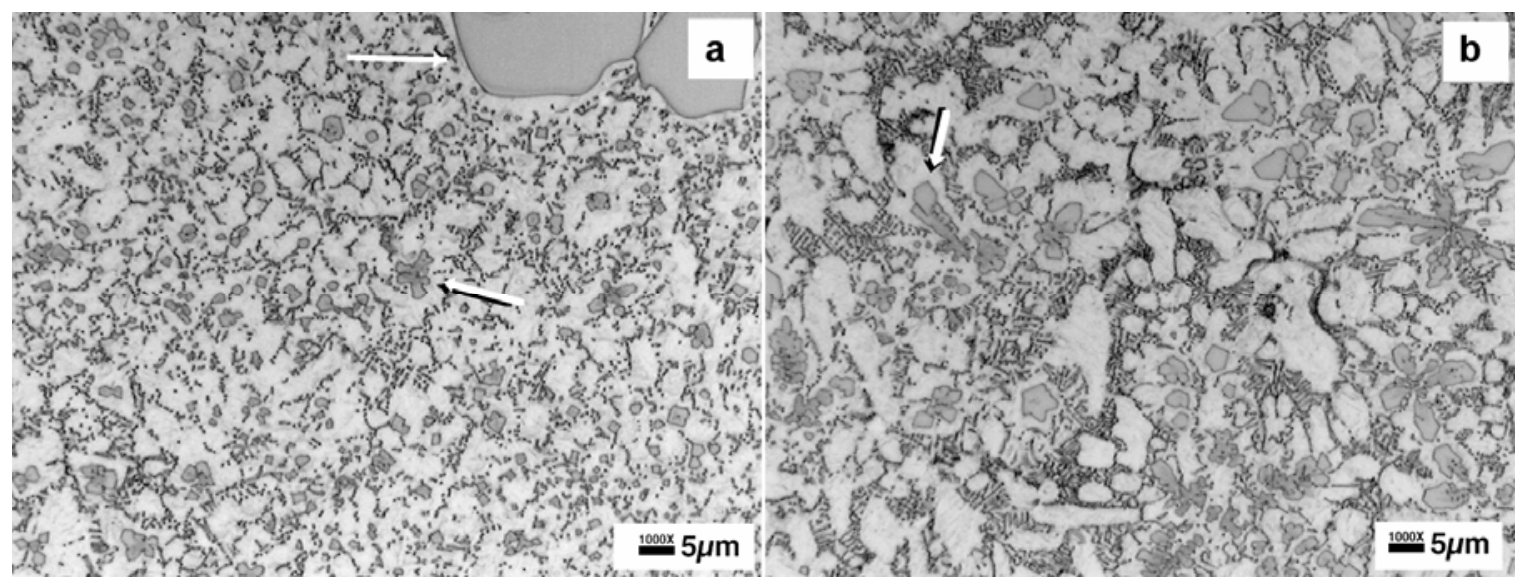

Figure 53 - Comparison of optical microstructures from the last deposit made with a direct diode laser source with (a) 100\% argon and (b) 100\% nitrogen shielding. The arrows show typical morphology of carbide particles. 


\subsection{INDUSTRIAL DEMONSTRATIONS}

Several demonstrations were conducted to determine the viability of composite coatings for industrial applications. These demonstrations were conducted in conjunction with the program's industrial partners. This included an industrial partner who is a leading manufacturer of plastic injection molding equipment and was interested in developing high wear resistant deposits for internal coating of injection barrels. Another sponsor pioneered the use of laser deposition technologies for producing tooling grade material and continues to be interested in highly wear resistant coatings for machine tools and other applications. A third industrial partner that participated in the program is the largest laser-based refurbishment organization within the U.S., and provides services to the energy production industry for applications that exhibit high temperature and corrosive environments.

\subsection{Industrial Demonstrations for Internal Cladding}

As an ongoing effort to develop a unique coating and process for internal laser deposition of plastic injection molding equipment, two evaluations were conducted using a precursor containing a metallic matrix and various hard particles. The precursor system was predeposited on mild steel specimens and laser processed using a proprietary process. The specimens were processed at the Applied Research Laboratory, Pennsylvania State University using a 14 kW $\mathrm{CO}_{2}$ laser and a $5 \mathrm{~kW} \mathrm{Nd:YAG} \mathrm{laser} \mathrm{having} \mathrm{fiber} \mathrm{optic} \mathrm{beam} \mathrm{delivery.}$

Four conditions were evaluated. Of these, two appeared to exhibit a relatively continuous deposition that was fairly uniform. These two specimens were identified as Specimen A which corresponded to WC deposited onto an external bar using the $14 \mathrm{~kW} \mathrm{CO}$ laser and Specimen $B$ which represented $B N$ deposited onto an internal shaft using the $5 \mathrm{~kW} \mathrm{Nd:YAG} \mathrm{laser.} \mathrm{Further} \mathrm{metallographic}$ 
analysis was conducted on these two specimens. Shown in Figures 54 and 55 are the processing arrangements representing Specimen A and Specimen B, respectively, and Figure 56 is a photograph of the surface of the bar that had the WC coating deposited using the $\mathrm{CO}_{2}$ laser.

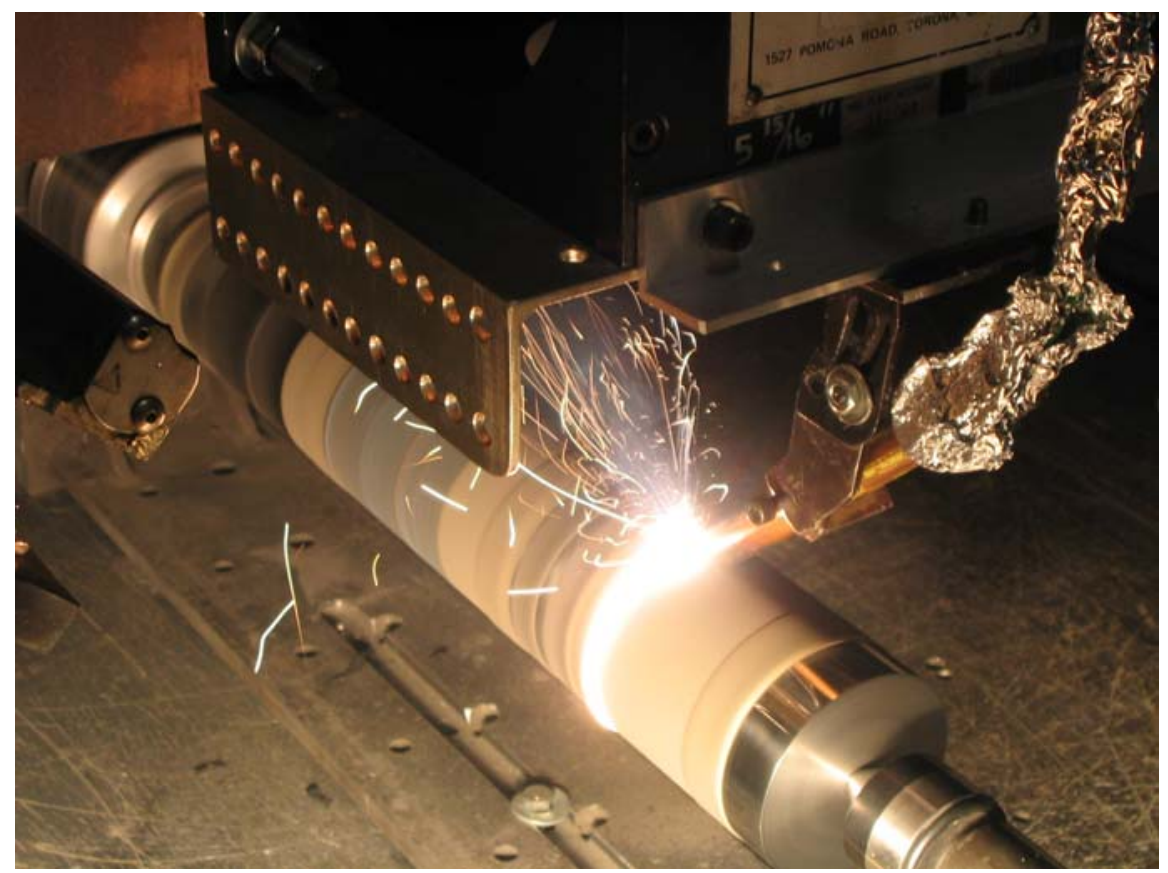

Figure 54 - Processing arrangement used for depositing WC onto an external bar using the $14 \mathrm{~kW} \mathrm{CO}_{2}$ laser. 


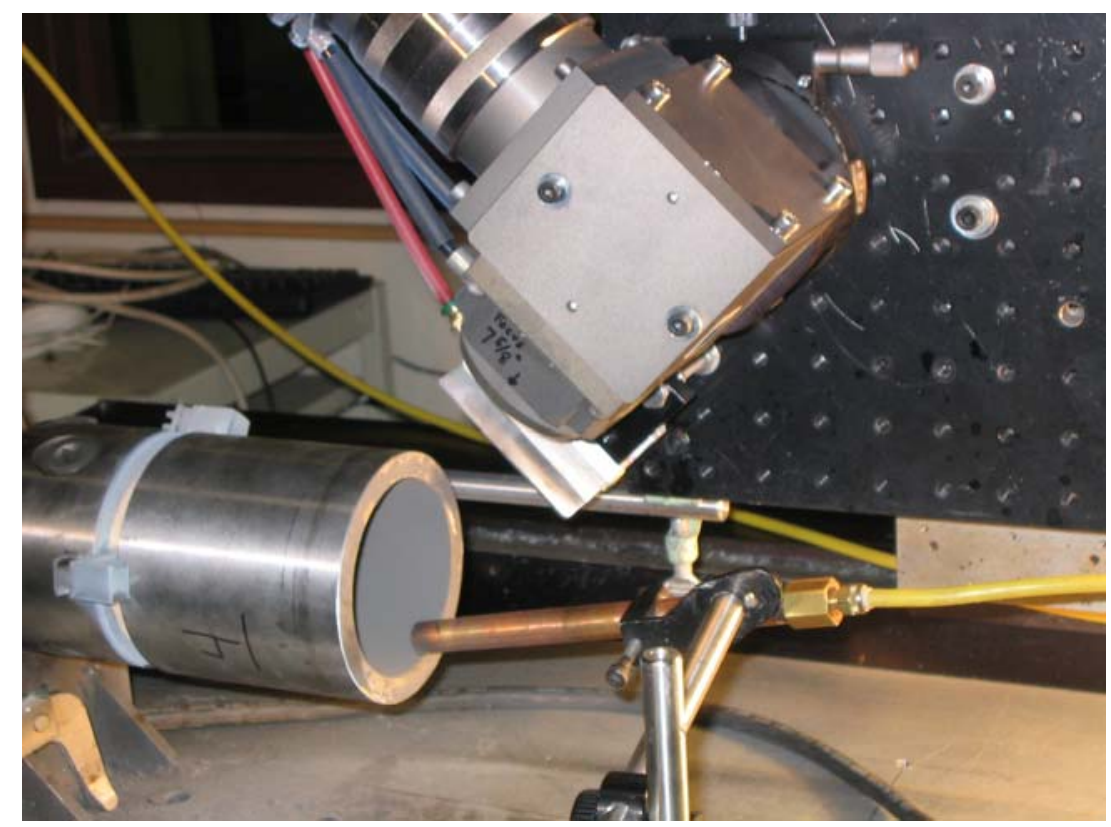

Figure 55 - Processing arrangement used for depositing $\mathrm{BN}$ onto surface of an internal shaft using the $5 \mathrm{~kW} \mathrm{Nd:YAG} \mathrm{laser.}$

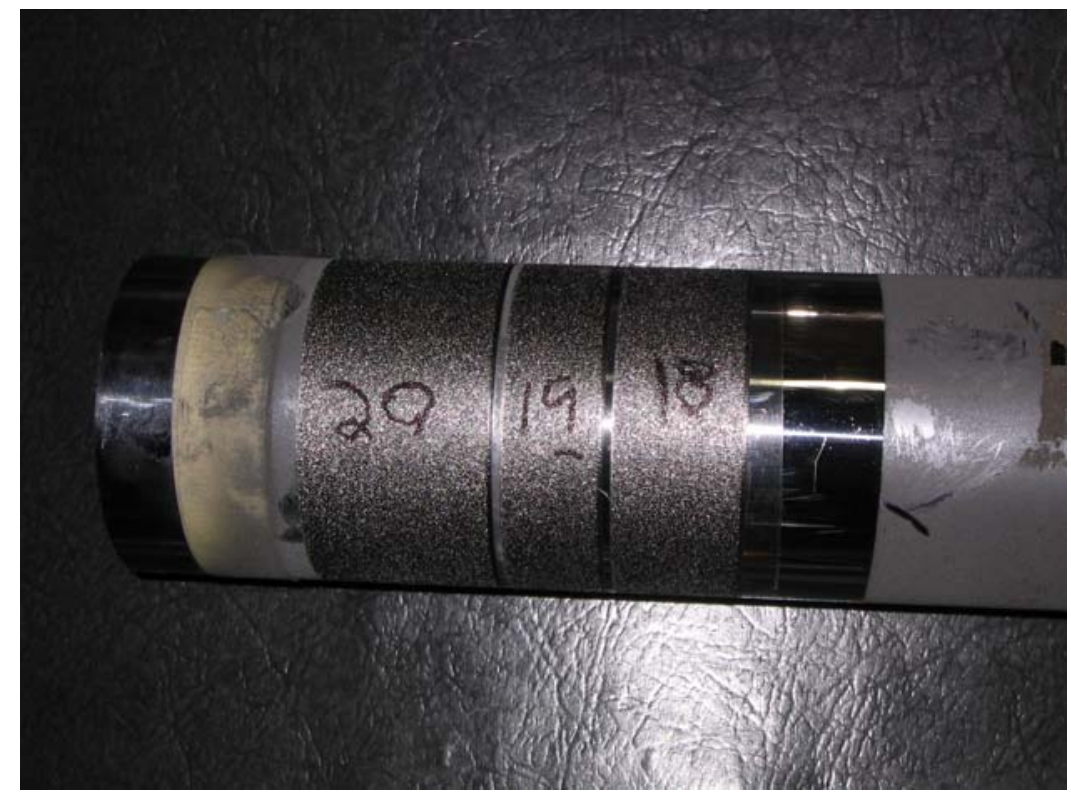

Figure 56 - Photograph of surface of bar representing the WC deposition using the $14 \mathrm{~kW} \mathrm{CO}$ laser showing deposition of coatings using three precursor thickness. 
Samples were removed from the two components and mounted and prepared using standard metallographic techniques. Initial metallographic examination was conducted without etching the samples. Figures 57 and 58 represent micrographs of the WC deposited using the $14 \mathrm{~kW} \mathrm{CO}_{2}$ laser (Specimen A) and the $\mathrm{BN}$ deposited using the $5 \mathrm{~kW} \mathrm{Nd:YAG} \mathrm{laser} \mathrm{(Specimen} \mathrm{B),} \mathrm{respectively,} \mathrm{in}$ the unetched condition. Although the deposits appear uniform in the unetched micrographs of Figures 57 and 58, focusing on the deposit/substrate interface was difficult, and indicated a curvature of the surface. Hence, the samples were removed from the metallographic mount for further inspection.

Figures 59 and 60 represent micrographs of Specimen A and Specimen B, respectively, in the etched condition. Again, these micrographs were obtained from the samples that had been removed from the metallographic mounts. A $10 \%$ hot oxalic acid reagent was used to etch the specimens for examination of the coating microstructure. This reagent, however, resulted in over etching of the steel substrate.

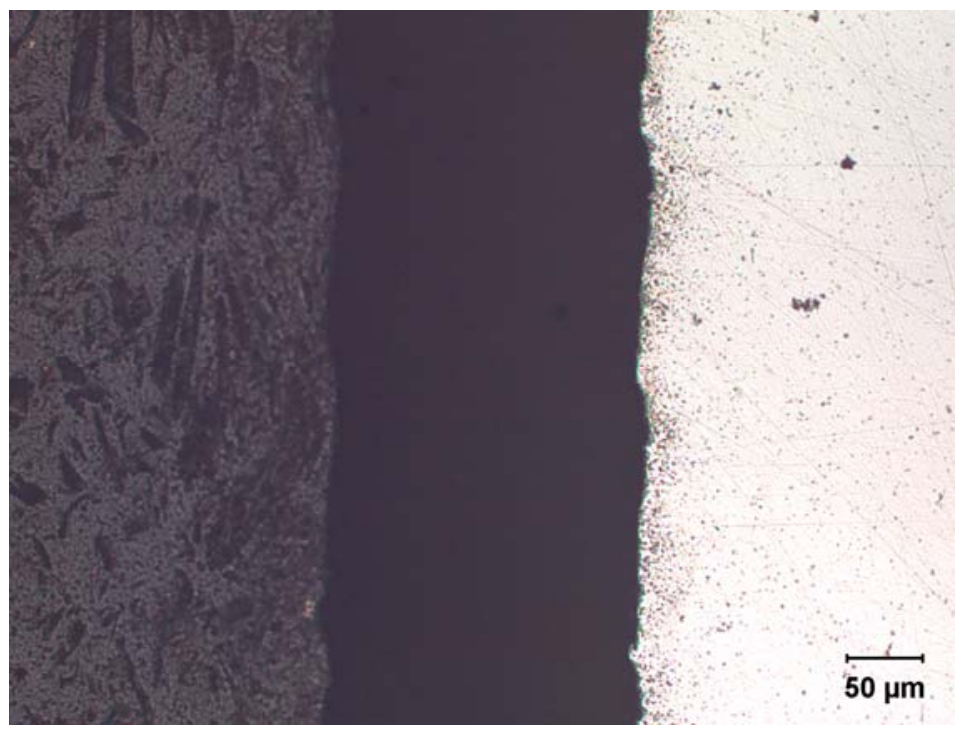

Figure 57 - Micrograph of Specimen A representing the WC deposit produced using the $14 \mathrm{~kW} \mathrm{CO}$ laser showing the deposit as the dark material in the center, the substrate as the bright material to the right, and the metallographic mounting material to the left is the (200X magnification, unetched). 


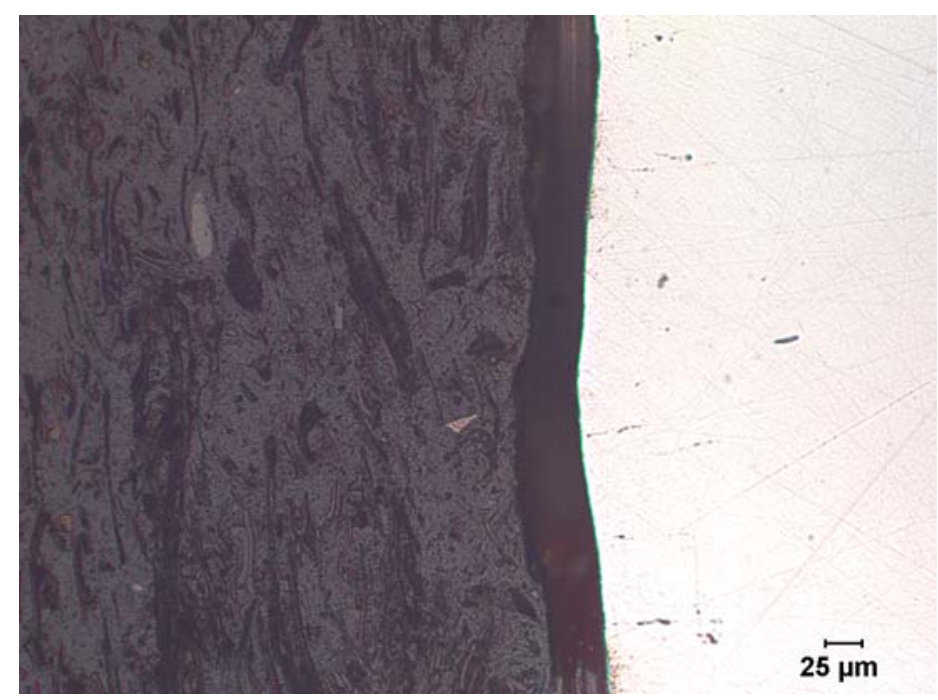

Figure 58 - Micrograph of Specimen B representing the BN deposit produced using the $5 \mathrm{~kW} \mathrm{Nd:YAG} \mathrm{laser} \mathrm{showing} \mathrm{the} \mathrm{deposit} \mathrm{as} \mathrm{the} \mathrm{dark} \mathrm{material} \mathrm{in} \mathrm{the}$ center, the substrate as the bright material to the right, and the metallographic mounting material to the left (200X magnification, unetched).

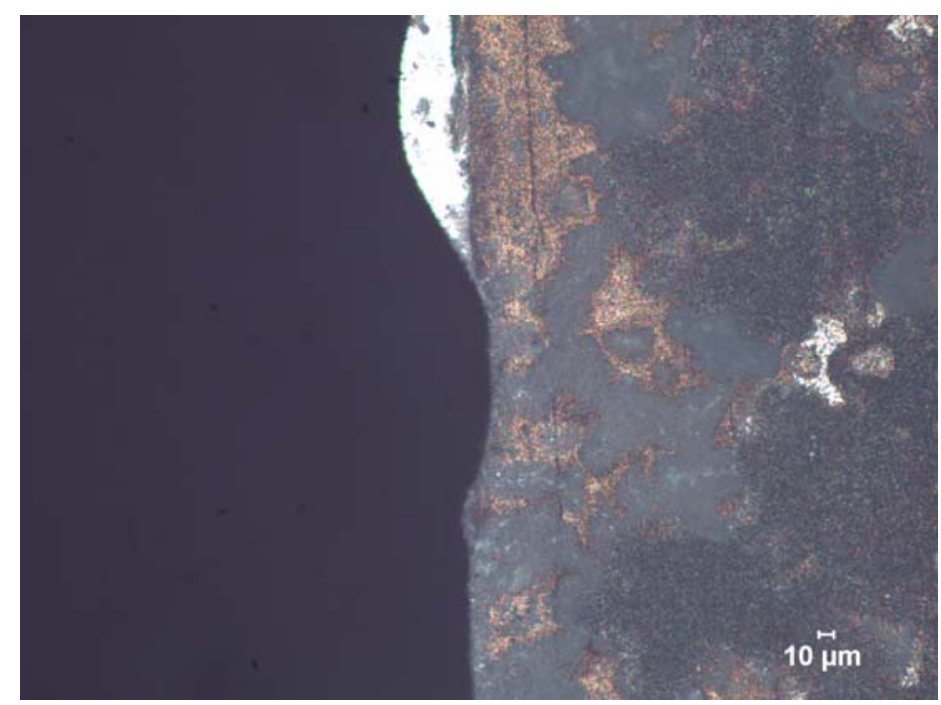

Figure 59 - Micrograph of Specimen A representing the WC deposit produced using the $14 \mathrm{~kW} \mathrm{CO}$ laser showing the deposit as the light material in the center and the substrate to the right (200X magnification, oxalic etch). 


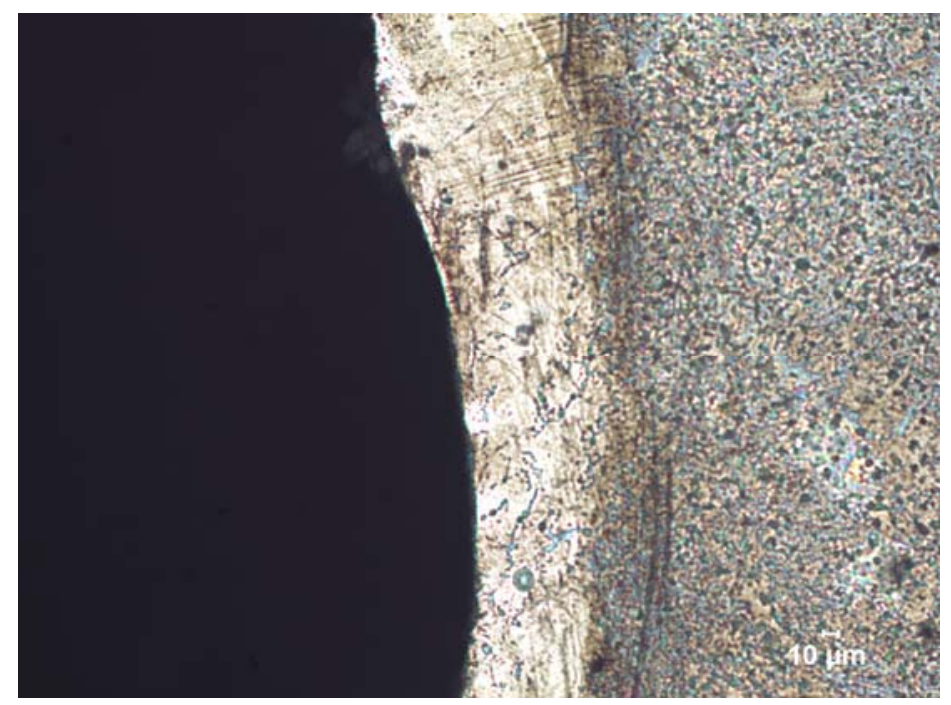

Figure 60 - Micrograph of Specimen B representing the BN deposit produced using the $5 \mathrm{~kW}$ Nd:YAG laser showing the deposit as the bright material in the center and the substrate to the right (200X magnification, oxalic etch).

Figures 61 and 62 represent micrographs of the WC deposited using the $14 \mathrm{~kW}$ $\mathrm{CO}_{2}$ laser and the $\mathrm{BN}$ deposited using the $5 \mathrm{~kW} \mathrm{Nd:YAG}$ laser, respectively, in the etched condition and at 500X magnification. In both figures, a white arrow indicates the deposited material, and the original interface between the substrate material to the right and the deposit is shown with a black arrow.

As shown in Figure 61, Specimen A representing the WC deposited produced using the $14 \mathrm{~kW} \mathrm{CO}$ laser exhibited a significant amount of dilution (melting) of the substrate and the presence of non-uniform regions (shown as the bright material). It is believed that the non-uniform material is high in the matrix material, which would be nickel. This high nickel area also shows possible indications of possible WC particles (shown as the gray areas within the bright region). The deposit (composed of the precursor and diluted substrate material) is between 20 and 100 microns $(\mu \mathrm{m})$ in thickness. A crack or discontinuity, which is believed to be the original surface of the substrate, is also evident in the micrograph of Figure 61. This linear discontinuity was observed over a relatively large distance within the specimen. It indicates that, although the surface of the 
substrate was melted during processing, complete fusion of the deposit and the substrate was not consistently demonstrated.

The deposit (composed of the precursor and diluted substrate material) of Figure 62 , which represents Specimen B or the the BN produced using the Nd:YAG laser, is approximately 50 to $100 \mu \mathrm{m}$ in width. It also exhibits a variation in thickness but not to the same degree as the WC deposit. A significant amount of second phase particles, such as $\mathrm{BN}$, in the deposit is not obvious in this micrograph. Good fusion between the deposit and the substrate was observed.

Microhardness measurements were also conducted on these specimens, and the microhardness profiles for the two deposits are shown in Figure 63. In both cases, the laser deposited materials exhibited hardness significantly greater than the substrate.

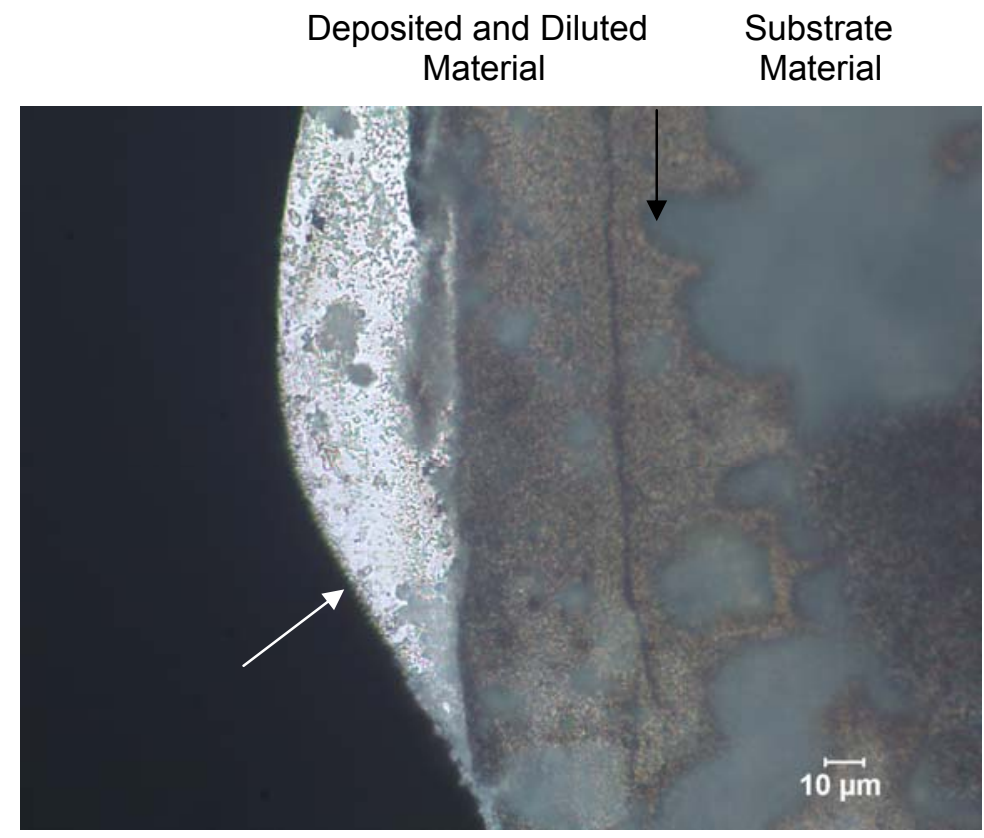

Figure 61 - Micrograph of Specimen A representing the WC deposit produced using the $14 \mathrm{~kW} \mathrm{CO}$ laser showing the deposit as the bright material near the center and the substrate to the right (500X magnification, oxalic etch). 


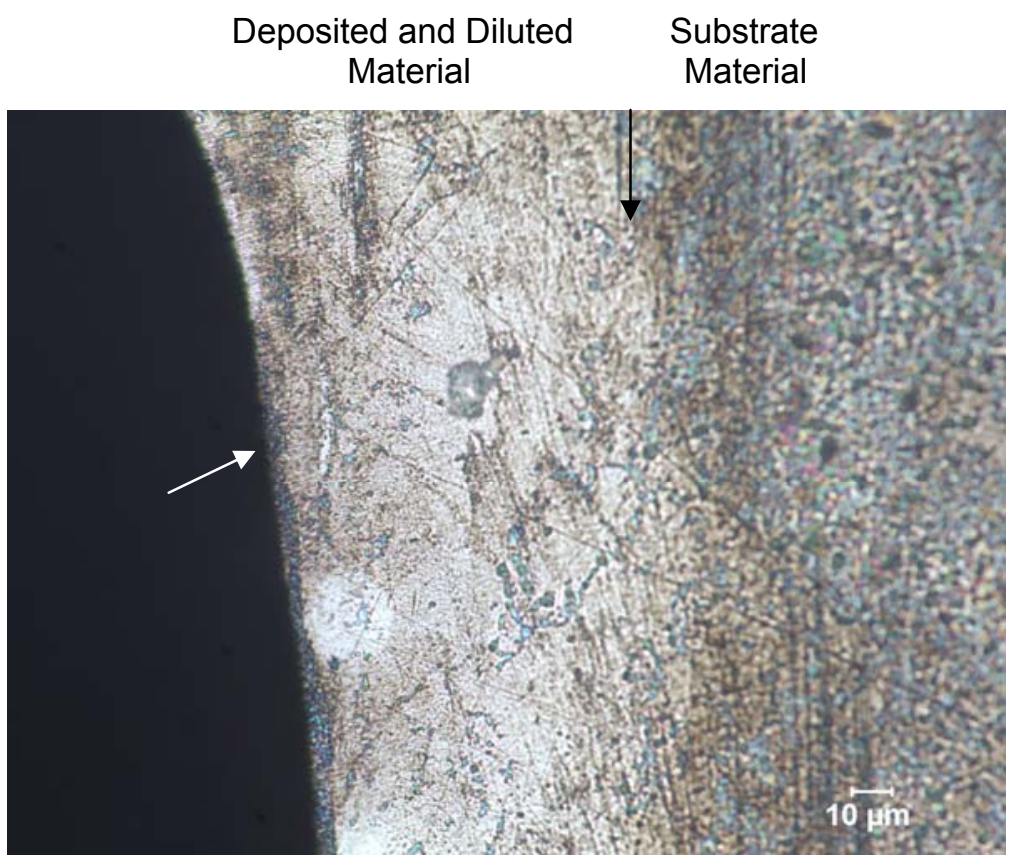

Figure 62 - Micrograph of Specimen B representing the BN deposit produced using the $5 \mathrm{~kW}$ Nd:YAG laser showing the deposit as the bright material near the center and the substrate material to the right (500X magnification, oxalic etch).

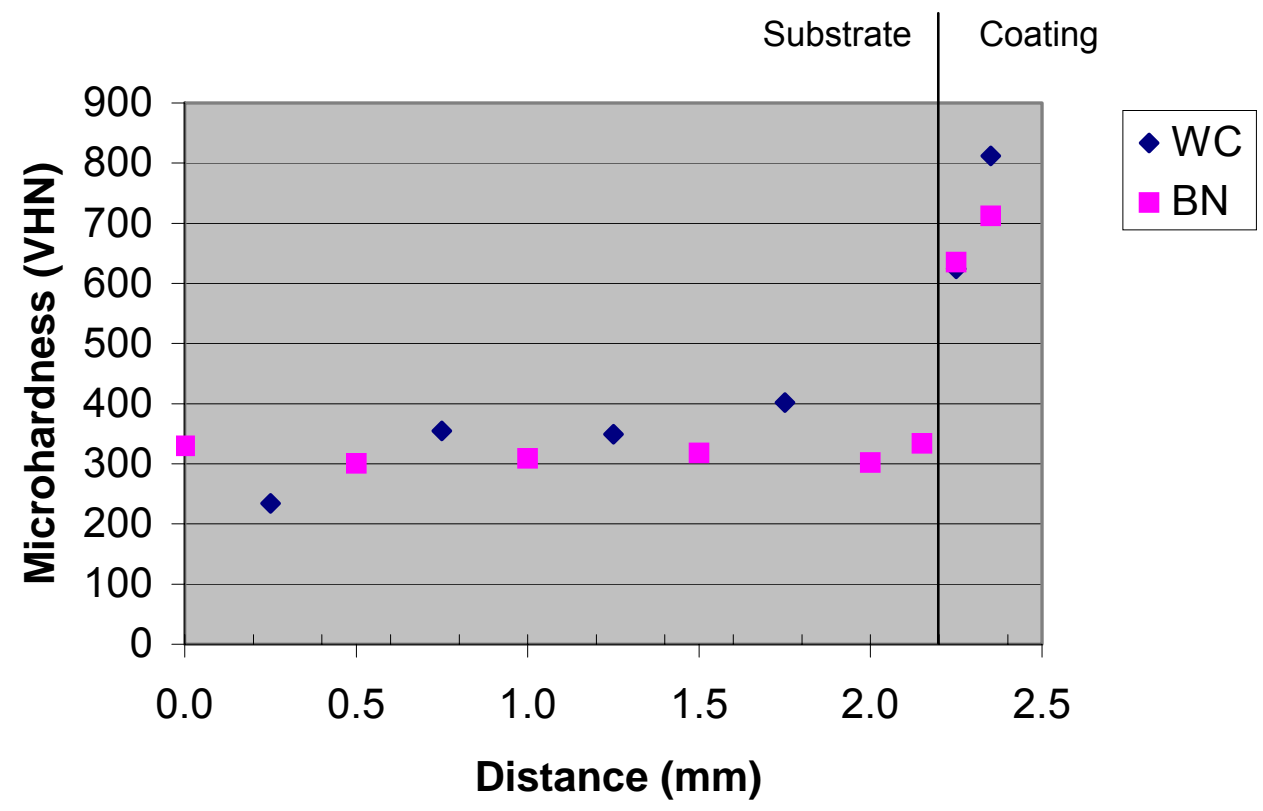

Figure 63 - Hardness profiles for the WC deposit produced using the $\mathrm{CO}_{2}$ laser and the BN deposit produced using the Nd:YAG laser. 
Additional metallographic analysis was performed on the WC precursor that was coating onto the steel shaft using a $14 \mathrm{~kW} \mathrm{CO}$ laser. In this analysis, a second specimen was removed from the shaft and metallographic specimens were mounted to represent the transverse and longitudinal views of the coated surface. The orientations for the transverse and longitudinal views are shown in Figure 64. It should be noted that the micrographs obtained during the prior metallographic investigation only involved longitudinal views.

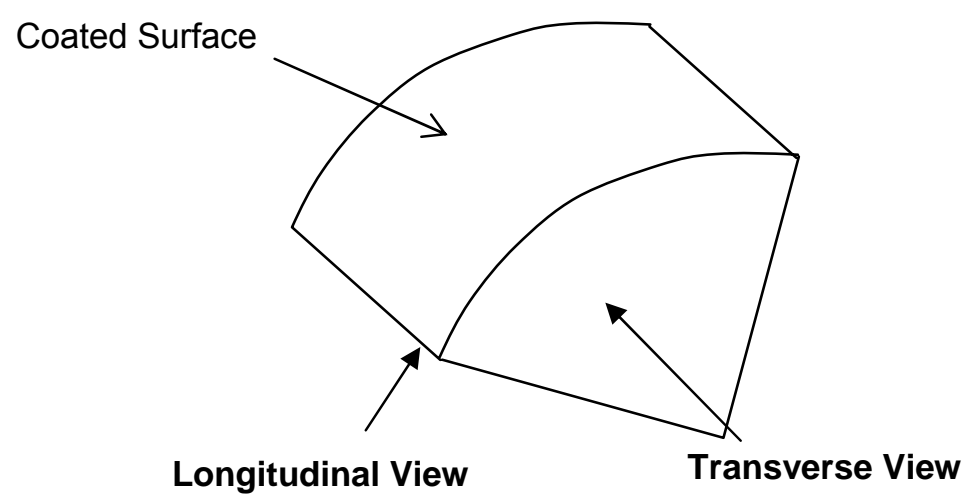

Figure 64 - Orientations of the transverse and longitudinal views represented in the attached micrographs.

Samples representing the longitudinal and transverse views were removed from the shaft using a diamond wafer saw and mounted in an epoxy (cold) mount using a vacuum assisted impregnation. These techniques were utilized to ensure no damage to the coating had occurred during preparation, and that close contact between mounting material and the coating was achieved. All photomicrographs were taken in the unetched condition.

Figures 65 and 66 are photomicrographs of the coating and substrate at the transverse viewing orientation at 250 and 500X magnifications, respectively. The coated layer is shown on the bottom of the micrograph. The coating appears to be approximately 30 and 50 microns in depth in this region. A small amount of a 
second phase, believe to be carbides, is dispersed within the coating. These are shown as the gray phase. Figure 67 is another micrograph at $500 \mathrm{X}$ magnification of the transverse view showing a nodular area that was periodically exhibited along the coating. The nodular area is approximately 40 microns in depth and contains more of the second phase particles, believed to be carbides.

Figures 68 and 69 are photomicrographs of the coating and substrate at the longitudinal viewing orientation at 250 and 500X magnifications, respectively. Greater undulation of the coating is exhibited in this viewing orientation and nodular areas were also observed. A crack is observed in the nodule, which could be the result of a high level of carbides present within the material. Figure 70 is another micrograph showing a longitudinal view of the coating with a carbide nodule. A crack is also seen in this nodule, and the crack is believed to be a lack-of-fusion defect representing the original surface of the substrate.

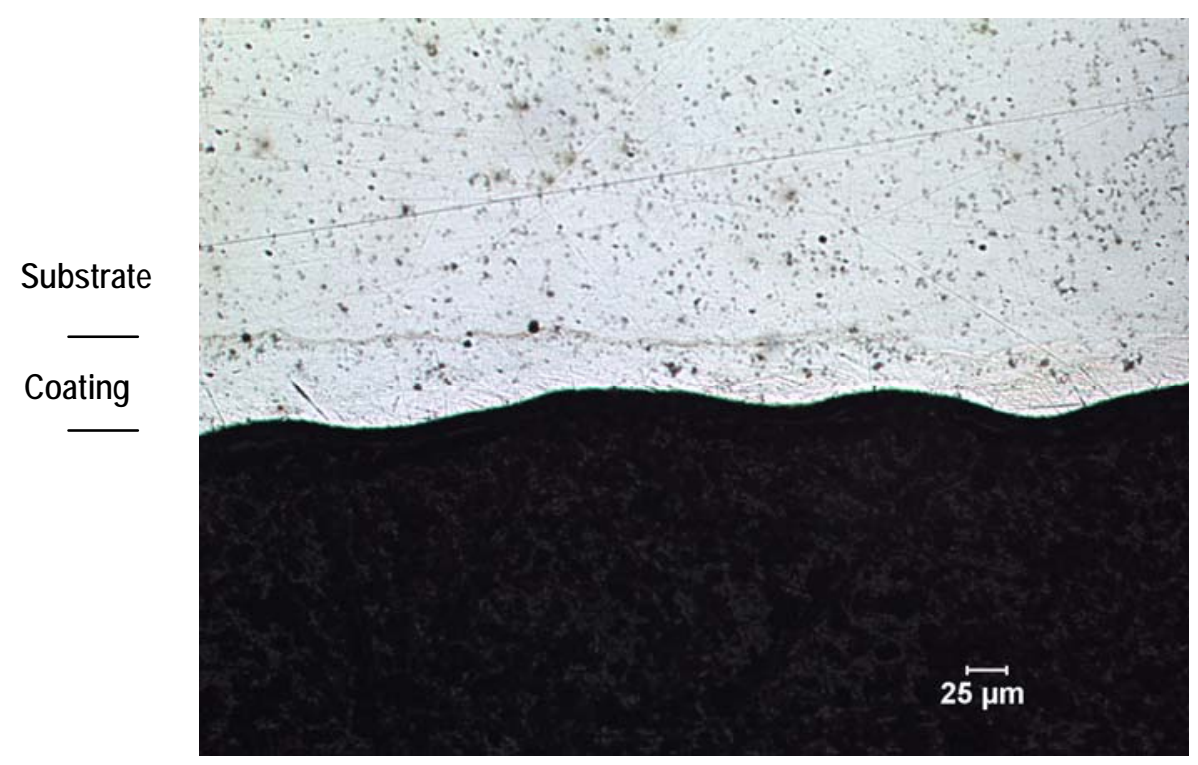

Figure 65 - Transverse view of Specimen A representing the WC precursor coating deposited on steel using a $14 \mathrm{~kW} \mathrm{CO}$ laser at $250 \mathrm{X}$ magnification (unetched). 


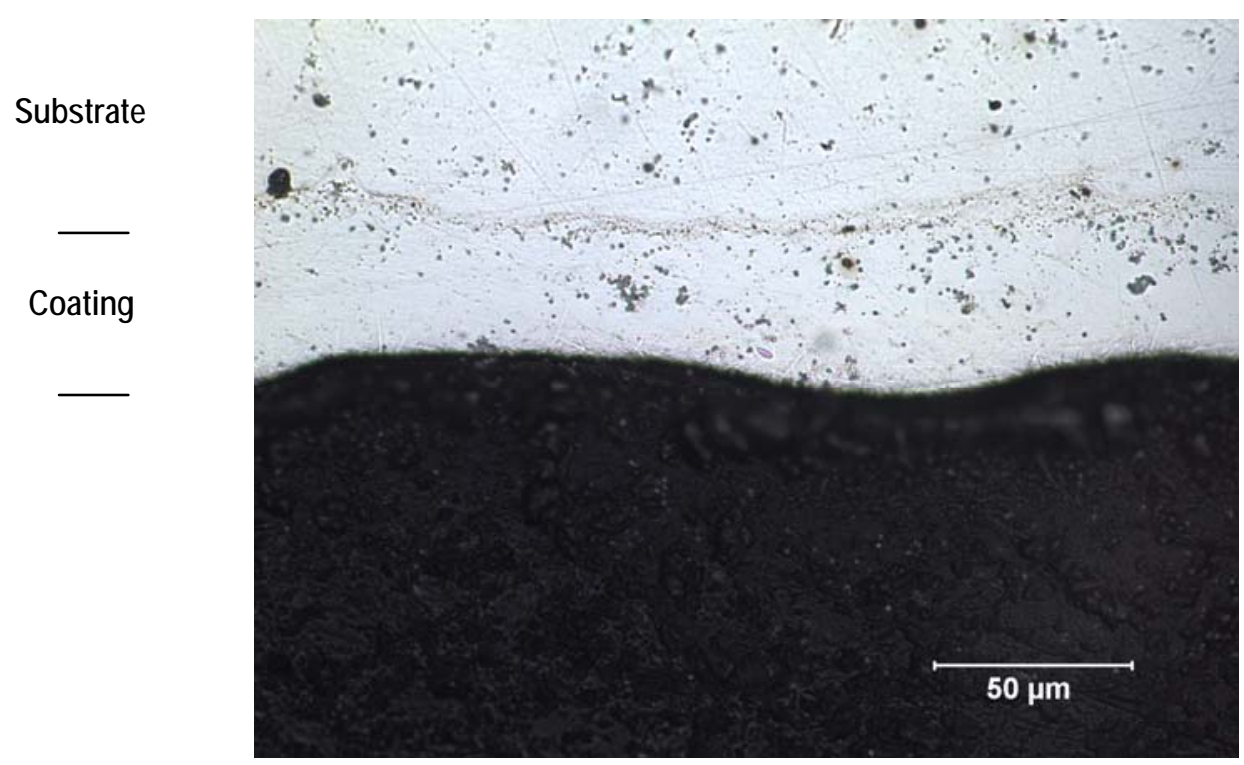

Figure 66 - Transverse view of Specimen A representing the WC precursor coating deposited on steel using a $14 \mathrm{~kW} \mathrm{CO}$ laser at $500 \mathrm{X}$ magnification (unetched).

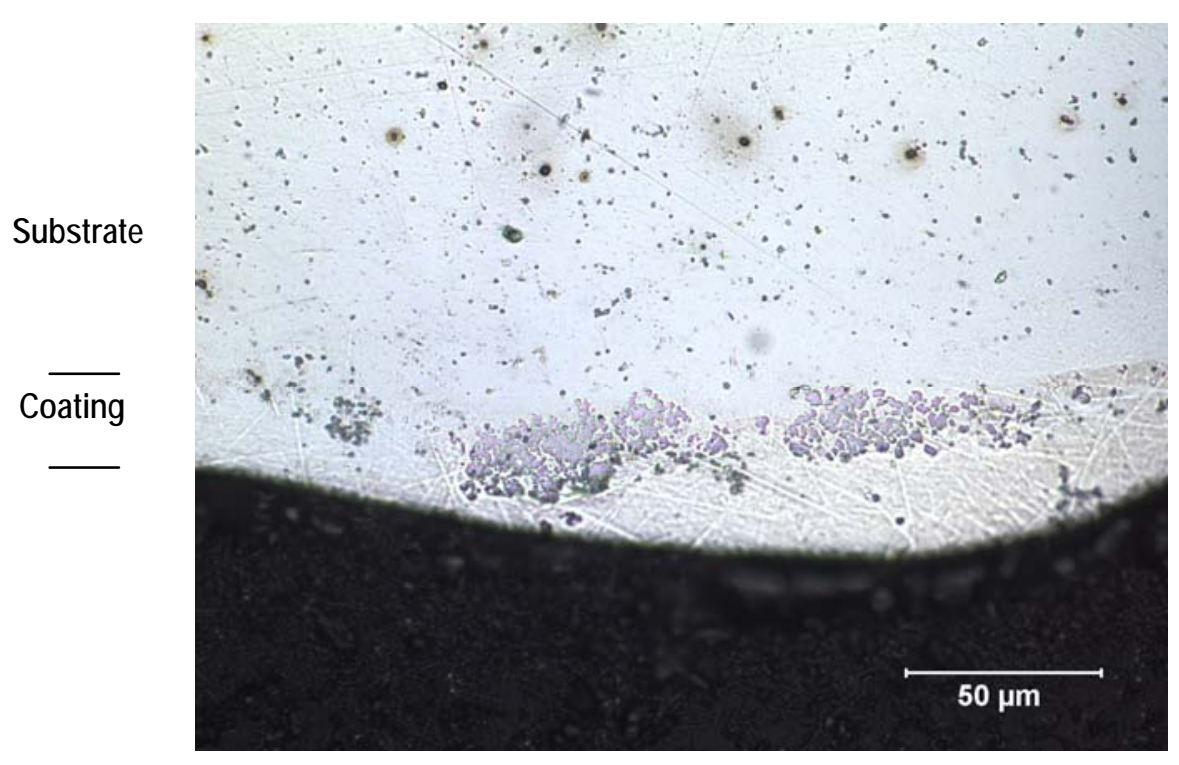

Figure 67 - Transverse view of Specimen A representing the WC precursor coating deposited on steel using a $14 \mathrm{~kW} \mathrm{CO}_{2}$ laser at $500 \mathrm{X}$ magnification showing nodule containing what is believed to be carbides (unetched). 


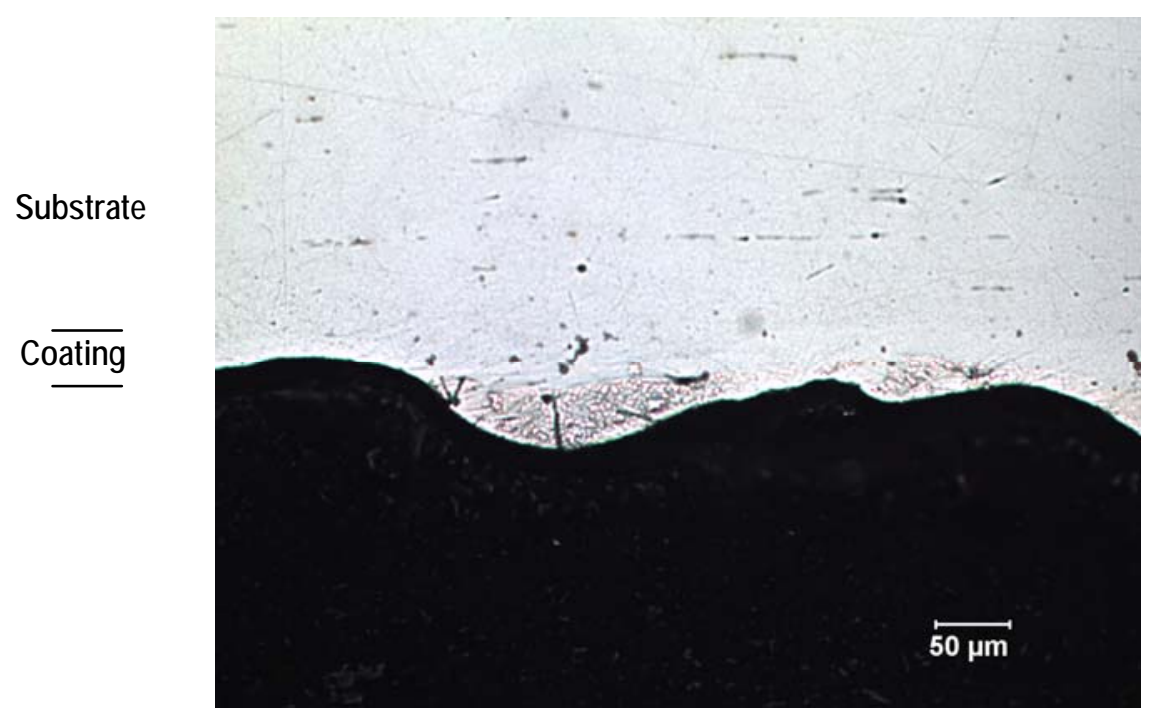

Figure 68 - Longitudinal view of Specimen A representing the WC precursor coating deposited on steel using a $14 \mathrm{~kW} \mathrm{CO}_{2}$ laser at $250 \mathrm{X}$ magnification (unetched).

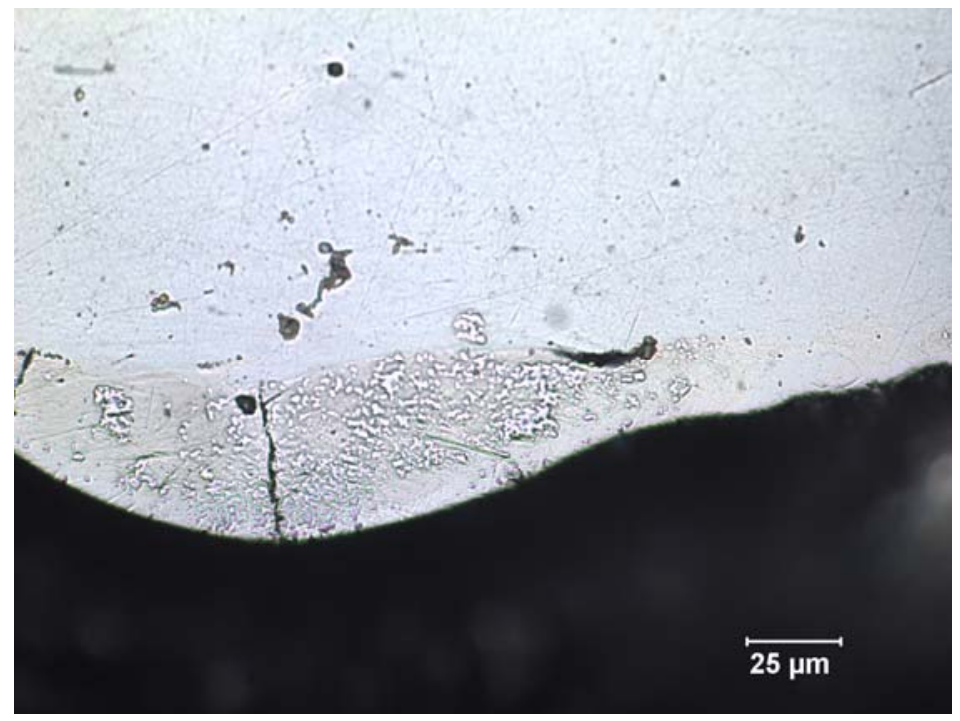

Figure 69 - Longitudinal view of Specimen A representing the WC precursor coating deposited on steel using a $14 \mathrm{~kW} \mathrm{CO}$ laser at $500 \mathrm{X}$ magnification showing nodule containing what is believed to be carbides (unetched). 


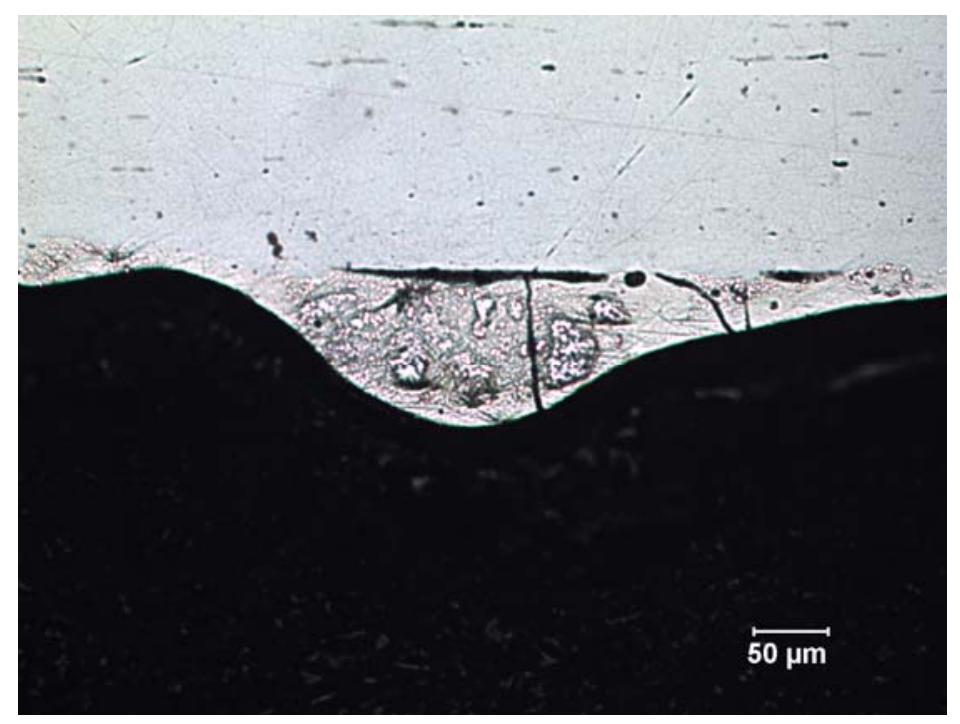

Figure 70 - Longitudinal view of Specimen A representing the WC precursor coating deposited on steel using a $14 \mathrm{~kW} \mathrm{CO}$ laser at $250 \mathrm{X}$ magnification showing carbide nodule (unetched).

In summary, metallographic evaluations were conducted on WC deposited onto an external bar using a $14 \mathrm{~kW} \mathrm{CO}$ laser and $\mathrm{BN}$ deposited onto an internal shaft using a $5 \mathrm{~kW}$ Nd:YAG laser. The results of this examination indicate that the deposits were on average approximately $75 \mu \mathrm{m}$ in thickness. Both deposits exhibited some variation in thickness, with the WC deposit showing a greater degree of variation. Lack of fusion to the substrate was observed for the WC deposit; whereas, the BN deposit exhibited good fusion into the substrate. The amount of second phase particles (WC or BN) remaining in the deposits could not be clearly ascertained. Hardness exhibited by both deposits was significantly higher than the hardness of the substrate material. Additional metallographic analysis was also conducted on the WC precursor coating deposited using a 14 $\mathrm{kW} \mathrm{CO}$ laser and support the earlier examination. The coating was found to be between 30 and 50 microns in depth. Some second phase particles, believed to be carbides, were present in the coating, with a greater level of this phase present within nodules that appeared periodically. Cracks were also apparent within this nodular region, which reinforces the belief that carbides heavily populated the nodular region. Some lack-of-fusion was observed when viewed in 
the longitudinal orientation, and which was also observed during the earlier examination. The lack-of-fusion defect is believed to be due to the use of inadequate energy, which would be a function of laser power and spot size, during processing. The use of the precursor for adding the coating material, which was chosen for ease of implementation for internal deposition, provided relatively thin coating thickness. This thickness is believed to be insufficient for the intended application, which requires post-coating finishing the internal surface.

\subsection{Industrial Demonstrations for Producing Tooling Material}

Industrial demonstrations were also conducted on components to achieve extremely high hardness for wear applications involving specialty tooling. These prototype components are applicable to deep hole drilling and machining for industries such as automotive, which requires exceptional wear resistance.

Shown in Figures 71 through 74 are photographs of components that were utilized for laser deposition using a Crucible Materials Corporation CPM REX 121 (Fe-3.4 C- 4.0 Cr- 9.5 Va-10.0 W-5.0 Mo-9.0 Co) powder, in combination with various levels of WC powder. The samples obtained from these components are designated as Specimens C, D, E, and F. The photographs inserted within the figures represent a magnified view of the region where the REX 121/WC powder was deposited. Figures 75 through 78 represent micrographs of the laser depositions of Specimens C through F, respectively. Based on the analysis of the micrographs, it appears that the loading of WC was not sufficient to achieve high volume fraction of hard particles within the REX 121 matrix; however, the WC particles that were added were efficiently retained. However, all articles were provided to the industrial partner for testing. 


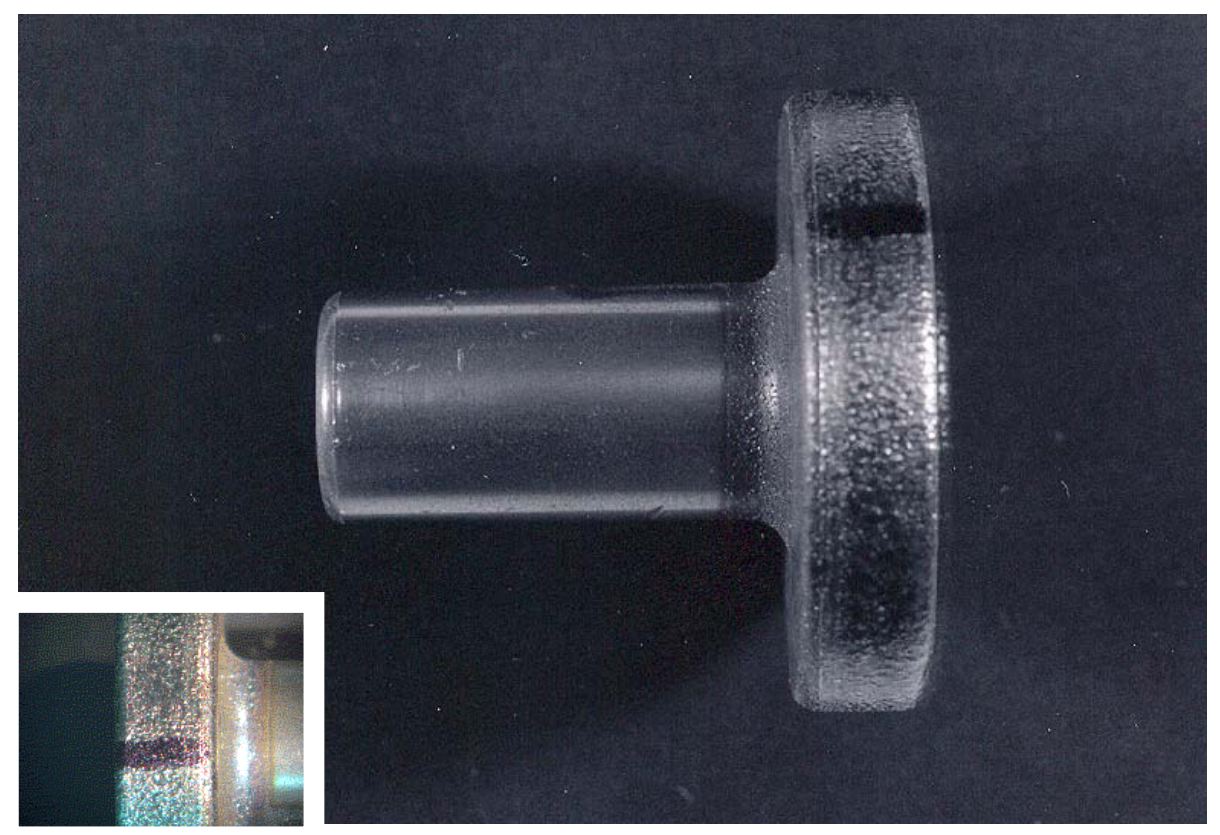

Figure 71 - Photograph of Specimen $\mathrm{C}$ with insert showing deposition and location of specimens that were removed for metallographic preparation.

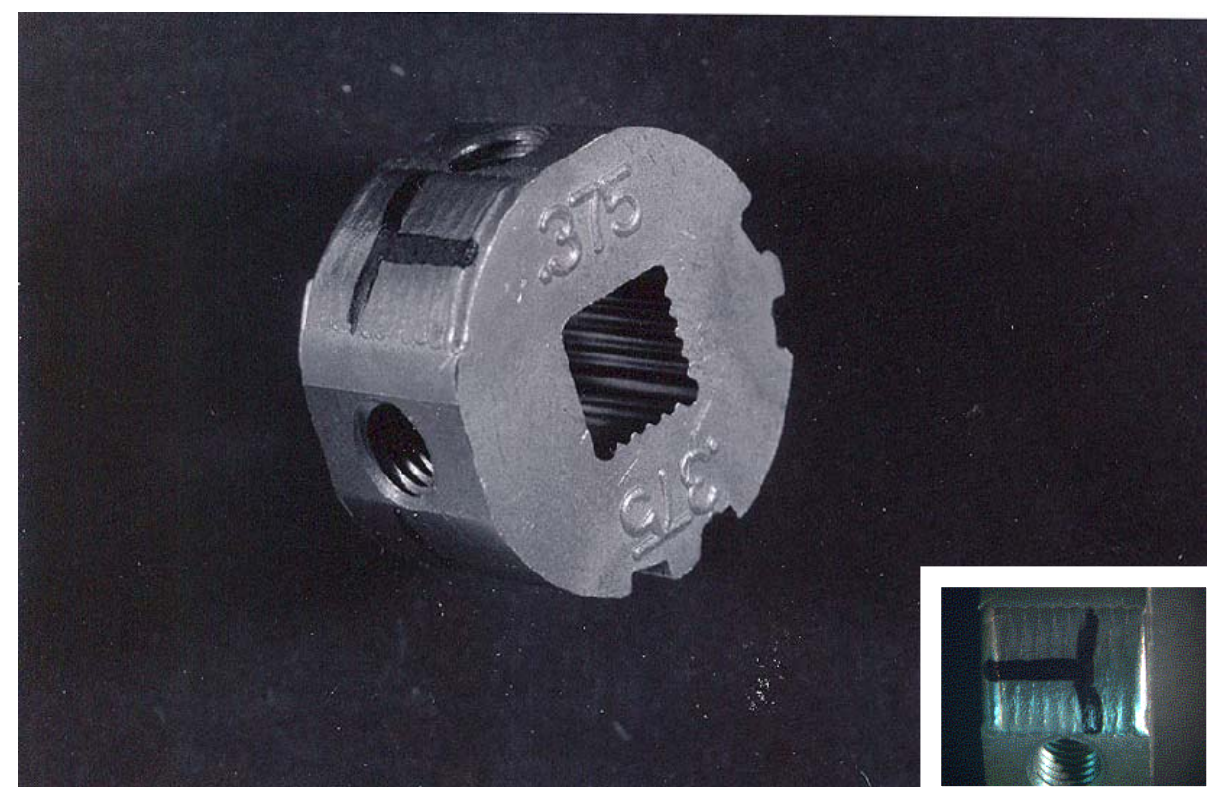

Figure 72 - Photograph of Specimen D with insert showing deposition and location of specimens that were removed for metallographic preparation. 


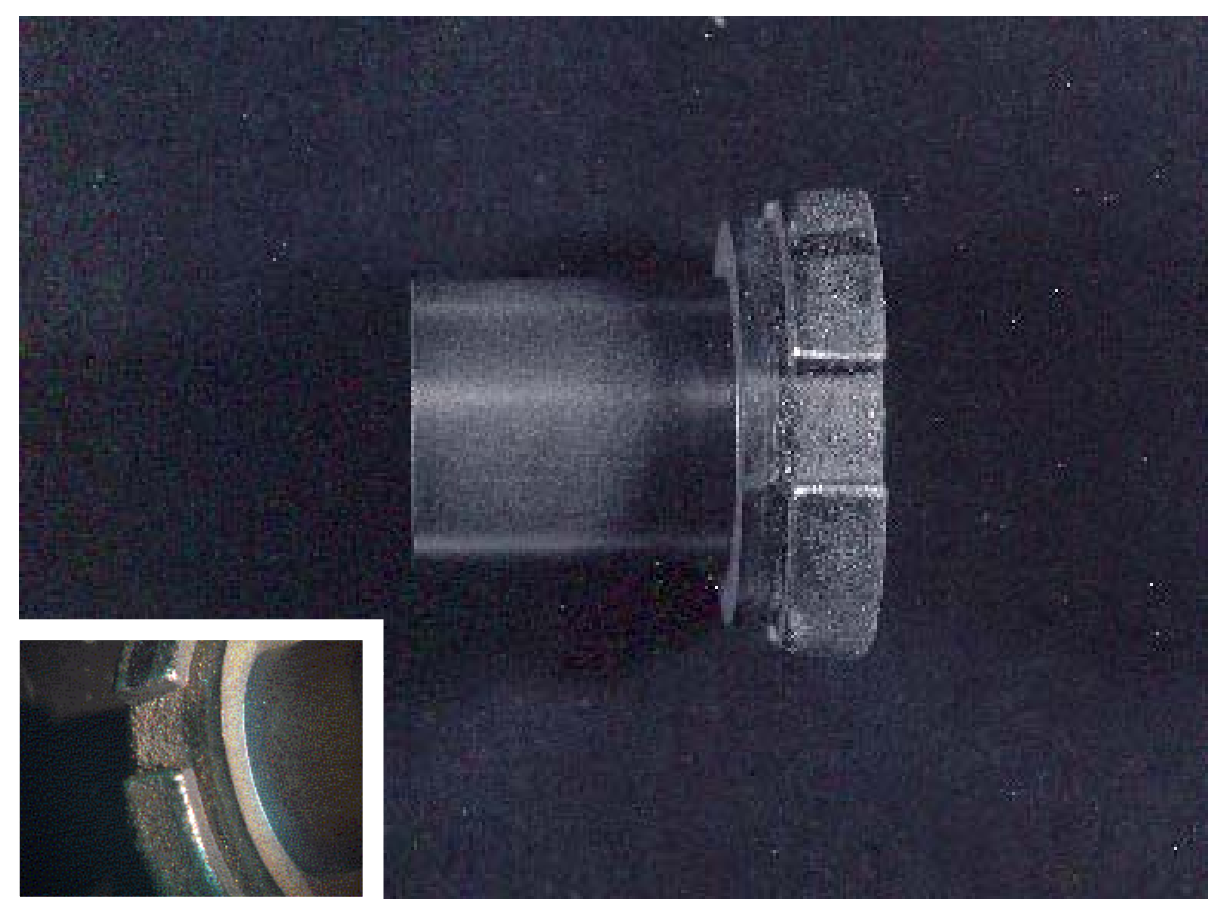

Figure 73 - Photograph of Specimen E with insert showing deposition and Location of specimens that were removed for metallographic preparation.

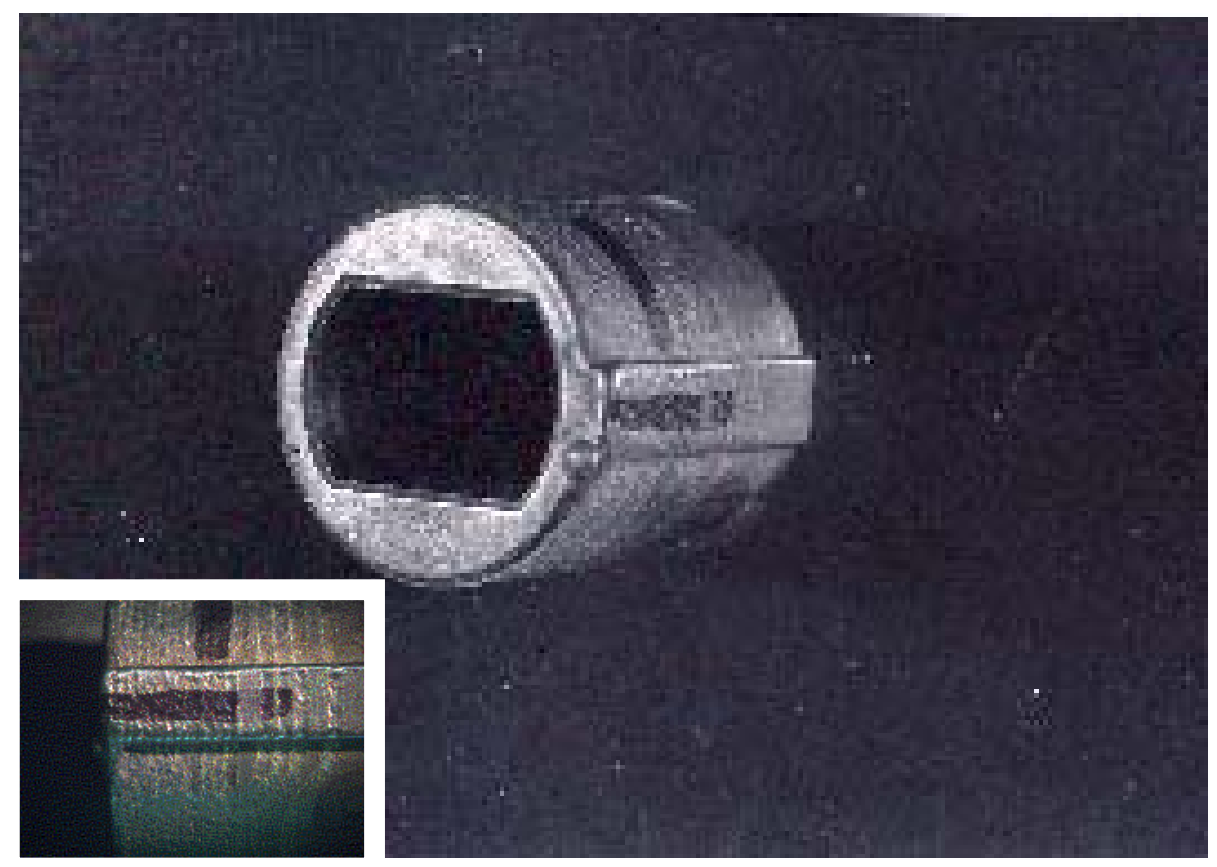

Figure 74 - Photograph of Specimen $\mathrm{F}$ with insert showing deposition and location of specimens that were removed for metallographic preparation. 


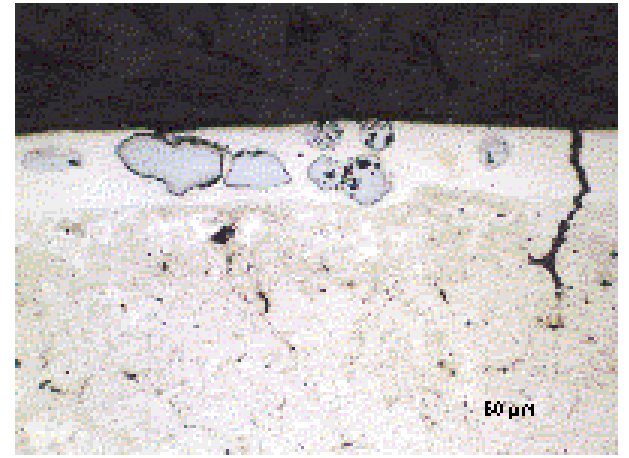

(a)

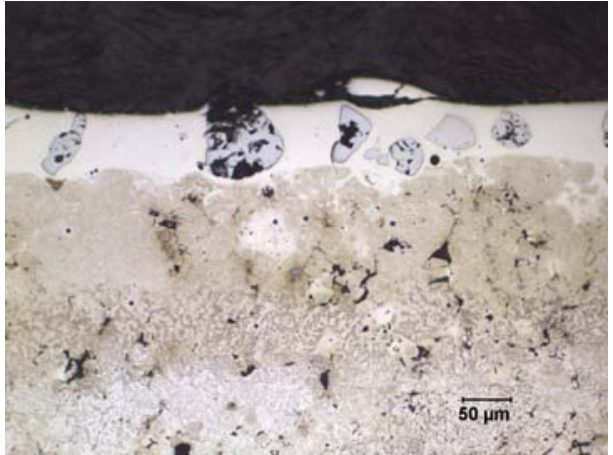

(b)

Figure 75 - Micrographs of Specimen C showing (a) transverse cross-section and (b) longitudinal section of laser deposition (Nital Etch, $100 \mathrm{X}$ Magnification).

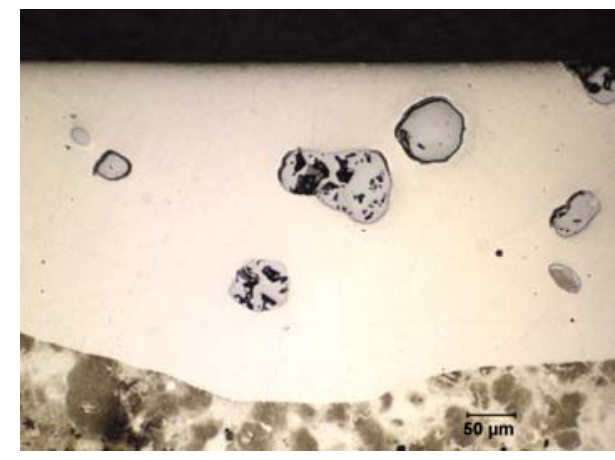

(a)

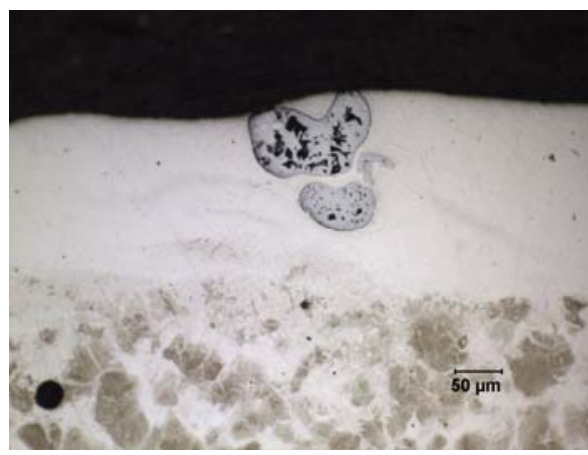

(b)

Figure 76 - Micrographs of Specimen D showing (a) transverse cross-section and (b) longitudinal section of laser deposition (Nital Etch, $100 \times$ Magnification). 


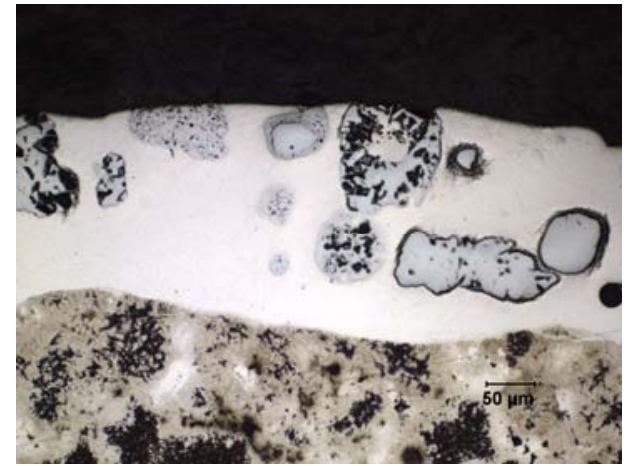

(a)

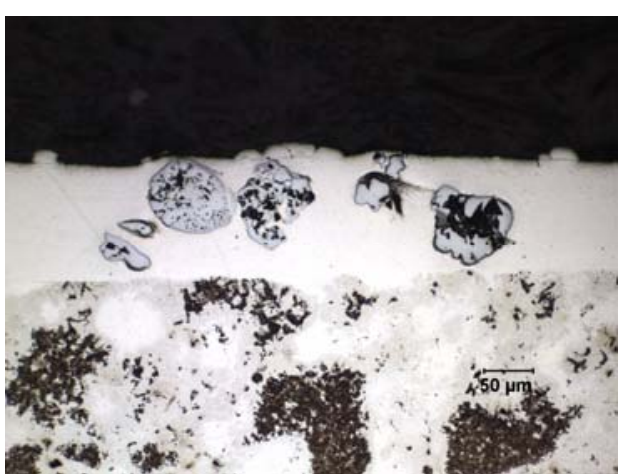

(b)

Figure 77 - Micrographs of Specimen E showing (a) transverse cross-section and (b) longitudinal section of laser deposition (Nital Etch, $100 \mathrm{X}$ Magnification).

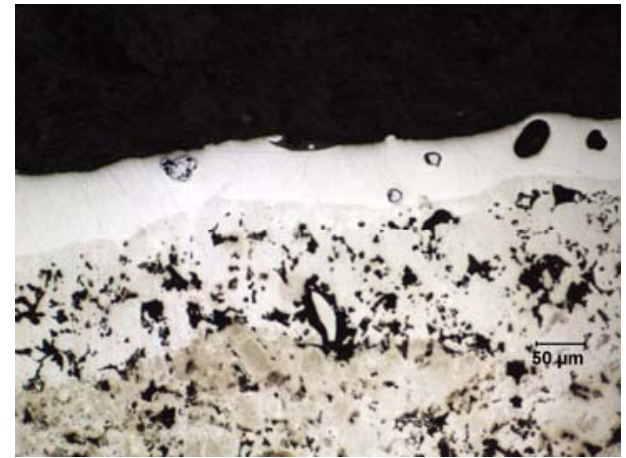

(a)

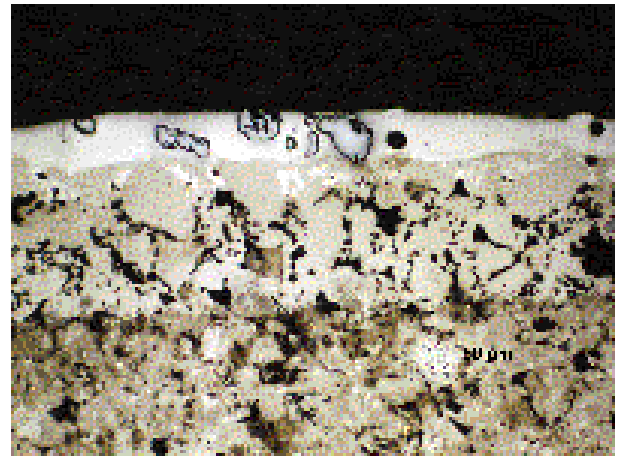

(b)

Figure 78 - Micrographs of Specimen F showing (a) transverse cross-section and (b) longitudinal section of laser deposition (Nital Etch, $100 \mathrm{X}$ Magnification). 


\subsection{COMMERCIALIZATION BENEFITS}

The primary economic benefit that was derived from this research was the identification of techniques and material systems capable of producing composite coatings. These coating offer improvements over current systems and may result in greater process efficiencies, increased performance, decreased down time, and lower cost replacement of exotic materials. Although the processing techniques and material selection tools that have been developed under this program may be applied to a wide range of materials, of particular importance is the identification of several material systems capable of maintaining or producing two-phase microstructures that result in increased hardness and potentially improved wear resistance over current laser deposits. This includes the use of: $\mathrm{TiC}$ and ferro-titanium in martensitic-grade stainless steel matrix material with and without the use of active $\mathrm{N}_{2}$ shielding gas, WC hard particles in a martensiticgrade stainless steel matrix material, WC and $B N$ in a nickel-based matrix material, and WC in highly alloyed iron-based matrix. The addition of common hard particles, such as WC or TiC, to matrix material composed of martensitic grades of stainless steel, such as alloy 420 or alloy 431 , offer opportunities for improved wear performance at relatively low material cost.

In several instances, industrial demonstrations of these alloy combinations were also conducted; however, the results of specific tests or evaluations conducted on these specimens are not available. However, the increased hardness exhibited by deposits having a composite microstructure has been documented during this work and anecdotal evidence suggests improved wear properties may be anticipated with these coatings, which of course, would be dependent upon the specific condition and environment. Because specific details concerning these improvements are not available, the probable impact of these coatings is discussed in general terms. It should also be mentioned that the analysis shown below represents an aggressive use of the technology and should be considered 
an optimistic perspective of economic improvements. However, in the case of abrasive wear, Nurminen, et al. has found that spherical WC or TiC added to high-alloyed ferrous matrix material lead to increased wear resistance [47].

It is anticipated that the implementation of the new coating technologies resulting from this research will be relevant to approximately $5 \%$ of future industrial applications involving wear and corrosion critical needs. It is also anticipated that the development of the composite coating techniques will result in a $1 \%$ improvement due to increased operational efficiency and life extension of effected components.

Based upon these assumptions, several cursory analyses may be conducted for several industries. The chemical, mineral processing, and agricultural industries all contain processes that have significant wear and corrosion concerns. It is estimated that the combined total expenditure in wear and corrosion critical processes for these three industries is $\$ 17.6$ billion. This estimate is based on utilizing $10 \%$ of the total expenditures, as defined in the Department of Energy Industry Profiles, for these industries. Using the assumptions defined above (5\% applicability with a $1 \%$ improvement), savings associated with the implementation of the composite materials developed under this program could account for approximately $\$ 8.8$ million in savings. It is also believed that the potential application of these coating and techniques to other industries, i.e. petroleum, primary metals, and forestry, this savings could approach a value of twice that which has been calculated above.

\subsection{Energy Savings}

The primary energy savings associated with the use of these coatings and techniques will be in the form of improved process efficiency and reduced downtime associated with repair and refurbishment of wear and corrosion critical components. A review of the Department of Energy Industries of the Future Roadmaps indicates a national need for improved materials throughout industry. 
Examples where these materials and techniques could result in energy savings, as described above, are: cultivation, harvesting, food processing, and textile manufacturer in the agricultural industry; mining, crushing, grinding, and sorting in the minerals industry; drilling, refining, and distillation in the petroleum industry; synthesis, separations, storage, and polymer production in the chemical industry; and rolling, forming, and casting in the primary metals industry.

Using the assumptions provided earlier, it is anticipated that the technology resulting from this research will be relevant to approximately $5 \%$ of future industrial applications involving wear and corrosion critical needs. It is also anticipated that this technology will result in a $1 \%$ improvement due to increased operational efficiency and life extension of effected components.

Based upon these assumptions, an analysis may be conducted for several industries. The chemical, mineral processing, and agricultural industries all contain processes that have significant wear and corrosion concerns. It is estimated that the combined total energy use in wear and corrosion critical processes for these three industries is 62 billion Btu per year. This estimate is based on utilizing $10 \%$ of the total expenditures, as defined in the Department of Energy Industry Profiles (mineral processing industry was estimated to use 2 quadrillion Btu/year), for these industries. Using the assumptions defined above ( $5 \%$ applicability with a $1 \%$ improvement), savings associated with development of advanced coatings technologies would be 31 million Btu/year. It is also believed that upon implementation of these coatings and techniques to other industries, i.e. petroleum, primary metals, and forestry, this savings would be anticipated to be significantly higher than the value calculated above.

\subsection{Environmental Benefits}

Key environmental benefits associated with the implementation of the composite coatings technologies will be in the form of reduced toxic effluent, process garbage, solid wastes, and green house gas emissions currently associated with 
industries, such as those involved in mining, petrochemical production, food and materials processing, textile fabrication, and primary metals foundries. The Department of Energy's Industries of the Future Roadmap goals for 2020 target a reduction of the current pollution index by as much as $50 \%$ for hazardous wastes, a $30 \%$ reduction in $\mathrm{CO}_{2}$ emissions $/ \mathrm{kwh}$, and the reduction of nonreusable materials by $20 \%$ (for materials technology alone).

Other examples of environmental benefits associated with the development of improved coating technologies, which are more difficult to quantify but never the less have important ramifications, are listed below.

(1) Toxic effluent, such as liquid discharge containing hexavalent chromium $\left(\mathrm{Cr}^{6+}\right)$, will be minimized by the substitution of advanced precursors for chrome plate replacement.

(2) Leaks in equipment from corroded or cracked materials, which can generate polluted surface water runoff, will be minimized by the design of corrosion resistant materials having superior wear properties.

(3) By the use of reaction kinetics and models, process garbage will be reduced through the design of more energy efficient materials and by lowering amounts of material rejected due to poor performance and processing flaws.

(4) Reduction of scrap metal will be realized through the development and fabrication of creep and corrosion/oxidation resistant parts having extended lifetimes.

(5) Recycling contaminated surplus/materials will be accomplished by determining the best systems approach for the recovery of raw materials.

(6) Due to greater materials performance and process efficiency, greenhouse gas emissions will be reduced.

(7) Combustion gas emissions (e.g., $\mathrm{CO}, \mathrm{NO}_{\mathrm{x}}, \mathrm{SO}_{\mathrm{x}}, \mathrm{VOCs}$, and particulates) will be reduced through the decrease in amount of fuel required to produce materials more efficiently. 


\subsection{ACCOMPLISHMENTS}

The accomplishments of this program fall into three categories: the creation of a methodology and supporting tools that enable specialized coatings and laser process parameters to be readily formulated, the demonstration of these techniques for specific industrial applications, and the dissemination of this technology to the scientific and industrial base. The development of standardized techniques using commercially available software, i.e. ThermoCalc $®$, coupled with accurate heat transfer simulations, to efficiently identify potential composite coating systems has been demonstrated. These techniques have been utilized to formulate several low-cost composite coating systems, based on WC or TiC particles in a matrix representing a martensitic grade of stainless steel, which have been demonstrated in the laboratory, and offer significant promise for improved the performance of critical components.

The dissemination of this technology has involved significant interaction with the industrial partners, providing presentations and publishing articles concerning this effort, and training of undergraduate and graduate students in the use of these methods. Close collaboration was cultivated with several of the industry representatives, and included in-depth technical exchange. Notably, the interaction with Spirex Corporation of Youngstown, Ohio; Praxair Surface Technologies, Incorporated of New Castle, PA; Alvord-Polk Corporation of Millersburg, PA; and Nuvonyx Incorporated of Bridgeton, MO during program execution was exemplary. Other industries, that could potentially benefit from this technology, were also continually engaged through presentations and publishing. A list of presentations and published articles provided by the primary investigators, Dr. R. P. Martukanitz and Dr. S. Babu, during this program follows.

1. Presentation provided to the Department of Energy Industrial Materials of the Future Review Meeting, Crystal City, VA, June 22-24, 2002.

2. Manuscript on "Development of Advanced Coating for Laser Modifications Through Process and Materials Modeling" presented at and published in 
the Proceedings of The 8th International Conference on Numerical Methods in Industrial Forming Processes NUMIFORM 2004, Columbus $\mathrm{OH}$, June 14-15, 2004.

3. Manuscript on "Dynamic Absorption of a Powder Layer" presented at and published in the Proceedings of the International Congress of Laser Applications and Electro Optics (ICALEO), San Francisco, CA, October 47, 2004.

4. Manuscript on "Energy and Mass Transport Model for the Laser Deposition Process" presented at and published in the Proceedings of the International Congress of Laser Applications and Electro Optics (ICALEO), San Francisco, CA, October 4-7, 2004.

5. Manuscript on "Reactive Shielding for Producing Advanced Coating Through Laser Surface Modification" presented at and published in the Proceedings of the International Congress of Laser Applications and Electro Optics (ICALEO), San Francisco, CA, October 4-7, 2004.

6. Laser Deposition of Tool Grade Material, published in Industrial Laser Solutions for Manufacturing, Vol. 19 (11), 23-25, 2004.

7. Manuscript on "Improving the Understanding of Laser Deposition Processes Through Process Simulation", presented at and published in the Proceedings of the $7^{\text {th }}$ International Conference on Trends in Welding Research, ASM International, June 2004.

8. Manuscript on "Design of Process-Material-Shielding Combinations for Hard Coatings Using Laser Surface Alloying", presented at and published in the Proceedings of the $7^{\text {th }}$ International Conference on Trends in Welding Research, ASM International, June 2004.

9. Manuscript on "Absorption of Laser Irradiation in Porous Powder Layers", presented at the $24^{\text {th }}$ International Congress on Application of Lasers and Electro Optics, October31, 2005.

10. Manuscript on "Reactive Gas Shielding During Laser Surface Alloying for Production of Hard Coatings", published in the Journal of Surface \& Coating Technology, Elsevier Press, 2005.

Finally, several students were intimately involved in the development of the numerical techniques used in the materials and process models, along with the application of this technology for formulating advanced coatings. This included: 
1. Dr. Shawn Kelly, who was a Doctoral student in Materials Science and Engineering at Virginia Polytechnic Institute and State University working with Dr. Babu, and who is now a faculty member at the Applied Research Laboratory, Pennsylvania State University,

2. Mr. Ryan McVey, who was a Masters Degree student in Engineering Science and Mechanics at the Pennsylvania State University working with Dr. Martukanitz, and who has recently accepted a position at the Johns Hopkins' Applied Physics Laboratory,

3. Dr. David Berry, who was an Undergraduate Honors Student in Materials Science and Engineering at the Pennsylvania State University working with Dr. Martukanitz, and who has recently received his Doctoral Degree from Carnegie Mellon University, and

4. Mr. Aaron Nabor, who was an Undergraduate Honors Student in Mathematics at the Pennsylvania State University working with Dr. Martukanitz, and is currently pursuing his Doctoral Degree at Princeton University. 


\subsection{CONCLUSIONS}

A program has been conducted by the Applied Research Laboratory, Pennsylvania State University and Oak Ridge National Laboratory to develop the scientific and engineering basis for performing laser-based surface modifications involving the addition of hard particles, such as carbides, borides, and nitrides, within a metallic matrix for improved wear, fatigue, creep, and corrosion resistance. This has involved the development of advanced laser processing and simulation techniques, along with the refinement and application of these techniques for predicting and selecting materials and processing parameters for the creation of new surfaces having improved properties over current coating technologies. This has resulted in the formulation of process and material simulation tools capable of examining the potential for the formation and retention of composite coatings and deposits produced using laser processing techniques, as well as positive laboratory demonstrations in producing these coatings. A premise of this work was that the application of thermo-kinetic models, coupled with accurate heat transfer simulations of the laser deposition process would provide a cost-effective method for designing and implementing composite coating systems, and this premise appears to be correct.

Several industrial partners, chosen based on their broad industry representation and interest in improved laser-based coatings, also participated during program execution. These companies included: Spirex Corporation of Youngstown, Ohio; Praxair Surface Technologies, Incorporated of New Castle, PA; Alvord-Polk Corporation of Millersburg, PA; and Nuvonyx Incorporated of Bridgeton, MO. In most instances, the industrial partners provided input into the requirements for improved deposition materials and helped identify potential application for the improved coatings, as well as provided materials and performance evaluations during process demonstrations. 
Results obtained during this program included details concerning material formulation and constitution for obtaining composite microstructures during laser deposition, as well as process related information to support this technology. Hence, conclusions based on this work are as follows:

1) An explicit finite differencing model used to describe heat transfer during the laser cladding process was found to accurately represent the degree of penetration into the substrate, which is an important parameter in process development. Since the model may be used to establish when adequate penetration is achieved within the substrate, it offers significant opportunities for use in establishing initial process parameters and decreasing costly experimentation.

2) It was also determined that the typical representation of the heat source by surface loading, which was utilized in the initial model, was inaccurate for simulation of complete thermal histories within the deposition layer.

3) It was proven experimentally that the laser energy is absorbed within the powder layer, creating volumetric energy absorption within the powder. A description of internal absorption was derived based on a Beer Lambert type relationship, which describes the energy density at any point within the powder layer under the laser beam. This relationship is now available for virtually any model and improves the accuracy of representing the interaction of the laser beam and powder layer.

4) An experimental method, utilizing an integrating sphere, was developed to measure the amount of energy transmitted through various thickness of a pre-placed powder layer. This technique was used to estimate the attenuation coefficients for pure iron and pure copper powders, each with three powder size distributions, during $\mathrm{CO}_{2}$ and $\mathrm{Nd}$ :YAG laser irradiation. The estimated attenuation coefficients representing the original powder

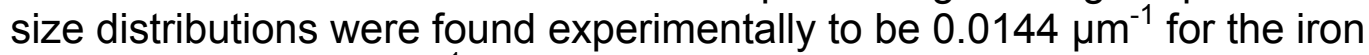
powder and $0.0113 \mu \mathrm{m}^{-1}$ for the copper powder.

5) It was demonstrated that implementing internal absorption into the heat transfer model does indeed have a significant effect on simulated temperatures, and that the thermal profiles generated by the model are fairly accurate with the incorporation of the internal absorption model.

6) The application of computational thermodynamic and kinetic models to design laser surface alloying materials was demonstrated and resulted in a vast improvement in the formulation of materials used for producing composite coatings. The methodology was used to identify materials to selectively modify microstructures for increasing hardness of deposits produced by the laser surface alloying process.

7) Computational thermodynamic calculations indicated that it was possible to induce the precipitation of titanium carbonitrides during laser surface 
alloying provided there is a sufficient amount of dissolved titanium, carbon, and nitrogen in the liquid steel. This was confirmed experimentally by using a powder mixture of 431-martensitic steel, titanium carbide powder, and nitrogen shielding, during laser deposition to produce deposits exhibiting relatively high hardness (average surface hardness of $724 \mathrm{HV}$ ). The hard microstructure was found to be related to the presence of undissolved coarse TiC particles, a dendritic and fine interdendritic Ti(CN) phase, and a large fraction of highly misoriented ferrite grains. The same approach was extended to direct diode laser processing and similar microstructures were attained.

8) The above analysis was extended to develop an in-situ precipitation of $\mathrm{Ti}(\mathrm{CN})$ during laser deposition. The Ti addition was achieving by mixing the 431 martensitic steel powders with Ferro-titanium. The dissolution of nitrogen was achieved by using $100 \%$ nitrogen shielding gas. As expected, experimental results showed precipitation of primary dendritic $\mathrm{TiN}$, fine ferrite grain size, and fine interdendritic eutectic ferrite $+\mathrm{Ti}(\mathrm{CN})$ microstructure.

9) Demonstrations were also conducted utilizing the tools developed during the program and resulted in several viable composite coating systems being identified. This included the use of $\mathrm{TiC}$ and ferro-titanium in martensitic-grade stainless steel matrix material with and without the use of active $\mathrm{N}_{2}$ shielding gas, WC hard particles in a martensitic-grade stainless steel matrix material, WC and BN in a nickel-based matrix material, and WC in highly alloyed iron-based matrix. Although these demonstrations indicated the potential of forming composite coatings, in certain instances, the intended industrial applications involved unique requirements, such as coating of internal surfaces, which hindered the full development of the improved coating technology.

10) Yet, it is believed that the addition of common hard particles, such as WC or $\mathrm{TiC}$, to matrix material representing martensitic grades of stainless steel offer opportunities for improved wear performance at relatively low material cost. 


\subsection{RECOMMENDATIONS FOR FURTHER WORK}

Although the program successfully developed simulation techniques for modeling the thermal process of laser deposition and the evolution of composite structures that could be produced using this method, and demonstrated the utility of these tools in identifying composite systems that would be relevant, the full demonstration of these techniques to actual applications lacked the necessary effort to finalize this task. Therefore, it is strongly suggested that these techniques be applied to the rapid identification, which they are now capable of performing, of applications that may dramatically benefit from the advanced coatings, and that full-scale industrial demonstrations be conducted. This will require additional process development, which was under estimated for this program, to satisfy the unique requirements of complex components that are of interest to industry. The ability to process complex geometries, such as internal cavities, will enable the advanced coatings identified under this program to be fully exploited by industry. 


\subsection{REFERENCES}

1. Babu, S. S., Martukanitz, R. P., Parks, K. D., and David, S. A., Met. And Mat. Trans. A, Vol. 33A, 1189, 2002.

2. Zhu, S. M., Wang, L., Li, G. B., and Tjong, S. C., Mat. And Eng. A A201, L5, 1995.

3. Colaco, R., Pino, C., and Vilar, R, Scripta Mat., Vol. 41, 715, 1997.

4. Martukanitz, R. P., Unpublished Research, Applied Research Laboratory, Pennsylvania State University, 2000.

5. ASM Handbook - Volume 6 (Welding, Brazing, and Soldering), Eds. D. L. Olson, T. A. Siewert, S. Liu, and G. R. Edwards, ASM International, 598, 1993.

6. Pelletier, J. M., Oucherif, F., Sallamand, A. B. and Vannes, Mater. Sci. Eng., Vol. A202, 142, 1995.

7. Ricciardi, G. Cantello, M., Molino, G., Varani, W., and Carlet, E., Key Eng. Mater., Vol. 46, 415, 1990.

8. Dehm, G. Scheu, C., and Bamberger, M., Proceedings of the Conference on Laser Materials Processing, LIA, Vol. 2, F-128, 1997.

9. Goldfarb, I. And Bamburger, M., Scripta Mat., Vol. 34, 1051, 1996.

10. Cooper, J. R., Dowson, D., and Fisher, J., Wear, Vol. 162, 1993.

11. Bhansali, K. J. and Mehrabian, R., J. Metals, Vol. 34, 30, 1982.

12. Simm, W. and Freti, S., Wear, Vol. 146, 105, 1989.

13. Zhang, Z. F., Zhang, L. C., and Mai, W. W., J. Mater. Sci., Vol. 30, 1961, 1995.

14. Lee, G. Y., Dharan, C. K. H., and Ritchie, R. O., Wear, Vol. 252, 322, 2002.

15. Axen, N., and Jacobson, S., Wear, Vol. 174, 187, 1994.

16. Axen, N., Alahelisten, A., and Jacobson, S., Wear, Vol. 173, 95, 1994.

17. Axen, N., and Jacobson, S., Wear, Vol. 178, 1, 1994.

18. Hosking, F. M., Folgar Portillo, F., Wunderlin, R., and Mehrabian, R., J. Mater. Sci., Vol. 15, 477, 1982.

19. Prasad, S. V. and Calvert, P. D., J. Mater. Sci. 15, 1746, 1980.

20. Araki, T., Nishida, M., Hirose, A., Yano, K., and Fujita, H., Trans. Japan. Weld. Soc., Vol. 24, 74, 1993.

21. Xu, B., Feng, C., Yang, J., Mocaxue Xuebao Tribology, Vol. 18, 322, 1998.

22. Zum-Gahr, K. H., Proceedings of the International Confernce on Wear of Materials Ed. K. C. Ludema, ASM, 793, 1985.

23. Khruschov, M. M. and Babichev, M. A., Friction Wear Mach., Vol. 12, 5, 1958.

24. Ashby, M. F. and Easterling, K. E., Acta Met., Vol. 30, 1969, 1982.

25. Schick, H. L., Thermodynamics of Certain Refractory Compounds, Academic Press, 1966.

26. Babu, S. S., David, S. A., Vitek, J. M., Mundra, K., and DebRoy, T., Sci. and Tech. of Weld. and Join., Vol. 4, 1999, p. 276. 
27. K. C. Hsieh, K. C., Babu, S. S., Vitek, J. M., and David, S. A., Mat. Sci. and Eng., Vol. A215, 84, 1996.

28. Han, Q. and Hellawell, A., Metall. Mater. Trans B, Vol. 28B, 169, 1997.

29. Melnychuk, R.M., B.S. Honor's Thesis, Engineering Science and Mechanics Department, 2005.

30. Carnahan, B., Luther, H.A., Wilkes, J.O., Applied Numerical Methods, John Wiley and Sons, Inc., New York, 431, 1969.

31. Croft, D.R., Lilley, D.G., Heat Transfer Calculations Using Finite Difference Equations, Applied Science Ltd., London, 56-66, 1977.

32. Callen, Herbert B., Thermodynamics and an Introduction to Thermostatistics, John Wiley \& Sons, Inc., New York, 252, 1985.

33. Rohsenow, W.M., Hartnett, J.P., Cho, Y.I., Handbook of Heat Transfer, McGraw-Hill, New York, 13.11, 1989.

34. Batchelor, G.K., O'Brien, R.W., Proceedings of the Royal Society of London. Series A, Mathematical and Physical Sciences, Vol. 335, 1682, 313-333, 1977.

35. Barbašin, E. A., Approximation of the Solution of Partial Differential Equations. American Mathematics Society, Providence, 463, 1963.

36. Holman, J.P. Heat Transfer. $4^{\text {th }}$ ed. McGraw-Hill, 342, 1976.

37. Poirier, D.R., Geiger, G.H., Transport Phenomena in Materials Processing, Minerals, Metals and Materials Society, Warrendale Pa, 1994.

38. Haag, M., Hugel, H, Albright, C.E., and Ramasamy, S., J. Applied Physics, Vol. 79, 1995.

39. Bohren, C. F., and Huffman, D. R., Absorption and Scattering of Light by Small Particles, John Wiley and Sons, 1983.

40 Martukanitz, R.P., Melnychuk, R.M., and Copley, S.M., Proceedings of the 23rd International Congress on Applications of Lasers \& Electro-Optics, Laser Institute of America, Vol. 97, 1404-1409, 2004.

41. Modest, M. F., Radiative Heat Transfer; $2^{\text {nd }}$ edition, Academic Press, 2003.

42. Reedy, J.F. (Ed.), LIA Handbook of Laser Materials Processing, Laser Institute of America, Magnolia Publishing, 5, 2001.

43. Pavelic, V., Tanbakuchi, R., Uyehara, O. A., and Meyers, P. S., Weld. J. Vol. 48, 295s-305s, 1969.

44. Martukanitz, R. P., Naber, A. C., Melnychuk, R. M., and McVey, R. W., 7th International Conference on Trends in Welding Research, ASM International, 59, 2005.

45. Labsphere: A Guide to Reflectance Coatings and Materials, www.labsphere.com/uploaddocs/A Guide to Reflectance Coatings and Materials_kb25.pdf, 2003.

46. Ready, J. F. (Ed.), LIA Handbook of Laser Materials Processing (LIA, Mangolia Publishing, 6, 2001.

47. Nurminem, Nakki, J., and Vuoristo, P., On the Wear Properties of Laser Coatings with High Carbide Concentrations, Proceedings of the 24th International Congress on Applications of Lasers \& Electro-Optics, Laser Institute of America, 698-653, 2004. 
